8)

Whis overomes

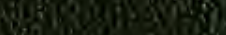

Why

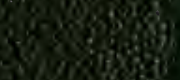
6. soras osing songengen sivengy 4.siveson yoses 6rows. Mon 1. 80.0780 . Sos on sing + 3.2564060 ins 1) a) ingon Sistosis. S.

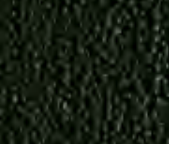

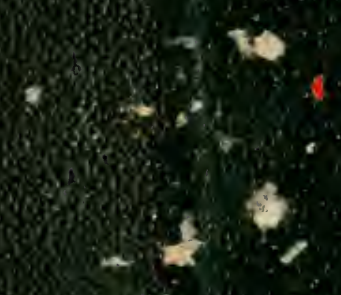

.

singeis

ingesion. D. $+4,6=$

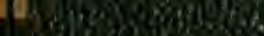
$2030 \mathrm{~s}$.

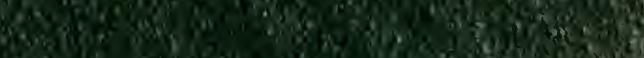
8.

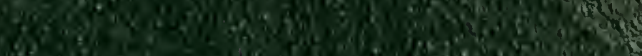
Son.

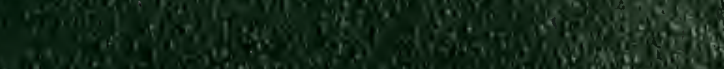
A2.

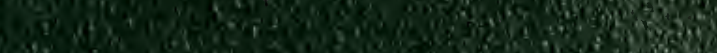
ingon a.9. tes. wos

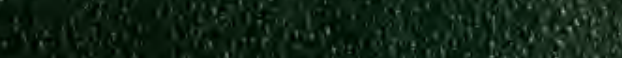

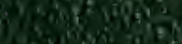
con Y(is)

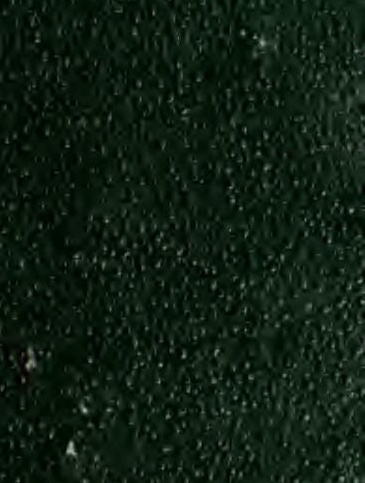




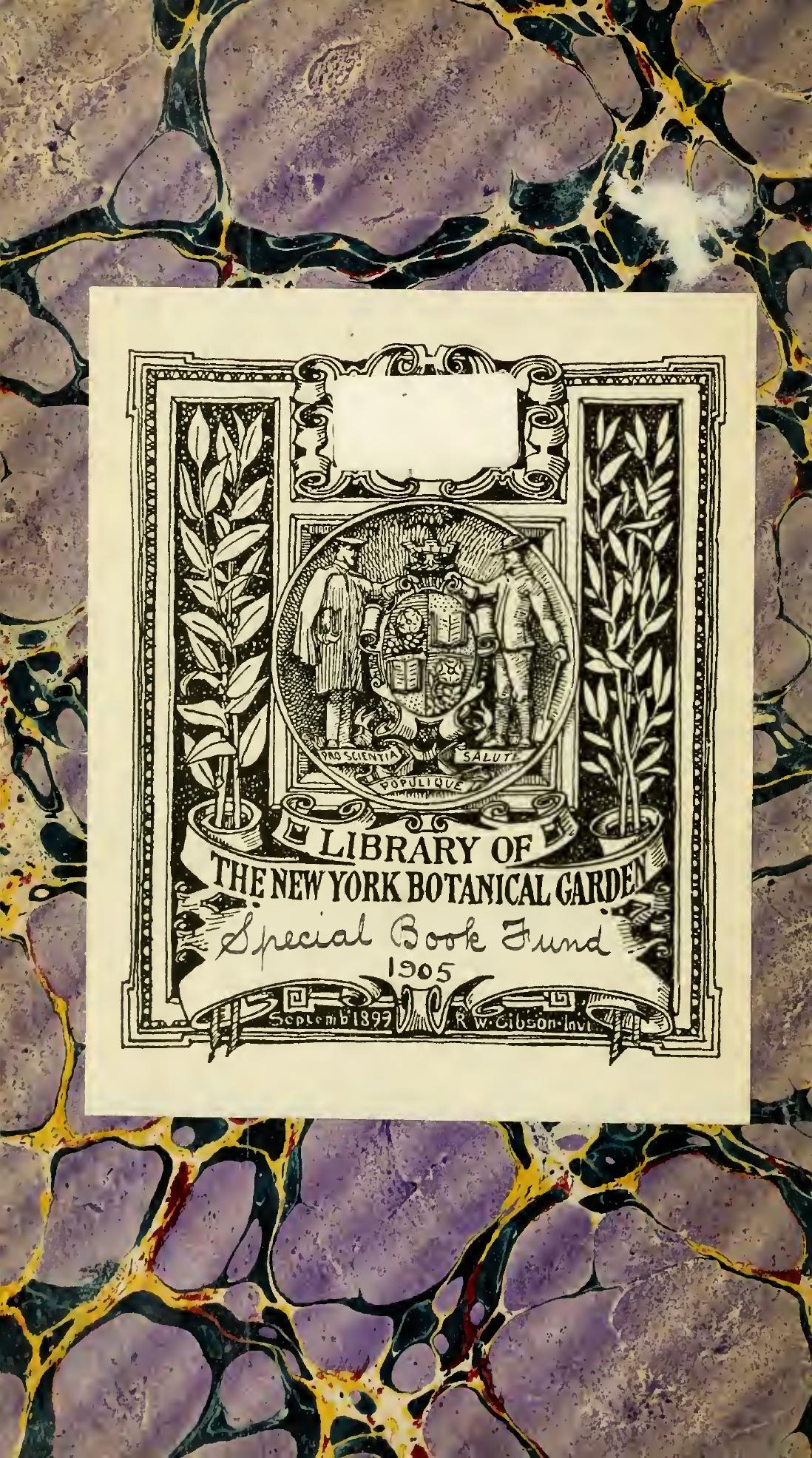




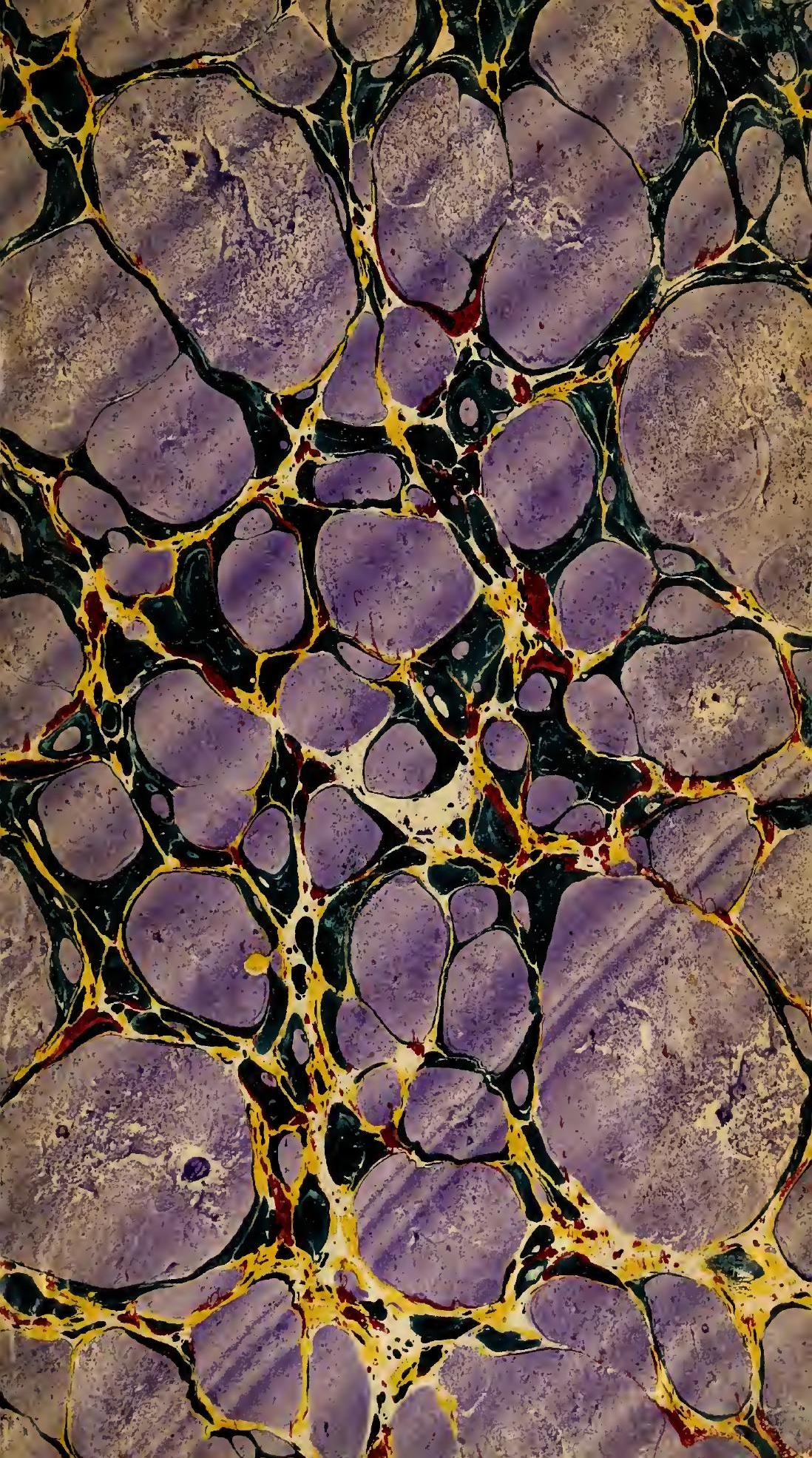





\title{
DE LA FÉGONDATION
}

\author{
II.X广 LES
}

\section{CRYPTOGA MES}

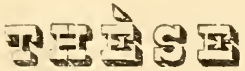

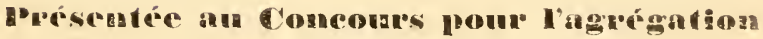

(SECTION D'HISTOIRE NATURELLE)

ET SOLTESLE A LA FICIITE DE MEUEGINE DE I'IRIS PAR

\section{LÉON VAILLANT}

I). M. P.

Licencié is sciences naturelles,

Hember te la sociéte de Bologis, de la Socirté philomaticune, te ta société grélugique de Trance, de la société d'Antluropologrie,

Hemlire eorrespondant de l'tradémie d'Arrac.

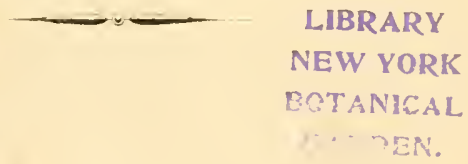

PARIS

F. SAVY, LIRRIRE-IETTEUR

2i. RUE HUTYFIIIL

186.3 


\section{$16 \mathrm{GLS}$}

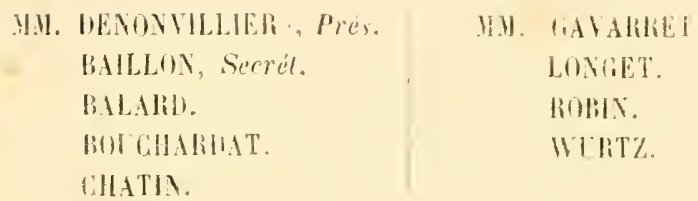

\section{CANDIDNTS}

\begin{tabular}{|c|c|c|}
\hline Pligniquate. & deciemecen nalurebles & 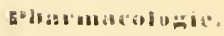 \\
\hline $\begin{array}{l}\text { WSLENET. } \\
\text { WSILATS. } \\
\text { HURIS. }\end{array}$ & $\begin{array}{l}\text { FOCRNIER. } \\
\text { DE SEYNES. } \\
\text { YIILLANT. }\end{array}$ & $\begin{array}{l}\text { IIEBERT. } \\
\text { MI!E ET. }\end{array}$ \\
\hline
\end{tabular}


I YIII.

E. MUSSAT, BOCOGILLON, MIPI MIINE-BLIWARDS.

PAU BFRT 

DE LA FÉGONDATION

D A I S
LIBRARY

NEW YORK BOTANICAL GARDEN.

\section{LES CRYPTOGAMES}

\section{INTRODUGTION}

Parmi les points importants de l'histoire naturelle que les recherches des savants modernes ont particulièrement fait progresser, la reproduction sexuelle des cryptogames peut être citée, à juste litre.

Bien que Limné, l'anteur de la nomenclature moderne, eut, en quelque sorte, pressenti ces découvertes, comme le pronve assez le nom quil imposa à ces régétanx, cependant quelques-uns de ses successeurs ne crurent pas devoir adopter cette L idéc et allèrent mème jusqu’à regarder ces c̀tres comme complétement agames. I la fin du sic̀cle

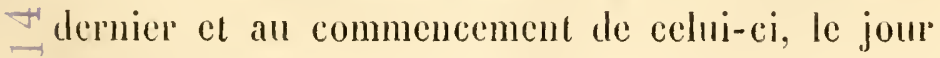


commenca cependant à se faire sur ec point, et les travaux de Vaucher, de Lamouroux, de Palisot de Bcauvois, etc., s'ils ne jugèrent pas complétement la question, au moins portèrent les esprits dans une roic meilleure. Mais e'est surtout dans Ies traraux des auteurs contemporains que l'on doit rechereher les documents les plus précieux. Nous aurons l'occasion, dans le cours de ce travail, d'indiquer les patients observateurs qui ont le plus contribué à ćlucider ces questions, aussi ne croyons-nous pas devoir ici nous appesantir sur leur énumération.

La marche que nous allons suivre sera plutôt analytique que synthétique, nous y sommes contraint et par la nature même du sujet, el par la nature des traranx qui s'y rapportent. D'une part les cryptogames forment un certain nombre de classes assez distinctes pour qu'on ait eru pouvoir admeltre entre elles une différence presque égale à celle qui sépare la grande division des végétaus phanérogames en dicotylédones et monocotylédones, on comprend donc a miori qu'on doive les examiner les unes après les autres. D'autre part, ces questions sont encore assez peu avancées pour que chaque travail ne puisse guère être considéré que comme une monographie d'une ou quelques espèces cxaninces par l'auteur, aussi ancune vue d'ensemble ne parait-elle, jusqu’ici, avoir été tentée.

Nous examinerons donc, au point de vue de la lécondation, chaeun des groupes isolément en nons 
basant sur la division la plus généralement adoptéc, qui partage les cryptogames en dix ordres:
$1^{\circ}$ Algues,
$6^{\circ}$ Characées,
$2^{\circ}$ Lichens,
$7^{\circ}$ Foug̣ères,
$3^{\circ}$ Champignons,
$8^{\circ}$ Équisétacécs,
$4^{0}$ Hépatiques ,
$9^{\circ}$ Lycopodiacées,
$5^{0}$ Mousses,
$10^{\circ}$ Rhinocarpées.

Dans chacune d'elles nous aurons un ou plusicurs types à étudier, sauf pour quelques-unes où nos connaissances sont encore fort bornées. Ce n'est qu'après ces études préparatoires que nous pourrons tenter d'établir, non pas une géinéralisation, mais plutòt une comparaison entre ce que peurent aroir de commun les phénomènes.

Nous serons souvent obligé de décrire arec les orģanes de la génération sexuelle les parties qui concourent à la génération asexuée, laquelle existe dans tous ces végétaux, ces questions étant parfois difficilement séparables dans l'état actuel de la science.

Avant d'aborder notre sujel, faisons remariner que les termes employés daus une des divisions pour désigner certains organes ne devront être regardés que comme s'appliquant à celle-ci, e'est un fait important à noter dans l'étude des régétaux inférieurs. Les cryptogamistes ont sourent non-senlement formé les mots avec uile prodigalité des plus exagérées, mais, soit par suite d'interprétations fautires que la science n'a pas confirmées, soit par 


\section{$-4-$}

une incuric fàcheuse, un mème nom, pris dans une classe, a été transporté dans la classe voisine avec un sens tout différent, et s'appliquant dans chacune d'elles à des organes non assimilables. Une simple révision de cette nomenclature serait sans doute fort utile, mais on ne saurait songer à l'entreprendre dans un travail de la nature de celui-ci, nous nous bornerons donc à prendre les termes usités par les auteurs en cherchant toutefois, autant que possible, à choisir ceux qui nous paraitront propres à éviter le mieux la confusion. 


\section{CHAPITRE PREMIER.}

\section{A I GUES.}

Ces végétaux ambigus, puisque pour quelques-mus d'entre eux les savants ne sont pas encore fixés sur la place qu'ils doivent occuper dans l'un ou l'autre des règnes organiques, ont de tout temps attiré l'attention des naturalistes, tant par leurs formes souvent bizarres que par l'éclat des coulcurs dont la plupart sont ornés. Toutefois, en ce qui concerne le point spécial dont nous avous à nous occuper, c'est dans les travaux de ces vingt dernières ammées à peu près qu'il faut puiser tous les renscignements précis sur la question de la fécondation. Au reste, ce fait résulte nécessairement de l'imperfection des moyens d'investigation que les savants ont pu avoir pendant longtemps à leur disposition.

Les travanx de Vaucher (1803), de Lamouroux (1805), de Léon Leclerc (1817), sont surtout descriptifs, bien que dommant quelques renseignements sur le mode de végétation desalgues tant marines que d'eau douce. En 1824, M. Gaillon publia quelques recherches et observa fort bien les mouvements des spores mobiles (zoospores), mais les 
idées bizarres de ce savant ne sont guère propres à élucider la question; il voulut voir dans les conferres une rémion de ces spores soudées bout à bout. Au reste, cette idće ne fut gunère adoptéc et défendue que par M. Desmazières (voy. Lettre sur l'animalité de quelques hydrophytes el des mycodermes en particulier'; 1828). Vers la même époque, M. Unger, par des observations directes, fit bien connaître la germination des zoospores qu'il regardail, suivant une opinion généralement admise à cette époque, comme des êtres passant alternativement de l'animalité à l'état de végétation.

Tous ces travaux tendaient à faire présumer que dans les algुnes le système unique de reproduction était dù à ces spores se formant évidemment sans le concours des sexes, et assimilables plutôt aux bourgeons et aux bulbilles des végétaux supéricurs qu'aux graines. Ces idées sont celles qui paraissent dominer dans les premiers écrits de MM. Agarth, Montagne, Decaisne. Cependant on savait déjà que pour les Zygnema existait un véritable accouplement, el les travaux de M. Morren, sur les closterrićes (1836), alors flottant entre le règne animal et le règne régétal, avaient montré la présence probable des deux sexes chez les végétaux inférieurs. Mais, a partir des travaux de M. Decaisne sur la classification des algues et des corallines (1842), des travaux faits en collaboration avec M. Thuret (1915) sur les arthéridies et les spores des fucus, du mémoire de Mur. Derbès et Solier sur les organes 
reproducteurs des algues (1850), la complication organique qu'on reconnut alors dans ces ètres indiquait déjà clairement chez cux l'existence des sexes. La confirmation expérimentale de la fécondation fut doméc par M. Thuret en 1853, et depuis les travaux de ce sarant, ceux de MM. Pringsheim, Cohn, de Bary, Petrowski, ete., sont venus corroborer cette donnée première et la rendre l'un des faits les micux acquis ì la science.

Pour exposer les observations apportées par ces savants nous prendrons l'ordre naturel et non l'ordre historique, en suivant la division généralement admise qui partage les Algुues en Zoosporées, Fucacées et Floridées, en faisant remarquer toutefois que cette classification doit ètre regardée comme fort imparfaite, car, même en adoptant les idées qui ont dirigé dans son établissement, il est difficile souvent de saroir à quel grompe rapporter une plante donnéc; mais, si l'on fait intervenir les idécs acquises dans ces derniers temps, elle devient complétement insuffisante.

Parmi les Zoosporées, le déreloppement des Conferves, qui constituent un des types les micux définis, a été fort bien étudié en particulier dans le Sphceroplea annulina' Agarth, sur lequel M. Cohn (1855) a donné des détails tiès-circonstanciés. Cette Algue se trouve dans les eaux douces oì elle forme d'ordinaire des amas de filaments verts entremelés les uns avec les autres, comme on l'observe fréquemment dans les véģétaux analogues de 
nos ruisseanx. Dans certains cas, la surface prend une couleur rouge vif due ì la présence des spores fécondées dont nous aurons à parler tout à l'heure. Si l'on examine à un grossissement conrenable la structure de ces filaments, on voit qu'ils se composent d'une série d'utricules allongés placés bout à bout, ou, si on le préfère, que le tube est subdivisé de distance en distance par des cloisons qui le partagent en loges oì vont se passer les phénomènes que nous allons passer en revue. La matière verte qui se voit dans ces loges ne les remplit jamais miformément, mais de grandes vacuoles transparentes et allongées la séparent en espèce de diaphragmes qui subdivisent la cellule, et contiement eux-mèmes des vacuoles plus petites avec des grains de chlorophylle. Suivant que dans cette cellule doirent se produire des éléments mâles ou anthérozoüdes, ou qu'il devra s'y former des éléments femelles ou spores, suivant, en un mot, que la loge deviendra une anthéridie on 1 sporange. le développement présente des modifications importantes.

La manière dont se forment les anthérozoüdes est fort exactement connue. Suivant M. Cohn, on voit les diaphragumes verts, séparés par les grandes vacuoles transparentes, changer d'aspect, la matière verte et les grains de chlorophylle disparaissent, et le tissu prend une teinte rougeâtre orangée toute différente, les petites vacuoles qui se trouvaient dans les diaphragmes subsistent sans subir ancune 
modification. Un peu plus tard, on voit la matière orangée se partager en linéaments, en granules, et, finalement, se résoudre en une multitude de corps claviformes, jaumàtres à leur partie renflée, transparents à leur partic amincie qui a reçu le nom de rostre, et portant sur cette dernière deux filaments vibratiles au moyen desquels le petit ètre peut se mouvoir d'abord dans l'anthéridie qui le contient, et plus tard à l'extérieur ou dans le sporange. Ces corpuscules mesurent environ $0^{\mathrm{mm}}, 008$ en longueur. Nous devons faire remarquer que le mode de fractionnement de la matière qui les produit, laquelle paraitrait se partager primitivement dans toute son étendue, mérite de fixer l'attention.

Si la cellule doit produire un sporange, les phénomènes sont tout différents. On voit d'abord les vacuoles se subdiviser et la matière verte ne lorme plus des diaphragmes, mais se trouve répandue tout autour des vacuoles dont le diamètre, réduit par le fractionuement, n'est plus assez considérable pour occuper tout le calibre de l'article. Les grains de chlorophylle subsistent également et se rassemblent en plusicurs masses écartées les unes des autres et disposées en série suivant l'axe du végétal. La matière verte se rassemble autour de ces masses comme autour de centres de développement, d'abord en amas irrégulièrement étoilés, plus tard il s'y adjoint une matière transparente, et la forme générale devient ovoïde; le rolume ne paraît avoir rien 
de bien fixe à cette époque. Enfin ces masses deviennent égales entre elles, se rassemblent en sphères parfaitement régulières; la matière verte, d'abord disséminée sans ordre, se multiplie et occupe toute la substance, sauf sur un point oì existe une sorte de calotte transparente qui n'est pent-être pas sans importance. Ces sphères molles et élastiques, dépourvues de membrane propre, constituent les spores, alors non fécondées el par suite improduclives, auxquelles M. Cohn a domné le nom de spores primordiales, nom qui peut leur être conservé. La grosseur moyenne de ces spores est de $0^{\mathrm{mm}}, 017$ à $0^{\mathrm{mm}}, 022$.

La formation des an thérides et des sporanges parait pouvoir se produire indifféremment dans une cellule quelconque prise isolément. Il s'ensuit qu'en considérant la suite des cellules qui composent un filament comme un individu, idée généralement arlmise, le sphecroplea annulina doit ètre regardé comme monoïque.

Pendant que le contenu des articles a subi ces profondes modifications, la paroi propre du végétal s'est altérée d'une manière peu sensible cи apparence, mais d'une faron très-importante quant aux résultats physiologiques. On roit certains points de cette paroi se perforer par une sorte de résorption; les ouvertures produites par ce phénomène, irrégulièrement placées et dont le nombre pour chaque cellule varie de deux ì six, ont un diamètre moyen de $0^{\mathrm{mm}}, 004$ i $0^{\mathrm{mm}}, 007 \mathrm{el}$ deriennent 
particulièrement risibles lor'squ'on a coloré la paroi par l'action de l'iode et de l'acide sulfurique. Ces ouvertures, qui se produisent aussi bien sur les anthéridies que sur les sporanģes, sont destinées à favouiser l'acte de la fécondation en permettant à l'anthérozoïde de venir se joindre à la spore primordiale. En effet, pen de temps après qu'elles se sont produites, on voit les anthérozoïdes qui s'agitaient faiblement dans la cellule sortir de celle-ci; s'ils en trouvent l'ouverture obstruće. on peut les observer pendant des heures entières cherchant à vaincre l'obstacle. C'est par l'extrémité du rostre que commence le dégagement de l'anthérozoïde qui au reste, chez toutes les algues, se meut toujours de cette facon, c'est-à-dire l'extrémité ciliće en arant; une fois libre, ses mourements prennent une agilité plus grande, et il cherche à se diriger vers les ouvertures des sporanges, il lẹs traverse comme il a traversé celles de la cellule productrice et peut alors se mettre en contact arec la spore primordiale. C'est toujours par le rostre que l'anthérozoïde touche la spore prinordiale, et c'est toujours aussi dans le point spécial de celle-ci dépourvu de matière verte que nous avous signalé plus haut. Plusieurs anthérozoüdes peurent se fixer à la fois sur une mème spore primordiale. Peu après le contact du rostre, le corpuscule s'applique par sa face latérale et perd sa forme en se liquéfiant en quelque sorte, si bien qu'il parait se fondre dans la spore, tontefois certains corpuscules rongeatres qu'il con - 
tientrestent visibles à la surface et paraissent rester ćtrangers à la fécondation.

Une fois fécondée la spore primordiale, qui doit alors prendre le nom de spore proprement dite, subit des modifications que nous devons brièvement signaler. Le premier phénomène consiste dans l'apparition d'une membrane externe, bien visible, à laquelle ne tarde pas de s'en adjoindre une seconde qui présente des prolongements externes irréguliers, et enfin une troisième qui reste simple; la première est rejetée. Le contenu change de couleur et devient rouge vif, ce que nous avons déjà signalé plus haut, en parlant de l'aspect de la plante en général. C'est vers cette époque pu'a lieu la dissémination par simple désagrégation de la membrane du sporange. La spore devenue libre ne donne pas naissance directement au végétal, mais, par un fait habituel chez les Algues dans le produit fécondé, elle fournit des Zonspores. On voit en effet son contenu se segmenter d'une façon régulière en 2, 4, 8, etc., parties, qui chacune donnent naissance à un corpuscule à couleurs vives, de forme un peu variable, pourvu de 2 cils flabelliformes, et qui se meut dans le liquide à la manière des Anthérozoödes dont nous avous parlé plus haut. Au bout d'un temps plus ou moins long suivant la saison, la zoospore, 'qui a perdu ses cils, germe en domnant naissance à deux prolongements opposés qui la métamorphosent en un tube dont le cloisonnement successif reproduira la plante mère. 
Tel est le eycle complet que parcourt le sphoeroplea annulina dans sa reproduction. Il est possible qu'en outre, comme chez beaucoup de végétaux voisins, la plante soit susceptible de produire directement des zoospores, mais nous n'avons pu trouver de renseignements à ce sujet.

Dans les IIydrotictyon, genre où M. Pringsheim a étudié avec grand soin la reproduction par zoospores (1860), aucun phénomène relatif à la fécondation n’a été signalé jusqu’ici. Remarquons toutefois que les organes reproducteurs mobiles sout de deux sortes distinctes et par Icurs dimensions qui les avaient fail désiģner sons le nom de macrogonidies el microgonidies par Alex. Braun et par leur mode de développement ultérieur. Les premicrs sont des zoospores à développement prompt et direct; les seconds au contraire, outre la longueur du temps qui peut séparer l'instant de leur émission de celui de leur développement, d'où le nom de zoospores permanents ou chronizoospores (Pringsheim) qui leur a été imposé, ne reproduisent pas directement le végétal, mais produisent dans leur intérieur de véritables zoospores. Or ces deux caractères, développement à longue portée, production endogène de bourgeons mobiles, carractérisent généralement les spores dues au concour's des sexes. On pourrait donc présumer que chez l'Iydrodictyon utriculatum qui a serviaux recherehes de M. Pringsheim existent des orģanes sexucls; mais, en l'absence de faits positil's, les considérations sur les- 
quelles nous nous appuyons ne peurent conduire qu'à une simple hypothèse.

Chez Ies Nostoc, que leur abondance a fréquemment fait examiner par les eryptogamistes, la génération sexucéc est cncore inconmue, et les recherches de M. Thuret (1844) n'ont rien fait connaître sous ce rapport. Il en est tout autrement chez les Spiro. Iygra, les Vaucheria, Ies Clostcrium; ce sont même ces végétaux qui, on peut le dire, ont donné l'éveil sur la reproduction sexuelle des algues, et le caractère le plus frappant de cet acte, l'accouplement de ces êtres, avait paru assez important à M. Decaisne, ì une certaine époifue, pour qu'il crut devoir faire, dans les Algues, une division spéciale pour ees végyétaux sous le nom d'Algce synsporece. Depuis la découverte de la sexualité des conferves ce caractère a perdu de sa valeur, et cette classe ne mérite pas d'ètre conscrvée.

Nous ne nous appesantirons pas sur les phénomènes de la fécondation che\% les Zygmema et les spirogyja. Chez les premier's, deux filaments comparables en tout à ecux des conferves étant placés l'mò à côté de l'autre, deux cellules qui sc correspondent àune mêmehauteur's'entoient mutuellement un prolongement, les extrémités se soudent, le diaphragme qui sépare les cavités disparaît, et le contenu de l'une passant daus l'autre, il y a formation d'me spore résultant du mólange des deux matières. la spore se développe dans l'une des cellules conjugnuées sans quion sache bien précisément s'il y a 
option pour l'une ou l'autre, ou si le développenent peut se faire indifféremment dans chacune d'elles, hypothèse qui paraîtrait la plus conforme aux faits, et mérite de fixer l'attention au point de vue de la sexualité en général. Dans d'autres plantes du même genre il parait ne pas y avoir conjugaison, suivant M. Thwaites, et le mélange des substances aurait lieu entre deux cellules consécutives d'un mème filament par résorption de la cloison qui les sépare.

Chez le Mongeotia genuflexa, appartenant à $\mathrm{un}$ genre très-voisin du précédent, M. Itziggsohn (1856) a observé un phénomène un peu différent. Après la conjugaison des deux filaments voisins, chacume des deux cellules forme, au point où la réunion s'est opérée, une petite éminence que l'auteur appelle verric muptiale. l'endochrome s'y ramasse et se divise en denx corps rerts, l'm globuleux, l'antre étoilé, bientôt pàlissant, et que l'auteur nomme astérosphérie, l'autre recevant la nom de globule sporigène. Celui-ci forme, en effet, la spore qui absorbe sans doute l'antre; car à la maturité il a tourjours disparm. La spore sort de la verrue et se divise cu 2, 4, 8 et mème 16 sporules filles qui reproduiscut la plante mère.

Quant aux Spirogyra, l'antenir que nous renons de citer a rapporté, en 1852, une observation que des recherches plus récentes, en 1856, paraissent confirmer et qui méritent d'ètre prises en considération. Il aurait vu, dans ces végétaux, de petits filaments spiraux contenus primitivement chacun 
dans une cellule mère. Ils sont sourent grroupés en petites masses arrondies, ce qui leur a fait donner, par M. Itzigsohn le nom de spermatosphéries; ces filaments, sans renflement, sans cils visibles, sont d'une grande mobilité. Ces corpuscules qu'on doit, sans nul doute, rapprocher des anthérozoïdes des autres algues n'ont pas, que nous sachions, été signalés dans les genres précédents des Synsporés.

Nous nous appesantirons davantage sur la reproduction sexuelle dans le genre Closterium, sa position dans la séric organique paraissant peutêtre cucore douteuse à quelques naturalistes. Les phénomènes dont nous allons parler, en les rapprochant complétement des Algures synsporées, ne doivent pas peu contribuer à les faire placer parmi ces végélaux, comme l'admettent au reste la grande majorité des botanistes modernes.

Ces c̀tres, remarquables par leur enveloppe siliceuse, sont commus depuis fort longtemps, puisquïls furent signalés par O.-F. Miiller, en 1786; depuis ils ont été fréquemment examinés, mais le travail le plus important dont ils aient été l'objet paraît ètre celui de M. Morren (1836) qui Jes a étudiés alvec très-grand soin. Depuis cette époque on s'est souvent occupé de ces ètres an point de vue descriptif, particulièrement en ec qui concerne leur enveloppe solide, mais un petit nombre de savants se sont livrés a l'étude de leur organisation. Nous devons cependant citer les noms de Thwaites, de Bary, de Foche. 
Lorsqu'unc clostérie se dévelople, on voit la spore yui lui donne naissance se polariser, suivant l'expression de M. Morren, c'est-à-dire que son contenu coloré ou endochrome, se rassemblant dans la zone médiane, laisse à ses deux extrémités des espaces plus clair's, la cellule s'allonge, et bientòt se produit une ligne blanchàtre qui la partage en deux cònes égaux ou inégaux. M. Morren croyait que ees derniers étaient seuls susceptibles de conjugaison; les recherches modernes ne paraissent pas avoir confirmé le fait pour toutes les espèces. La Clostérie se divise bientót en deux parties réellement distinctes, une cloison se produisant au point précis où se trouve la ligne blanche médiane; elle peut alors ètre comparée à une conferve à deux loges. Ses dimensions angmentent el la matière verte qu'elle contient s'accroit proportionnellement; en même temps, dans chacun des espaces vides laissés aux deux pôles, on voit se développer une cellule qui grossit rapidement el dans laquelle se lorme une grande quantité de corpuscules rougeàtres. Arrivée à un certain degré de développement, celte cellule se segmente et chacune des cellules secondaires se développe comme celle qui lui a donnć naissance en se remplissant de corpuscules colorés, de telle sorte qu'au bout d'un certain temps on peut en distingner un assez grand nombre dans l'intérieur de la Clostérie. M. Ehrenbergo, considérant ces êtres comme des animaux, voulut voir dans ces points rouges les yeux qu'il avait rencontrés ayant 
celte teinte chez certains infusoires; le développement seul des cellules secondaires enlève toute probabilité à cette hypothèse, abstraction faite de la nature végétale bien constatée de ces Clostéries. N. Morren croit plutòt qu'il faut voir dans ces points rouges l'analogue des corpuscules fécondants, ce que nous nommons Anthérozoüdes, auquel cas la cellule devrait prendre le nom d'Anthéridie. Parmi les arguments que l'auteur apporte pour justifier cette théoric, celui qui nous parait avoir le plus de poids est tiré de la disparition de ces corjus au moment de la conjugaison, alors que la matière verte ou endochrome acquiert les propriétés de la spore. Cet culochrome, pendant que ces changements se passaient aux pòles de la Clostérie, s'est lui-même modifié; il s'est entouré d'une membrane qui le limite nettement. C'est lui qu'on doit considérer comme l'organe femelle; mais, suivant qu'il n'y aura pas ou qu’il y aura conjugaison, les modifications qu'il subit présentent de notables différences.

Dans le premicr cas, les deux masses d'endochrome contenues dans la Clostéric se font jour directement an dehor's, entrainant avec elles les spores nombrenses (Propagules de Morren) qui se sont développées dans son intérieur par simple segmentation. Il ue paraît pas alor's y avoir en lécondation, contrairement à ce que pense M. Morren, el l'on pourrail mème se servir des planehes jointes it son mémoire pour témoigner contre lui, 
puisque, dans tous les cas où il a représentri les utricules vidant leur contenu sans conjugaison, il a toujours figuré les cellules à corpuscules rouges (Anthérozoüdes), intactes aux pôles de la Clostéric.

Dans le cas d'accouplement les phénomènes sont beancoup plus compliqués, mais rappelleut absolument ec.que nous avous vu chez les Zygnema. Les individus qui doirent se conjuğuer étant placés l'un en face de l'autre, une des celiules de chacun d'eux envoie un prolongement formé par les membrancs internes, l'enveloppe coriace s'étant résorbéc en ce point. Quand les prolongements sont aprivés en contact l'un de l'autre, ils se soudent, et le diaphragme qui les sépare se résorbant, denx cellules des deux elostéries peurent librement communiquer l'une aree l'autre. Mais en mème temps dans chacune d'elles la cloison qui séparait les deux cellules a disparu, de telle sorte qu'en réalité les deux cavités entières des elostéries sont en communication. On roit alors toutes les grandes cellules à endochrome, au nombre de quatre, deux pour chaque individu, se rendre dans le tube de conjugaison qui se dilate considérablement el s'y réunir en une seule masse qui va donner la véritable spore (Séminule, Morren, Les cellules à points rouges ont disparu pendant ces phénomènes ef paraissent s'itre fondus dans les masses à endochrome. Ce fait, comme nous l'avous dit, est le meilleur argument qu'on puisse invoquer poury voir l'analogue des anthéridies. La spore une fois 
forméc se développerail directement en une closlírie qui ne différerait en rien de celles que fournissent les propagules.

Ce mode de reproduction a, comme on le voit, les plus intimes rapports avec celui des autres algues synsporées; on doit seulement remarquer ici l'apparence bien nette d'un organe distinct pour chacun des sexes, fait qu'on peut supposer chez les Spirogyra, d'après les remarques de M. Itzigsohu, mais que l'on n'a pas encore reconnu chez les Zygnema.

Chez les Diatomées, d'après les recherches de M. Thwaites, les phénomènes de la fécondation sont tres-roisins de ce que l'on observe chez les Clostiries. Chez l'Ennotia turgidu, les individus, qui paraissent moins nettement divisés en denx cellules que dans le genre que nous avons précédemment examiné, s'enroient chacun denx tubes de conjugaison, un supérieur, un inférieur. L'endochrome s'anasse dans ehacun d'enx, mais le contenn, an lien de rester indivis, se fractionne de telle sorte que chatque amas penferme bientiot une quantité considerable de corpuscules reproducteurs. Les tubes de conjugaison ainsi métamorphosés en sporanģes acquièrent des dimensions considérables el stupassent bientot notablement en volume les diatomécs qui leur ont donnć naissance. La carapace de celle-ci s'est partagée en denx parties qui sont placées de chaque côté des sporanges accrus. Ln fail improptant a noter est que pendant tout le temps 
de la fécondation et du développement des corps reproducteurs les deux individus accouplés sont enveloppés d'une sorte d'atmosphère mucilagineuse qui s'accroît avec cux. C'est par la destruction de ce mucilage et des sporanges que se fail la dissémination. Les phénomènes sont les mènes dans le genre Epithemia. Dans les genres Cosmarium el Staurastrum, observés par M. de Bary, les individus ne s'enverraient qu'un prolongement: cet antenr a ajouté sur le développement des spores dans ces régétanx, immédiatement après la fécondation, des délails curieux qui se rapprochent beancoup de ce que nous arons signalé pour les spores fécondées du Scepleroplea ammulina.

Avant de passer à l'étude de la fécondation chez les Fucacées nous ne pourons pas passer sous silence les faits curicux relatifs à la reproduction des lolrox. Ces ètres présentent, à un bien plus haut degré que les précédents, ce caractère tlambiguité qui fait qu’on peut hésiter à les ranger dans le règne animal on dans le règne végétal, et la question paraît encore être en suspens; si, en effet, en France les Volroces sont généralement regardés comme animaux, en Allemagne on les réunit aux Aggues, el c'est ce point de rue qui parait aroir tonjours dirigé M. Cohn dans les nombrenses et intéressantes recherches dont ee grroupe a été pour lui l'objet.

Chez le lok'ox globator on recommail deux motes de génération, l'un par proliféralion des cellules, mode qui n'a rien de spécial à ces itpes at sur 
lequel nous ne nous arrêterons pas, l'autre dì au concours des sexes et qui présente, on doit le recommaitre, de nombreux points de ressemblance avec ce qu'on observe chez les Algues. L'espèce dont nous parlons ici se présente, on le sait, sous l'aspect de sphères verdâtres élégamment réticulées, d'un tiers de millinùtre ì 1 millimètre, et se mouvant dans l'ean arec une certaine agilité. La structure de ces corps est des plus simples : ils se composent d'une enveloppe de cellules juxtaposées el ne forment qu'une seule rangée; à l'intérieur, existe un mucilage transparent. Toutes les cellules de l'enveloppe sont susceptibles de la génération sexuclle, mais $u n$ certain nombre d'entre elles seulement peuvent donner naissance aux organes soit mâles, soit femelles. Ceux-ci, dans le bolvox: globator dont nous nous occupons ici, sont rémis sur le mème individu. D'après M. Cohn, e'est done une espèce monoïque; mais il importe de signaler dès à présent certaines espèces, comme le Vol'ox minor, chez lesquelles les sexes se trouvent sur deux individus dillérents et par conséquent qui sont dioïques. bans l'espèce que nous prenons pour type les cellules sexuclles ne tardent pas à se distinguer des cellules simples par leur accroissement plus considérable et l'amas de matière rerte qui s'y conrentre. Ces premiers déreloppements sont communs anx sporanges comme anx anthéridies, mais phus tard ces organes se diffépencient d'une manière notable. Les cellules femelles en se déreloppant des- 
cendent dans la cavité centrale an traver's du mucilage qui la remplit, en se dirigeant vers le centre de la sphère; elles grossissent considérablement vers ce point, tandis qu’à leur point de départ de la membrane enveloppante elles restent étroites ; aussi lorsqu'clles ont acquis toute leur taille on peut les comparer, suivant l'expression de M. Cohn, à une bouteille lisée par son goulot à la paroi interne de l'enreloppe gémérale. Dans l'intérieur de chaque sporange la matière verte s'accroit au fur et à mesure du développement et finit par former un gros globule qui est en tout comparable à ce que nous connaissons déjì dans les Sphceroplce cimnulina sous le nom de spore primordiale. L'organe femelle a acquis vers cette époque $u$ diamètre de $0^{\mathrm{mm}}, 0.5$.

Le développement des organes mâles représente exactement dans ses conmencements ce que nous venons de roir pour le sporange; senlement quand la matière verte qui remplit la carité a acquis $\mathbf{m}$ certain volume, au lieu de ne former qu'une scule masse, on la roit se segmenter d'une manière régulière, mais en deux scns seulement, ce qui fait qu'au lieu de s'étager les uns au-dessus des autres, les corpuscules imumbrables qui résultent de cette division se disposent suivant une surface courbe qui tapisse l'intérieur de la cellule où se fait le développenent. Bientot chacune de ces parties subit des modifications qui ront la métamorphoser en véritable anthérozoule. l.e changement le plus important consiste dans la production de deux longs 
cils au moyen despuels le corpuscule se meut d'abord lentement dans l'intéricur de l'anthéridic; bientòt sa forme et sa couleur changent, il s'allonge, se renfle à une de ses extrémités, s'atténue ì l'autre qui représente le rostre et porte des cils flabellilormes; il devient jaunâtre et renferme quelques granules colorés. Les anthérozoüdes sor-tent enfin de la carité qui les renferme et se répandent dans le mucilage central. Le mode suivant Iequel s'opère cette déhiscence n'est pas exactement connu, mais celle-ci parait s'effectuer par rmpture de l'anthéridic. Les anthérozoüdes s'agitent alor's avec vivacité et eherchent à pénétrer dans l'iuléricur des sporanges; la voic qu'ils suivent pour arriver jusqu'i la spore primordiale est égament encore obscure, mais cependant on les voit an bout d'un certain temps en contact direct avee celle-ci, et la fécondation est alors opéríc, comme Ir prowvent suffisamment les changements subsciquents qu'on remarque el d'où résulte la formation des membranes de la spore proprement dite.

Dans un travail plus récent, M. H.J. Carter (1859), sans infirmer complétement ces observations, a été conduit it regarder le Volvox globator comme diö̈que. Ces faits ne changent du reste en rien l'essence du phénomène de la fécondation.

Nous devous faire remarquer ici que ee mode de reproduction sexuclle paraît offrir des différences notables avec ce que M. Balbiani a fait comnaitre chez les infusoires dans ces dernières années, et 
tendrait par suite à faire rejeter les êtres dont il s'agit parmi les Algues, suirant l'idée de MN. Cohn, Carter, elc., quelque singulier que puisse paraitre un végétal doué de mouvements aussi nets et aussi continus à toutes les périodes de son existence. Au reste un élément important manque encore pour juger cette question, c'est l'histoire complète du déreloppement qui est imparfaitement conmu en ce qui concerne les spores.

Dans les premiers types des Fucacíes nous trourons de nombreux points de ressemblance avec ce que nous arons vu dans le groupe précédent, sauf la localisation plus avancée des organes de la reproduction. Le genere Iancheria, dont l'organisation a ćté ćtudiée arec un grand soin par M. Pringsheim (1855), nous servira de type.

Le I'ancheria sessilis, qui a fait le sujet de ces observations, est me petite plante d'eau donce qui, pour sa structure, se rapproche beaucoup des Conferves et consiste en un tube cloisonnć, ramifié généralement et rempli de matière verte. En deux points très-rapprochés d'un même tube, on voit se former deux petites saillies qui dès l'abord se distinguent facilement l'une de l'autre, et par la rapidité de leur croissance, et par leur forme. L'une se développe très-vite, c'est une sorte de tube qui bientòt se recourbe en hameçon et aupuel on a domné le nom de cornicule; ce sera l'organe màle, l'anthíridle. L'autre ne forme d'abord qu'une bosselure 
élargyie qui s'accroît lentement et montre tonjours une grande tendance à prendre une forme sphérique et beaucoup moins de longueur que l'anthéridie; ce sera l'organe femelle, le sporange. Ces deux parties sont à cette époque en libre communication avec l'article de la plante dont elles dérivent et leur contenu ne diffère pas.

En snirant le copnicule dans sou développement. on le voit s'allonger et se recourber sur lui-mème en corne de bélier; à un certain moment une cloison se prodnit dans son intéricur, mais en laissant la moitié ou les deux liers inférieurs en libre communication arec la plante mère. C'est dans la loge supéricure que vont se passer les plus importantes modifications. La prenière, qui précède mème un pen la formation de la cloison, consiste en un changement dans la nature du contenu de l'extrémité du cornicule: les granulations y deviennent plus ténues, le liquide s'éclaircit, en sorte qu'an moment de la séparalion il ne contient plus que de fines granulations moléculaires. Bientòt diuns ce plasma apparaissent des corpuscules en bâtomnet, doués d'abord d'un moilvement obscur, mais qui phus lard s'agitent avec une assez grande rapidité. Lorsqu'on les examine isolés et sortis de l'anthéridie, on voit qu'ils se composent d'un corps allongé mesurant environ (2)m,, 012 , marqué d'un point brun et pourvu de deux cils yni ne sont pas, comme daus les corpuscules analogues que nous avous vus jusqu'ici, placés à l'une des evtrémités, mais sont l'un ree's 
le centre, l'autre à la terminaison; leur direction est aussi différente en ce qu'ils se placent sur le prolongement l'un de l'autre, en se portant l'un en a vant, l'autre en arrière, au licu de se diriger d'un même côté. L'aspect, les monvements de ces corpuscules, et, comme nous le rerrozs, leurs usages, ne peuvent laisser aucun doute sur leur nature; ce sont les anthérozö̈des. (M. Prinģsheim préfère leur donner le nom de spermatozoüdes.

Pendant ec temps, le développement de la bosselure roisine du cornicule, qui doit domner naissance au sporange, a continté à s'accuser; sa taille s'est beaucoup accrue el elle forme comme une petite sphère soudée au tube du Vaucheria et en libre communication arec sá cavité. Son contenu, d'abord idenlique à celıi de la plante mère, ne Larde pas à se modifier, mais d'une faron tonte différente dès l'abord de ce que nous avous vu dans l'orģane mâle. Au lieu de s'éclaircir, le liquide se charge de granules de nature graisseuse el de chlorophylle. Peu de temps après, apparaît subitement à la base de la sphère une cloison qui ferme l'ouverture de communication entre celle-ci el la cellule mère; ce phénomène se produit dans le sporange un pen après l'époque où, d'une facon analoģue, l'extrémité du cornicule s'est séparće de la carité commune. En mème temps, la forme s'est un peu modifiéc: la sphère u'est plus aussi régulière, elle pousse, et cela précisément du coté de l'anthéridie, une sorte de prolongement qui, suivant l'expression de M. Pringss 
heim, lui donne l'aspect d'un orule semi-anatrope.

Aussitòt que la cavité du sporange est nettement limitée, on voit les gros granules qu’il contient et la matière colorante se rassembler au centre, sous forme d'un amas opaque entouré d'une substance mucilagineuse épaisse qui en occupe la périphérie, d'abord d'une facon à peu près égale, mais qui bientôt semble s'accumuler en plus grande quantité dans ce prolongement dont nous avons parlé plus lıaut. Cette matière paraît surtout destince à opérer la déhiscence du sporange, pour permettre l'arrivée de l'anthérozoüde jusqu'à la spore primordiale qui n'est autre chose que l'amas central. En effel, par suite de l'abondance de la matière muqueuse, on voit la paroi du sporange s'amincir, puis se perforer: cette matière fait alor's saillie à l'extérieur, el la plus grande partie se sépare sous forme d'un globule hyalin, qui, pendant un certain temps, reste adhérent ì la partic interne par une sorte de pédicule, ec qui a pu induire en crreur certains olsservateurs touchant la manière dont s'opère la fécondation.

Au moment où ces phénomènes qui font communiquer la cavité du sporange avec l'extérienr s'accomplissent, la déhiscence de l'an théridie a éģalement lieu: elle consiste en une perforation de l'extrémité du cornicule, laquelle semble dépendre de la résorption du tissu en ce point. Les corpuscules fécondateurs se répandent alors dans te liquide ambiant et s'y agitent avec vivacite; un grand 
nombre se dirigent ver's l'ouverture du sporange et on les voit essayer de parvenir jusqu'à la spore primordiale dont ils ne sont plus séparés que par une couche peu épaisse de matière muqueuse, la plus grande partie de celle-ci ayant été expulsée conme on l'a vu plus haut. Quoique le nombre des corpuscules fécondants qui se trouvent à l'ouverture puisse ètre très-considérable, un seul paraît généralement traverser la couche muqueuse, et le premier phénomène qui suit la fécondation, c'est-à-dlire la formation d'une membrane enveloppant la spore, ferme tonte possibilité de contact entre le contenu du sporange et l'extérieur. L'anthérozoüde fécondateur reste pendant un certain temps visible à la surface de la spore an-dessous de la membrane enveloppante, il paraît mème y acquérir un volume un peu plus considérable, mais au bout de quelque temps il disparait sans laisser aucune trace visible de son existence.

Les parois de l'anthéridie vide ne tardent pas à se détruire, et tout le cornicule lui-mème disparait. Quant à la spore, après différentes modifications dans son contemu et ses enveloppes, modifications sur lesquelles nous u'avons pas ici ì insister, elle se détache de la plante mère, et, prar sa germination, reproduit directement un tube de Vancheria.

Telle est la série des phénomènes indiquée par M. Prinģsheim, el la clarté des détails nous laisse peu de doutes sur l'authenticité de ces observations. Toutefois d'autres naturalistes, et en particu- 
lier M. Karsten (1855), ont cru recomnaître un mode tout différent de fécondation, et, revenant à l'ancieme opinion de Vaucher, croient qu'il y a conjugaison réelle entre le sporange et l'anthéridie, au moins dans certains cas. La partic prolongée du sporange, dont nous avons parlé, viendrait se mettre en contact arec le cornicule, et une perforation se produisant en ce point, on conçoit que le mélange des substances s'effectuerait facilement. Dans d'autres cas rapportés par le mème auteur, la matière fécondante sortirait de l'anthéridic sous forme d'une sphère mucilagineuse dans lapuelle seraient les anthérozoüdes, sphère qui viendrait se mettre en contact avec la spore primordiale par l'ouverture du sporange. Des observations ultéricures pourront scules apprendre ce qu'il faut penser de ces différentes théories; on peut d'ailleurs présumer que, suivant les cas, elles peuvent toutes se réaliser.

Dans la famille des OEdogoniées, comprenant jusqu'ici les denx seuls genres OE:dogonium et Bulbochecte, les phénomènes de la fécondation présentent une complication que nous n'avons pas rencontrée dans les plantesprécédentes, par l'intercalation dans certains cas d'un végétal réel spéciat, chargé de fournir l'authéridie. La petitesse de ces algues d'eau donce facilitant les observations, elles ont été fréquemment examinées par les naturalistes, el les travaux de MN. Pringsheim, de Bary, Vaupell, etc., en font les végétaux inférieurs lẹs micux 
connus peut-ètre sous le rapport des phénomènes de la reproduction.

Ces algues sont formées de filaments cloisommés simples, dans le genre OEdogonium, ramifiées dans les Bulbochcele; c'est là la principale différence qui les distingue. La reproduction a lieu, d'une part, par zoospores produites dans les cellules sans l'interrention des sexes; d'autre part, par des spores proprement dites dues au concours d'anthéridies et de sporanges. La formation des zoospores ne doit pas nous arrèter ici; nous nous bornerons à rappeler qu’elles se développent isolément dans un grand nombre de cellules végétatives, qu'elles en sortent sous la forme ordinaire de spores ciliées, el donnent directement naissance par développement prompt à une plante complète.

La reproduction par sexes diffère assez dans les détails, quand on considère telle on telle espèce, pour qu'il soit difficile de l'exposer d'une manière goénérale; nous préférons prendre un type, et, après avoir étudié les phénomènes de sa génération, nous pourrons plus facilement faire comprendre ce qui a lieu dans les autres cas.

Dans l'OEdogonium ciliatum que M. Pringsheim a particulièrement éludié, si l'on considère un des filaments constituant une plante complète, on y recomnaît trois espèces de cellules : les unes, les plus nombreuses, dans lesquelles se forment les zoospores dont nous avons parlé plus hant; d'autres généralement espacées sur la longueur de la tige, 
remarquables par leur grossemr ; cést là que se déreloppent les spores proprement dites; nous pourrons done les désigner sous le nom de sporanges (oogonium, Pringsheim); enfin une troisième espèce de cellules placées vers l'extrémité du filament, audessus des sporanges, et qui donnent naissance à des corps qu'on pourrait au premier abord confondre avec les zoospores, mais qui en diffèrent absolument par leur destination, et auxquels nous donnerons dès à présent le nom d'androspores, nom que leur a imposé M. Pringsheim. Étudions plus en détail ces deux dernières espèces de cellules.

Les sproranges dans l'OEdogonium cilintum se différencient des autres cellules an premier coup d'oil par leur forme ventrue el leur contenu plus opaque formé de granulations plus voluminenses; leur dimension est d'environ $0^{\mathrm{mm}}, 0$, Les grannlations sont rassemblées au fond de la cavité dont elles occupent la plus grande partie; dans la parlie supérieure se trouve un petit disque mucilagineux transparent; l'ensemble de ees parties constitue la spore primordiale. Jusqu'anx approches de la fécondation, le sporange el son contenu n'éprouvent ancune modilication; ver's eette éporpue une rupture se fait au point où le sporange s'unit avee la cellule qui lui est supérienre, de telle sorte que celle-ci se détache en totalité on en partie, et la cavité conmmique avec l'extérienr. En mème temps, du cóté de la portion mucilagineuse de la spore primordiale, an point où vient de se faire la 
séparation, on roit s'élever un tube qui sort 111 jeu de la cavité sporangique, et s’incline latéralement. Ce tube, qui paraîtrait dépendre d'une membrane spéciale se produisant alor's autour de la spore, a reçu de M. Pringsheim, à cause de ses usages, le nom d'utricule copulatrice.

Revenons aux cellules où se forme l'androspore et au développement de celui-ci. Elles se distinguent des cellules végétatives ordinaires pa leurs dimensions moindres, mais au reste leurs caractères el leurs formes sont les mêmes; l'androspore qui s'y produit, dans son mode même de végétation et son aspect, diffère si pen des zoospores qu'on trouve dans les cellules véģétatives ordinaires, qu'Al. Braun les avait confondus en donnant aux uns le nom de macrogonidies, tandis qu’il dommait aux autres celui de microgonidies, faisant allusion à leur caractère le plus saillant, la différence de taille. Ces corpuscules, arrivés à leur ćtat complet de développenent, s’échappent des ameanx qui se désarticulent à ce moment et nagent librement dans le liquide; ils sont ovoïdes, remplis de matière verte dans leurs quatre cinquièmes postéricurs environ, avec un rostre transparent entouré d'une comronne de cils yui leur permet de se monvoir avec agilité dans le liquuide ambiant. An bout d'un certain temps, on les voit venir se fixer par le rostre sur les sporanges dans une position qui serait invariable pour ehaque espèce; dans l'ofdognnium ciliatum, e'est à pen près 
vers la moitić de la hanteur de la paroi. Les cils tombent, et cette sorte de spore mobile subit alors une réritable régétation qui va la changer en organe producteur des éléments mâles de la génération, d'où le nom d'androspore. Les phénomènes qui se passent alors rapprochent encore les androspores des zoospores véritables. Le corpuscule une fois fixé se segmente par la production d'une cloison horizontale en deux cellules, l'une basilaire, l'autre supérieure; cette dernière se divise également bientòt de la mème manière, et daus chacune des cellules résultant de cette subdivision on voit se former un amas d'endochrome qui s'organise bientôt pour produire un véritable anthérozoïde cilié, en tout comparable à ceux que nous arons eu l'occasion d'étudier jusqu'ici. Au moment de la fécondation, la partie supérieure de l'anthéridie (nom que doit prendre l'androspore arrivé ì ce point de développement) se détache comme une sorte de couvercle, et l'anthérozoïde supéricur peut librement s'échapper; ce n'est que plus tard, par résorption de la cloison qui l'emprisonne encore, que le second corps fécondant pourra se trouver libre.

Mais avant d'étudier la manière dont l'antlıérozoïde vient se mettre en contact avec la spore primordiale, indiquons en peu de mots les quelques dilférences qu'on rencontre daus la disposition des organes sexucls chez les plantes voisines de celle que nous renons d'étudier. Dans l'OEdogonium ci- 
liatum que nous avons pris pour type, la plante peut renfermer à la fois les cellules simples produisant des zoospores, des cellules femelles et des cellules produisant des androspores; comme c'est de ces derniers que dérivent les corpuscules mâles, la plante peut à la riguenr être considérée comme monoïque; mais, comme, d'un autre còté, la production des anthéridies demande une nouvelle végétation intercalaire, et qu'on peut alors, arec juste raison, regarder les corpuscules màles comme produits par une nouvelle plante, le végétal peut ètre considéré aussi comme diö̈que; M. Pringshem a cru devoir imposer un nom particulice ì celte combinaison, celui de gynandrosporic. Il cxiste en mème temps dans cette espèce des individus tout à fait asexués et ne se reproduisant que par zoospores, cela porte donc à trois le nombre des modes de végétation : $1^{0}$ les individus asexués, $2^{\circ}$ les individus gynandrosporiques, $3^{\circ}$ les individus mâles provenant des androspores.

Dans l'OEdogonium setigerum le développement est le mème; seulement les androsplores sont produits par des individus dilférents de ecux qui donnent naissance anx sporanges. Chez un grand nombre d'espèces du mème genre, les anthérozoïles, au lieu de se produire par l'intermédiaire d'un androspore végétant, naissent directement dans certaines cellules qui sont de véritables anthéridies; dans la majorité des cas, les plantes sont dioïques; cependant, chez un petit nombre de plantes, il y a 
monacic. Toujourss à còté des individus sexués existent des individus agames.

Les plantules dérivant des androspores et qui domnent naissance aux anthéridies offrent aussi quelques diflérences qui portent spécialement sur le plus ou moins grand développement qu'elles sont susceptibles d'acquérir. Dans le cas le plus simple, l'androspore ne se subdivise pas en cellules végétatives, et sa cavité domne directement naissance à deux anthérozoïles. D'autres fois, et e'est le eas que nous avous examiné, il se forme deux cellules, l'une basilaire, véritable cellule végétative, l'autre terminale, dans laquelle les deux anthéridies prennent naissance; la cellule basilaire ne se développe jamais au delà et finit par s'oblitérer. Dans d'antres cas enfin, le nombre des cellules est beancoup plus considérable; la cellule inférieure reste toujour's simplement végétative, les autres an contraire sont anthéridiennes. Nais ici, quand les anthérozoüles ont quitté leurs cellules productrices, la cellule basilaire produit dans sa cavité un bourgeon mobile qui n'est antre chose fu'une androspore. guant aux odogonium, chez lesquels les anthérozoïdes se produisent directement sans formation de plantule màle spéciale, leur développement n’offrant rien de particulier, nous ne croyons pas devoir nous y arrèter.

De quelque manière qu'ait été produil le corpuscule màle, on le voit, alussitòt après sa sortie de l'authéridie, s'agiter daus le liquide, et se diriger 
vers le sporange, dont la déhiscence s'est opérée par le procédé que nous arons décrit plus hant en détail. La transparence de ces végétaux, la grossenr assez considérable du spermatozoüde, en facilitant les observations, ont permis anx naturalistes de préciser très-cxactement les phénomènes, et ess faits peurent jeter un grand jour sur la théorie de la fécondation en général. Dans le cas oì l'anthéridie est fixée sur le sporange. l'issue de l'anthérozoïde se fait presque en face de l'onverture que nous avons signalér à l'extrémité du tube de l'utritricule copulatrice, il s'y engage aussitot, et parvient jusqu'à la spore primordiale, à laquelle il s'attache par le rostre; bientot ses mouvements s'affaiblissent, il s'applique par le cóte sur la portion mucilagineuse oì il adhérait, se liquéfie, et, suivant l'expression de M. de Bary, "se fond à la fin tont entier daus le globe de la spore, de mème qu'une petite goutte d'eau se fond dans une plus grosse." Il ne reste bientôt plus trace de l'anthérozoïle, sauf les quelques granules colorés qu’il renfermait dans son intérieur et qui finissent par disparaître. M. Pringsheim croit anssi devoir admettre, d'après ses nombreuses observations, cette fusion intime des substances miles et femelles. M. Vaupell cependant, se fondant sur les phénomènes qu’il a décrits ehez l'cedogonium setigerum (18.59), pense que le contact seul suffit. Il lui paraitrait en effet difficile, dans cette espèce, que l'anthérozoüde pénćtrât par la petite ourerture qui 
s'est formée sur le sporange; il dit d'ailleurs n'avoir jamais pu observer cette pénétration. Dans ses études algologiques, M. Petrowski (1861) a apporté, en faveur de la théorie de MM. Pringsheim el de Bary, de nouveaux documents qui paraissent de nature à entrainer les convictions; une partie de ces observations répète celles de M. Pringssheim, et l'auteur dit avoir très-clairement reconnu le mílange des denx substances que suivait immédiatement la formation de la spore. Mais, dans un cas curieux, cet observatenr vit un anthérozoïde engraģé assez avant dans l'ouverture copulatrice et sa partic antérienre y était déjà entrée profondément lorsqu'un rotateur l'avala en l'arrachant du sporange. Après une heure et demie d'observalion, aucun des phénomènes qui indiquent la fécondation de la spore primordiale ne s'était produit: le contact des deux substances n'avait done pas sulfi pour produire leur aclion réciproque.

Ia spore primordiale une fois fécondée subit les changements qui doivent l'amener à l'état de spore proprement dite; elle s'entoure de membranes; la portion mucilagineuse avec larnelle s'est fusionné l'anthérozoüde se fond clans la masse générale, qui se seģmente; le sporange s'est alors décomposé, el la spore tombe. Elle est désormais apte à reproduire la plante mère au bout d'un temps variable, suivant les circonstances. Cette reproduction ne se fait pas directement, mais le contenu de la spore se partage en 1 m certain nombre de corps ciliés et 
mobiles, de véritables zoospores qui seront les corps germinateurs. Nous n'avons pas besoin de faire remarquer la concordance parfaite de ce cycle avec celui que nous avous ru chez les conferves pour le Sphceroplea anmulina. Nous retrouvons encore ce double mode de reproduction par capsules à germination prompte. zoospores, par corpuscules i) germination à longue portée, spores.

Nous u’avons pas parlé jusqu’ici du gemre Bulbochcete, et nous ne croyons devoir le signaler qu'en passant; si, au point de vue de la végétation, il présente des particularités importantes qui le distinguent du genre OEdogonium, particularités sur lesquelles M. Pringsheim a donné des renseignements très-circonstanciés, au point de vue de la reproduction les phénomènes sont irlentiruement comparables.

Les Saprolégniées sont de petites algues aquatiques dont la reproduction va nous offrir des phénomenes des plus curieux rappelant la conjugaison des algues synsporées. L'espèce la plus commune, le Saprolegnia ferax, Kütz (Achlyen prolifera, Nees d'Esbeh, se rencontre très-fréquemment sur le corps des mouches et autres insectes lorsque les cadarres de es petits animaux se tronvent ì la surface de l'eau; ils forment une petite masse blanchâtre formée de filaments à pen près rectilignes; d'autres se trourent sur le corps des poissons, des salamandres; ell 111 mot, toutes les espèces sont parasiles des animaux ou des végétaux, ce qui les avait 
fait, à une certaine éporfue, rapprocher des champignons dont d'ailleurs ils ont en partie le mode de végétation. Tons ces ètres ont le double mode de reproduction que nous avons dejà signalé par spores mobiles ou zoospores, par spores immobiles ou spores proprement dites. Les phénomènes offrent assez de différence dans les diverses espèces pour que nons soyons obligé d'adopter la marche que nous avons suivie précédemment, d'étudier d'abord un type en indiquant ensuite les modifieations que présentent les esperces voisines.

Le Saprolegnia monoïca, ćtudié arec grand soin par M. Pringsheim (18.59), se trouve, comme le Saprolegnin ferax, sur le cadave des mouches immergées; ces deus espèces n'ont mème pu être dislinguées que depuis les recherehes failes sur leur mole de reproduction sexuelle. Les Zoospores se forment dans des cellules terminales el n'offrent, dans teur développement, rien qui mérite d'ètre cité.

Ce sont des cellules placées également an bout des rameanx qui domnent naissance au sporange, et elles se distinguent très-facilement, anssi, dès 18.50, M. Thuret, en Jes observant, avait-il parfaitement reconnu qu'il fallait admettre, daus ces plantes, un double mode de reproduction, bien qu'i cette époque on ne comnit pas encore la reproduclion sexuelle de ces êtres. Leur forme est très-exact'ment sphérique, lenr enveloppe simple et homogìne. le contenu, d'abord finement granuleux et 
demi-transparent, devient un peu plus opaque, puis se segmente, mais ce dernier phénomène n'est pas rógulier, et la substance se sépare plutòt en espèces d'amas mal limités et de forme trés-rariable. Ces masses, d'abord adhérentes à la paroi, ne tardent pas à s'en isoler et prennent une forme arrondie mieux définie, jusqu’à ce qu'enfin, se détachant, elles flottent librement dans la cavité sous forme de petites sphères d'eggal diamètre, parfaitement homogènes et sans membrane propre apparente. Ces corps ne sont antre chose que les spores primordiales; V. Pringsheim leur domne le nom de gonosphióies. En mème temps, la membrane de la cellule enveloppante s'est modifiée sur certains points, elle s'amincit de distance en distance et le sporange finit par présenter en ces endroits des ouvertures arrondies, que l'action de l'acide sulfurique et de l'iode rend bien visibles, comparables à celles que nous avons signalées sur le Sphceroplea anmulina; leur usage est du reste le mème, elles doivent permettre l'entrée des corpuscules fécondants.

La structure des anthéridies est plus singulière. On voit dès les commencements dı développement du sporange des ramifications en nombre variable, à ce qu'il semble, se produire an-dessous de ce dernier sur l'article qui le supporte; elles peuvent se subdiviser elles-mèmes et viennent se placer tout antour du sporange. A leur extrémité se passent alors des phénomènes analogues à cenx que nous arons déerits dans le cornicule du Vaucheria; le con- 
tenu prend un aspect spécial, puis un diaphragme vient transformer cette extrémité en une cellule où se développeront les anthérozoïdes. La structure de ceux-ci n'est pas exactement conmue, attendu que, par suite mème du mode de fécondation que nous allons décrire dans inn instant, il est difficile de les observer it l'état de libertí; cependant leurs mouvements de trépidation dans l'intérienr de la cellule où ils se produisent portent à penser qu’ils sont pourvus de cils vibratiles el peu différents de ceux que nous arons pencontrés jusqu’ici dans différents genres d'Algues. Bien arant que les anthérozoïdes se montrent doués de mourement, les rameaux qui supportent les anthéridies se sont rapprochés du sporange au point de le toucher par leur extrémité qui s'applique sur sa surface; ce phénomène a lieu vers l'époque ou le contenu plasmatique commence it ébancher les spores primordiales. Les amincissements de la membrane sporangique dont nous avons parlé se trourent en rapport avec les anthéridies, el, quand la perforation se produit, celles-ci culvoient, dans l'intérieur du sporange, une sorte de boyau qui pénètre jusqu'au centre de la sphère el y conduit les corpuscules fécondants. La profondeur it laquelle parviennent les anthérozoürles créc une des principales difficultés de lemr élude, attendu qu'en ce point ils sont cachés par l'amas des spores primordiales. Le phénomène de la fécondation accompli, les spheres s'entourent d'une double memhrane ch la dissémination se lait par simple pupture 
du sporange. Suivant M. Pringsheim, dans la suite du développement, la spore proprement dite à laquelle il dome le nom d'oospore peut, en gुermant, donner directement naissance an végétal parfait; d'autres fois, au contraire, comme l'a observé V. Cienkowsky, cette reproduction n'a lien que par l'intermédiaire de zoospores, comme dans le Spheroplea annulina, les OEdogonium et les Bulbochcete. Ces auteurs se sont également assurés que la spore fécondéc et développée consepve très-longtemps la propriété germinative.

En ce qui concerne le Saprolegnia ferax, les phénomènes de la fécondation sont moins bien connus; mais cependant ce qu'on en a pu observer indique une grande conformité avec ce qui se passe dans l'espèce précédente; il paraitrait senlement y aroir ici diö̈ité. Les traraus de M. Lnger (1843), de I. Thuret 1850), portent spécialement sur la reproduction ascxuclle par zoospores; toutefois ce dernier avait observé et fiğuré des sporanges mùrs qui, comme nous l'avons dit, le portaient ì supposer un second mode de génération. Le développement de ees organes femelles ne diffère en rien de ce que nous avons décrit dans le Saprolegnia monoïca, les perforations mimes s'y retronvent, et rons ces faits avaient été parfaitement décrits et figurés par M. Thuret, jusqu'ì ces perforations mèmes. Quant aux anthéridies, ce paraissent ètre des cellules fu'on rencontre sur de petites plantes distinctes de celles qui portent les sporanges et daus lesquelles 
se produisent des corpuscules qui ont évidemment la forme des anthérozoüdes. Ils consistent en petits corps ovoüdes de $0^{\mathrm{mm}}, 008$, pourvus de deux cils vibratiles et se mouvant arec assez de rapidité. On peut admettre arec grande vraisemblance, suivant l'opinion de M. Pringsheim, que ce sont réellement des corps ficondants, car ils ne se rencontrent que dans les espèces à sporanges non entourés d'anthéridies; cet auteur s'est d'ailleurs assuré qu'ils sont incapables de germer, ce qui empèche de pouvoir les confondre avec des Zoospores, dont leur petit volume les rend en outre bien distincts. Quant à la facon dont ils gagnent la spore primordiale, le fait n’a point encore été observé, mais ce que nous avons décrit dans des cas analogues, en particulier dans le genre Sphleroplea, nous fait suffisamment comprendre quils pénc̀trent par les ouvertures de la paroi du sporange.

Dans le genre Pyllium, très-voisin du précédent et dont les espèces vivent en parasites sur diverses plantes aquatiques, et en particulier dans les cellules de quelques Algues synsporées, les phénomènes de la génération sexuelle dans la seule espèce où ils soient connus, le Pythium monospermum, sont trèsanalogues à ce que nous arons décrit chez le Saprolegnia monoïca. Dans le voisinage du sporange, qui ici n'est pas toujours terminal et ne contient qu'une spore primordiale, se développent un ou deux filaments à l'extrémité desquels se troure l'anthéridie qui s'applique contre l'organe femelle et y fait 
pénétrer un prolongenent par des ouvertures qui se sont produites à cel effet. Le petit nombre d'anthéridies permet fort bien de constater que ces ouvertures pouvant se former également daus des points où il n'y a pas contact de l'organe màle, elles sont bien dues récllement à la constitution mème de la paroi du sporange.

Chez les régétaux marius du groupe qui nous occupe, et en particulier chez les Fucus, la taille relativement beaucoup plus considérable des individus entrainant dans les organes de la reproduction un développement proportionnel, ceux-ci ont de tout temps été signalés par les naturalistes. Les travaux descriptifs de MHI. Decaisne et Thuret (1844), ceux de MM. Derbès et Solicr(1850), en firent comnaitre la structure avec ume précision telle qu'au point de vue anatomique des faits de détails sculs ont pu, depuis, y être ajontés. Quant aux usages physiologiques, ils étaient encore fort obscurs lorsqu'en 1853 M. Thuret fit connaitre ses expériences sur la fécondation chez le Fucus vesiculosus, expériences qui furent la première notion positive sur la reproduction sexuelle des Aggues, et qui doivent ètre regardées comme le point de départ de toutes les recherches postérieures dont plusicurs ont déjà été exposécs plus haut.

Dans les Fucus les organes de la reproduction sont situés dans des cavités placées sur des points de la fronde variés suivant les espèces et auxquelles on a domué le nom de Conceptacles. Elles sont exac- 
tement closes de toutes parts, saul en un point on existe un petil pertuis nommé ostiole, par lecuel doil s'effectuer la sortic de la maticre contenue. Dans le conceptacle se trouvent trois sortes d'organes, les sporanges (auxquels on dome parfois, à tort, le nom de spores), les anthéridies el les filaments cloisomués qu'on pourrait nommer. paraplyyses. Ces derniers ne sont que des productions de cellules dont le ròle, dans les phénomènes qui nous occupent, est accessoire et se borne au plus à aider à l'issue des deux premières espèces d'or'ganes qui, eux, agissent activement dans la reproduction.

Les organes femelles, sporanges, el les organes màles, anthéridies, peurent être placés dans le même conceptacle, el la plante est dite hermaphrodite; tantôt alor's ils sont irrégulièrement entremèlés les uns avec les autres (Pelectia canaliculata), d'autres fois ils affectent une disposition régulière, les sporanges se trouvant par exemple au fond de la cavité, landis que les anthéridies se groupent au pourtour de l'ostiole (Cymaduse tuberculata). D'autres fois le conceptable ne renferme qu'unc espèce de corps reproducteur, el la plante peut alor's étre monoïque (Fucus nodosus) ou dioïgue (Fucus serrutus). Ces deruières espèces ont élé le plus habitucllement l'objet des expériences sur la fécondation, Ja disposition des organes domnant de grandes facilités pour les effectuer.

Si l'on cxamine le déreloppenent des organes femelles, daus le fucus vesiculosus par exemple, on 
voil que le sporange dérive de la prolifération de certaines cellules de la paroi du conceptacle, qui prennent un développement assez rapide. Elles se divisent bientòt, par une cloison horizontale, en deux cellules superposées; la cellule basilaire ne s'accroît pas, et sert simplement de point d'attache à la supérieure dans ladpuelle vont se passer les phénomènes principaux. Le premier consiste dans l'accumulation d'une matière verdâtre opaque, qui distend considérablement sa cavité en lui faisant prendre une forme plus ou moins sphérique. On voit vers cette époque apparaître huit noyaux, antour desquels la substance ne tarde pas à se segmenter, de manière à former autant de cellules de formes polyédricues par suite de la pression qu'elles exercent les unes sur les autres; ce sont antant de spores primordiales qui tendent de plus en plus à devenir parfaitement sphériques.

La paroi du sporange est double : la membrane externe a reçu le nom de périspore, l'autre le nom d'épispore; cette dernière parait en connexion intime avec les huit spores incluses. En effet, alt moment de la déhiscence, le périspore venant à se lendre, les corpuscules contenus n'en sortent pas moins en une scule masse, rémis qu'ils sont par l'épispore. Si cette masse se trouve en contact avec l'ean de mer, on ne tarde pas à voir l'épispore se dissoudre sur un point de sa circonférence, el les spores faire hernic à l'extéricur avec une troisic̀me membrane ténuc, hyaline, qui paraît former un sac 
cloisonné en autant de loges quil y a de spores. Cette dernic̀re tunique adhère assez intimement ì l'épispore, pour qu'en sortant elle retourne celui-ci comme un doigt de gant; elle ne tarde pas à se dissoudre, et met ainsi en liberté les spores primordiales qu'elle contient. Celles-ci se présentent alor's sous la forme de petites sphères homogènes, parfaitement régulières, d'un diamètre de $0^{\mathrm{mm}}, 06$ ì $0^{\mathrm{mm}}, 07$, et dépourvues de membrane, suivant M. Thurel et M. Pringsheim.

Dans les conceptacles màles, on voit se développer ì la base des paraphyses surtout, mais aussi à une certaine hauteur sur elles, des cellules allongées, ovoüdes, renfermant d'abord un contenu gramuleux qui ne tarde pas à s'organiser en corpuscules doués de mouvement, qui ne sont antre chose que les anthérozoïles; chaque cellule est done une véritable anthéridie; elle est forméc, comme le sporange, de deux membranes: l'extérieure, qui se rompt au moment de la déhiscence, et laisse échaplper les anthérozö̈des enveloppés d'une seconde membrane qu'on peut comparer à l'épispore, mais bien plus ténue et fugace, qui se détruit avec une grande facilité, en laissant les corpuscules fécondateurs nager librement daus le liquide qui les entoure. Ceux-ci sont ovoüles, ils présentent un point rouge bien visible, el denx cils vibratiles dirigés l'un en avant, l'autre en arrière, et l'incigale longuenr; le plus court parait placé à l'extrémité lat plus étroite qui se dirige toujours en araut, el que 
nous arous appelée le rostre; le second s'insère sur le point rougge et traîne derric̀re l'anthérozoïde. Les organes sexucls une fois commus, il nous reste à ćtudier l'action réciproque des uns sur les autres, et les conditions de diö̈eité du Fucus vesiculosus rendent les expériences faciles et démonstratives. Si on examine, surtout pendant l'hiver, des frondes de cette plante non immergées, mais dans une atmosphère humide, conditions qui se trouvent ordinairement réalisées lors du rellux, on ne tarde pas à voir les ostioles des conceptacles donner issue aux organes qu'ils contiemnent, spores entourées de l'épispore d'une part, anthérozoïdes de l'autre; on pent supposer que la dessiceation de la fronde, la disposition des paraphyses, sont la cause effective de ce phénomène. Les corpuscules forment alor's sur les conceptacles des petits amas verdàtres pour les spores, orangés pour les anthérozoïdes, et on peut, en les examinant au microscope, recomnaitre très-facilement leur composition. Il est également possible, en les. conservant isolés pendant un certain temps, de reconnaitre que les corpuscules mobiles sont incapables de germer et ne sont donc pas des zoospores, ce que MM. Decaisne et Thurel avaient démontré dès 1844, et aussi que les spores primitives se décomposent au bout d'un certain temps sans germer ni présenter aucun des phénomènes dont nous allons avoir à nous oceuper.

Si l'on examine une portion de chacune des matières verte et orangée placées dans une petite 
quantité d'eau de mer, on ne tarde pas à voir les spores primitives d'une part, les anthérozoïdes de l'autre, en liberté daus le champ du microscope; ees deruiers s'aggitent avec beaucoup de vivacité et se rendent sur les spores en si grand nombre que s'ils atteignent celles-ci encore renfermées dans lá membrane hyaline intra-épisporique, avant la déhiscence complète, ils peuvent arrêter ce phénomène en formant un revêtement qui sans doute empêche l'action de l'eau sur la membrane. S'ils rencontrent les spores primitives libres, ce qui est le cas ordinaire, ils se fixent sur elles par leur rostre d'abord, puis par le côté; le long cil vibratile se portant toujours à l'extéricur, l'ensemble de ceuxci forme une sorte de comromme rayonnante agitée d'un mouvement de trépidation qui ne tarde pas à se communiquer à la sphère enveloppéc, laquelle se met à tourner sous les yeux de l'obscrvateur avec une grande rapidité. Celte rotation qui est fort habituclle ne paraît pas cependant indispensable à la fécondation; elle se fait dans le sens où lc plus grand nombre de cils sont dirigés, de sorte que si, pendant que le phénomène a lieu dans $u$ sens, de nouveaux anthérozoïdes viennent s'adjoindre aux premiers, on peut voir la spore s'arrêter un instant puis tourner en sens inverse. Au bout d'un certain temps, la rotation diminue d'activité et finit par cesser complétement. La durée de ce phénomène est d'environ une demi-heure. Des changements importants se passent alor's dans la 
spore primordiale, qui devient la spore proprement dite; le premier consiste dans l'apparition d'une membrane nettement limitée. N. Thuret a donné un moyen qui nous paraît très-propre à rendre ce phénomène visible, c'est l'emploi du chlorure de zinc. Cette substance a la propriété de resserrer cu quelque sorte la subslance de la spore, de manière à en faire exsuder une sorte de mucilage qui paraît servir de substratum à la matière verte. Si l'on fait aģir ce réactif avant la fécondation, le mucilage apparaît sur les bords de la sphère et y forme des prolongements qui s'étendent irrégulièrement dans toutes les directions. Dix minutes seulement après le contact des corps fécondants, la matière mucilagineuse se trouve visiblement empêchée dans sa diffusion par une membrane qu'elle soulève régulièrement tout autour de la sphère. Cette membrane s'épaissit de plus en plus et finit par ètre facilement perçue sans l'action d'aucun réactif.

Ici se présente encore la question de savoir si l'anthérozoïde agit par contact ou doit se fondre et pénétrer dans la spore. M. Thuret penche pour la première de ces opinions, bien que dans une lettre publiée en 1859, dans les innales des sciences naturelles, ce savant paraisse moins affirmatif. M. Pringshein, au contraire, croit à la fusion des deux substances, et se fonde surtout sur la présence constatéc par lui de granules rouges sous la membrane de la spore, granules qui ne lui praraissent pouroir se rapporter qu'aux corpuscules ana- 
lognes quion roit dans les anthérozoides; le reste de la substance de ceux-ci aurait disparu pour accomplir la fécondation. Sans se prononcer aclucllement entre deux aussi habiles observateurs, on ne peut cependant nier que les faits connus dans d'autres végétaux analoğnes donnent un graud poids à l'opinion de M. Pringsheim.

Les spores me fois fécondées, le végétal se reproduit directement sans formation intermédiaire de zoospores.

Dans les autres Fucacécs, les phénomènes fondamentaux paraissent identiquement comparables, la disposition des organes senle offrant certaines différences accessoires sur lesquelles nous ne croyons pas devoir nous appesantir. Notons toutefois gine la fécondation ne s'opère qu'entre les produits d'une mème espèce, ce que les expériences de M. Thuret démontrent évidemment.

Chez les Floridées, les phénomènes de la fécondation sont beancoup moins bien conmus que dans les groupes précédents. l.es organes de fruetification sont triples; les uns fournissent des corps reproducteurs au nombre de quatre dans chaque cellnle, auxquelles on a donné pour cette raison le nom de tétraspores. Chacun d'eux est susceptible de ggermer et de reproduire directement la plante; ce seraient done les analogues physiologicques des zoospores. Dans d'autres organes dits anthérilies se trouve une grande quantité de corpuscules qu'on 
regarde comme des anthérozoïdes, mais dont l'usage est loin d'être hien connu; ils sont privés de monvement, transparents, sphériques ou discoüdes. Enfin, dans de véritables conceptables se rencontrent d'autres corpe qui sont peut-ître les organes femelles, spores ou sporanges; cependant ils paraissent susecptibles de germer spontanément; M. Pringsheim ne serait pas éloigné de supposer qu'ils produisent les organes fenclles par une végétation secondaire, comme nous verrons plus tard cela se produire chez des cryptogames plus élerées. Ces notions, on le roit, sont très-vagues, et bien que la nature des organes fasse présumer l'evistence des sexes chez les Floridées, de nourelles recherches seraient indispensables pour fixer ce point de la seience; ce doute, au reste, se retroure dans les deux ordres que nous allons maintenant examiner. 


\section{CHAPITRE II.}

\section{LICHENS.}

Sous le point de vine descriptif, les végétaux dont nous arous maintenant à parler ont été l'objet de travaux nombreux et importants, mais, malgré l'élude attentive qu'on a faite de leurs orģanes reproducteurs, les phénomènes de la fécondation, qunelque probable qu'elle soit, doivent être regardés comme étant encore complétement inconnus; aussi serons-nous bref en ce qui les concerne.

On voit à la surface des plaques foliacées coriaces qui composent les lichens et qu'on connaît sous le nom de thalles, trois sortes d'organes regardés comme servant à la reproduction :

$1^{\circ}$ Les Apothécies.

$2^{\circ}$ les Spermogonics.

$3^{\circ}$ Les Pycnides.

Les premiers et les troisièmes fournissent sans ancun doute des corpuscules qui peuvent reproduire la plante; les seconds sont considérés comme formateur's des éléments mâles.

Les apothécies sont généralement regardées comme étant les véritables organes femelles. Ce sont des cavités comparables an conceptacle des finces, ayant une paroi distincte du tissu ambiant et à lapruelle on donne te nom d'hypothecium. Le 
contenu comprend les paraphyses et les théques. Les premières consistent en des filaments cloisonnés qu'on a pris à tort pour des organes mâles, mais qui ne sont que des produits celluleux destinés sans doute à favoriser la dissémination des spores; leur ensemble a été nommé thalaminm. Les thèques se trouvent placées entre les paraphyses; ce sont les organes essenticls de la reproduction; leur forme est généralement celle d'une cellule allongée ovoïde, renfermant un nombre plus ou moins considérable de spores. Celles-ci paraissent se former simultanément dans tout le blastème épanché dans la cellule, an moins quand clles sont peu nombreuses. A l'état de maturité, c'est-ì-dire possédant la propriété de germer, elles se composent d'un contemu homogène et de deux tunicpues, l'épispore et l'endospore. Les paraphyses et les thèques, à la rémnion desquelles les cryptogamistes donnent le nom de thecium, en appelant la couche la plus superficielle epithecium, sont unies par une sorte de mucilage destiné sans doute à faciliter le glissement des parties lor'sque les spores doivent sortir du conceptacle; on l'appelle gélatine hyméniale. On tronve encore dans les apothécies des corps qu'on rencontre aussi dans la couche moyenne du thalle et qu'on appelle gonidies; mais ils ne paraissent pas servir spécialement it la reproduction.

Les spermogonies ont la structure générale des apothécies; dans win conceptacle on trouve des 
filaments cloisonnés dits stérygmates, comparables aux paraphyses, et des corpuscules appelés spermaties, qu'on regarde comme représentant les corpuscules fécondants et comparables aux spores. L'agencement de ces parties n'est cependant pas le même absolument, attendu qu'ici les spermaties ne sont contenues daus rien que l'on puisse comparer aux thèques et naissent directement à la surface des stérigmates. Nous arons ru, au reste, quelque chose d'analogue dans la disposition des anthéridies et des sporanges, par rapport aux paraphyses, chez le fucus vesiculosus.

Les pycnides ont été considérées par certains anteur's comme des parasites, mais M. Tulasne, en 1852, a parfaitement démontré que cette opinion n'était pas vraiscmblable et qu'il fallait y voir des organes sporigènes supplémentaires. Ce sont encore des conceptacles dans lesquels se trourent des organes susceptibles de germination et supportés sur une seule cellule basilaire, d'où le nom de stylospores qui leur a été donné.

Quelle est maintenant la valeur réelle de ces différents organes? Jusqu’ici on n'a pu mettre en avant que des hypothèses plus ou moins probables, mais aucune observation probante n'ayant été citée, nous croyons devoir passer légèrement sur ce sujel.

La ressemblance des thèques avec les sporanges de diverses cryptogames est évidente, mais les spores qu'elles contiennent doivent-elles être rappor- 
tées à des bourgeons mobiles, comme les zoospores, ou à des spores fécondées? En tout cas, cette fécondation doit s'opérer de très-bomne heure, car la germination possible des spores à l'intérieur des thèques encore retenues dans l'apothécie et intactes n'est pas douteuse.

Quant aux fonctions probables des spermaties, on invoque leur non-faculté germinative, fait qui parait bien constaté, pnis leur forme, leur conleur, leur transparence, leur petitesse, leur nombre, ete. Ce ne sont que des probabilités. Le seul fait que l'on puisse récllement invoquer est celui de certaines espèces, telles que le Sticta limbata, le Sticta aurata, et quelques autres qui, dioïques et n'ayant pas en Eurpe d'individus à spermogonies, ne donnent pas de fruits, tandis qu'en Amérique ils en produisent. Ce fait, s’il se généralisait, serait sans doute d'un très-grand poids.

Dans ces dernières années, M. Karsten (1860) crut, dans le Conogonium andinum, avoir trouvé le véritable mode de fécondation des Lichens. Pour lui, autour de l'apothécie naissaient des filaments comparables à ceux du Saprolegnia monoïca, lesquels fournissaient les ćléments fécondants. M. $\mathrm{Ny}$ lander, dont la compétence en un pareil sujet ne saurait ètre contestée, a montré que M. Karsten avait pris pour une apothécic naissante $m$ jeune rameau; ces observations ne méritent donc pas d'ètre prises en considération, ce seul fait les infirmant complétement. 


\section{CHAPITRE III.}

C.II I MPIGNONS.

Les Champiğnons sont peut-être de tous les végétaix cryplogames ccux sur lesquels l'attention s'est portéc le plus tôt, et on a cherché à toutes les époques à tronver l'explication de leur reproduction. La façon dont un grand nombre, et quui peuvent atteindre des dimensions considérables, apparaissent en quelque sorte subitement, était faite pour frapper vivement les observateurs les moins ex ercés; aussi, dans les écrits des plus anciens natura listes, Théophraste, Pline, Dioscoride, les trouvon s-nous très-clairement mentionnés. Ces anteur's n'y voyaient qu'une viscosité née de la putréfaction, et ces idées de génération spontanée ont toujours été en grande faveur relativement à l'origine de ces végétanx; Morison les regardait comme produits par un mélange de soufre arec la graisse de la terre; Dillen les désignait sous le nom de plan tes nées d'une fermentation putride; Necker jes croyait une nonvelle rémion des éléments organiques ou du tissu cellulaire des régétaux, et voulut en faire un règne à part sous le nom de Rigne mésimal; de nos jours, an reste, on a pu 
voir que ces théories comptaient encore quelques r'ares partisans. Cependant, dès ces époques, d'autres observateurs, Tournefort, Micheli, Haller, etc., admettaient la propagation de ces végétaux par semences. Maintenant ces idées peuvent être regardées comme hors de tonte contestation, et les travaux de MM. Thuret, L.-R. et C. Tulasne, Léveillé, Montagne, etc., ont clairement montré que la difficulté n'était pas d'expliquer comment pouvaient se propager les Champiğnons, mais plutôt d'interpréter les différents usages des nombreux corps reproducteurs dont sont pourvus ces végétaux.

Nous n'essayerons pas d'entrer dans le détail descriptif des nombreux appareils existant dans les différentes plantes de ce groupe, d'autant plus qu'au point de vue spécial de la reproduction sexuelle nous en lirerions peu de renseignements. Chez les Hypoxylés (Sphoria, Melanconium, etc.), M. Tulasne décrit quatre organes de reproduction: les conidies, dont la nature comme corps susceptibles de germination paraît très-évidente; les stylospores contenus dans les pycnides et comparables peut-être aux parties ainsi dénommées des Lichens; ces deux espèces d'organes sont sans doute des bourgeons mobiles, et rien n'y lait supposer ume action fécondante préalable; les spermatics renfermées dans les spermogonies, corps qui, malggré leur nom, ne doivent pas être considérés comme élant certainement les organes mâles, mais qui cependant ne paraissent pas susceptibles de 
germer, au moins dans les circonstances ordinaires; enfin les véritables spores endothèques, qui peuvent, par analogie, ètre rapprochées de celles des Lichens et sont pent-être des corps fécondés. Ici, comme chez les plantes précédemment étudiées, la germination dans l'intérieur des thèques n'est pas douteuse.

Au reste, toutes les questions relatives aux usages de ces organes sont encore compliquécs de difficultés très-orandes résultant de confusions sur la nature et la réalité de certaines espèces. En effet, on a décrit comme végétanx parasites de ccrtains Champignons leurs organes de fructification; c'est un point sur lequel M. Tulasue a particulièrement insisté.

Enfin, une considération que l'on ne doit pas perdre de vue, c'est une la faculté germinative derant probablement exister dans toutes les parties de ces végétaux inféricurs à un degré plus ou moins développé, on pourail être tenté de prendre pour des fructifications à bourgeons mobiles des parties qui ne méritent pas ce nom à proprement parler. Il faut, au reste, convenir que ces choses sont si connexes, qu'en théoric on peut regarder leur distinction comme purement abbitraire. C'est sans doute à ces causes qu'il fant attribuer les dissidences qui partagent sourent d'éminents cryptogamistes dans la deseription des organes d'un même végétal; ainsi, pour les Erysiphe, M. Tulasne admet trois sortes d'organes repro- 
ducteur's, tandis que M. Berkeley en déerit einq.

Quels sont de tous ces organes ceux qu'on peut regarder comme pouvant être rapportés à la génération sexuelle? Cette question, dans l'état actuel de la science, est complétement insoluble. On peut dire que les appareils à spores endothèques, lor'squ'ils existent, sont de tous les organes ceux qui rappellent le plus les organes femelles, mais ce n'est qu'une simple analogie. Qunant aux organes mâles, ils paraissent complétement inconnus. M. Thuret, dans ses recherches sur les anthéridies (1851), dit avoir examiné arec M. Lércillé sur le mycelium des Erysiphe " de pelites vésicules pédicellées, aux"(puelles le ròle d'organe fécondant semble assez bien "convenir, "mais celle idée ne parait pas depuis cettc époque aroir été reprise par jersonne. Dans les champignons basidiosporés, on trouve entre les organes qui leur ont valu cette dénomination des cellules fort déreloppées et très-différentes par leur forme de celles rui les avoisinent; on a également voulu y voir des organes mâles (Corda); ce sont les cystirles; mais on doit les regarder comme des cellules végétatives hypertrophiées el n'ayant aucun rapport direct arec la génération : c'est l'opinion que senble admette M. Léveillé et que partage M. de Seynes.

Avant de terminer, indiquons um fait avancé par M. A. de Bary, relatif à la germination des spores de quelques Champignous (Cysinpus candidus, C. cubicus, peronospora devastatrix), lesquels ne 
domncraicnt pas directement naissance aux filaments du mycelium, mais se segmenteraient en fournissant de véritables zoospores à cils vibratiles et comparables à ceux des Algues, lesquels zoospores reproduiraient le végétal primitif. Or M. Tulasne, dans des espèces voisines, ayant décrit la germination directe des spores, on serait tenté de se demander s'il y a là quelque différence tenant à ce que de ces corps reproducteurs les uns dérivent du végétal par bourgeonnement, tandis que les autres seraient le résultat du concours des sexes. Ce ne sont là que de simples hypothèses basées sur l'analogic que présentent ces phénomènes avec ceux qu'on remarque chez certaines Algues, cl en particulier sur Ie Saprolegnia ferax, qui d'ailleurs présente tant de points de ressemblance avec les véritables champignons.

Toutes ces questions ne pourront sans doute s'élucider que quand, par l'étude des germinations, comme celles tentées par M. de Seynes, on sera arrivé à comnaître d'une manière certaine le développement de ces végétaux : ce que nous allons voir dans les familles suivantes nous montrera assez quelle peut être l'importance de cette méthode. 


\section{CHAPITRE IV.}

HÉPATICÉES.

Malgyré leur petit volume, les végétaux dont nous devons parler actuellement ont depuis longtemps fixć l'attention des cryptogamistes, et d'importants travaux ont été publiés sur leur structure; aussi peuvent-ils être rangés parmi les mieux connus. Les organes de la reproduction présentent chez tous, dans leurs parties fondamentales, de grandes ressemblances, et aussi avec ceux qu'on rencontre dans les familles que nous allons avoir à examiner dès à présent; nous croyons donc devoir les décrire avec quelques détails.

Le Marchantia polymorpha, plante commune dans nos pays sur les sols humides et ombragés, nous servira de type. Les magnifiques recherches dont il a été l'objet et qui sont consignées dans le remarquable travail publić sur sa structure par M. de Mirbel en font la plante la mieux conmue du groupe, surtout en y joignant les travaux postéricurs de MM. Bischoff, Thuret, Grocnland, etc.

Ce végétal se présente sous l'aspect de lames vertes étendues horizontalement sur le sol, irrégutlièrement lobées sur les bords; c'est ce qu'on ap'- 
pelle le thalle. Cette partie est généralement parconrue par une sorte de nervure visible surtout en dessous, où sa couleur est souvent un peu différente de celle des parties avoisinantes; cette nervure, arrivée à l'extrémité du thalle, se redresse en une petite tige cannelée sur le côté qui correspond à la fice inférieure, et supportant à son extrémité une sorte de chapeau, de disque lobé ou découpé sur les bords; c'est là que se trouvent les organes sexuels mâles ou femelles. Outre ce mode de reproduction, la plante a ce qu'on peut appeler des bourgeons, lesquels se produisent sans le concours des sexes.

Les disques mâles qui sont portés sur des pieds distinets. car la plante est diö̈que, sont simplement lobés sur les bords, sans profondes découpures; leur face supérieure est concave et cribléc à la maturité d'un très-grand nombre de petites ouvertures dont nous comprendrons plus tard l'usage. Ce disque a la structure du reste du végétal; c'est un amas de cellules revètu d'une cuticule bien nette et présentant à sa surface des stomates sur la structures desquels M. de Mirbel a particulièrement insisté; leur présence entraine celle de vastes méats intercellulaires placés au-rlessous d'eux. Mais ce qui caractérise l'individu, ce sont des cavités en forme de bouteilles dont le fond serait tourné vers la face inféricure du chapean, tandis fue le goulot est en rapport avec la face opposée; ces organes, dans lesquels se forment les éléments fécondateurs mâles, sont les anthéridies (Zoothèques, Gottsche). 
Si on les suit dans leur développement, on voit, dans les points où ces corps doivent apparaittre des amas de cellutes se distinguer par la nature de leur contenu; peu à peu, autour de ces amas, les cellules du parenchyme forment une enveloppe propre, distincte en ce que les éléments qui la constituent sont dépourvus d'endochrome. Les cellules contenues se présentent alor's sous la forme de petits utricules cubiques dans lesquels se tronvent un corpuscule qui n'est autre chose qu'un anthérozoüde (Phytozoaire, Gottsche). Tantòt ce corpuscule sort de sa cellule formatrice dans l'intérieur mème de l'anthéridie, tantòt il est exjulsé avec elle, mais daus ce cas il he tarde pas à la rompre et se meut alors en liberté. Le contenu de l'organe mâle est projeté au dehor's par une ouverture qui se fait à l'extrémité du goulot de l'espèce de bouteille dont nous avons prarlé, et ce sont précisément ces ouvertures qui forment à la face supérieure du chapeau ces petits pertuis que nous avons signalés plus hant. Les anthérozoïdes ont une forme un peu dilférente de ceux que nous avons déerits chez les Algues; ils sont beancoup plus allongés, effilés et terminés par deux soies de très-grande dimension; avant leur issue hors de la cellule productrice, ils sont roulís en hélice dans son interieur. Leur vivacité est extrème, et M. Thuret dit u'avoir pu les figurer qu'après leur dessiccation.

Les chapeanx où se trouvent les organes femelles diffèrent au premier coup d'oil des précédents par 
les profondes découpures qui les partagent en lanières épaisses et arrondies à leur face supérieure; le disque, pris dans son ensemble, a aussi une autre forme, sa face supéricure étant convexe. Leur structure générale est, au reste, celle que nous avons décrite en parlant des organes mâles. C'est à la partie inféricure des lanières que se trouvent les organes femelles auxquels on peut donner le nom de sporanges. M. de Mirbel a décrit leur développement avec grand détail. C'est d'abord une masse celluleuse verte qui ne diffère guère, du reste, dı tissu, et qu'on doit à celte époque appeler archégone ; elle contient la spore primordiale. La forme générale est aussi celle d'une bouteille, mais renverséc. Les utricules de la périphérie se soudent entre eux de manière à former une membrane qui limite l'organe, sauf à la partic libre, où se trouve une oulverture, tandis que les cellules centrales disjointes subissent des modifications très-différentes, suivant le rôle qu'clles sont appelées à jouer. Les unes s'allongent considérablement et prennent une couleur sombre; on voit à leur surface se dessiner une ligne spirale, indice d'une division qui partage bientòt la cellule en deux filaments entortillés l'un avec l'autre; on leur' a donné le nom d'élatères, el leur usage est sans doute relatif à la dissémination des autres cellules renfermées également dans le sporange. Celles-ci ont subi des changements d'une toute autre nature; leur contenu s'est partagé en deux, puis en quatre parties qui s'entourent d'une 
membrane propre et s'isolent bientòt par résor'ption de la cellule mère; elles se trouvent alors libres au milieu des élatères, ce sont les spores. Ces corpuscules reproducteur's susceptibles de germer se composent de deux tuniques renfermant un contenu homogène.

Outre l'enveloppe dont nous avons parlé, le sporange est entouré, dans quelques espèces, de plusieurs autres membranes comnues sous les noms de périgone, de périchèse, parties dans lesquelles M. Bischoff a roulu voir l'analogue du périanthe des fleurs phanérogames.

On trouve encore à la surface du thalle des organes d'une forme très-élégante connus sous le nom de corbeilles (Scyphules). Lors de leur matuturité, on voit dans leur intérieur des corps verdatres composés d'un assez grand nombre de cellules et supportés par une cellule basilaire plus développée. Ces organes, comparables aux stylospores des lichens, sont également capables de germer el de reproduire la plante, mais sans doute comme bourgeons, c'est-à-dire sans fécondation préalable.

Les organes sexuels dans les autres Hépaticées présentent d'assez nombreuses modifications qui portent surtout sur des différences de position. Les organes femelles présentent une forme à peu près constante, leurs enveloppes seules diffèrent; tonjours ils sont renflés à la base et surmontés d'un tube plus ou moins long, ce qui depuis longtemps 
les avait fait comparer aux ovaires des phancerogames; tantòt seulement la partie qu'on peut désigner sous le nom de style est dirigée en bas, comme dans les IIarchantia, tantòt au contraire daus une position inverse. Les anthéridies peuvent être isolées, soit pédicellées, comme chez le rossombronia pusilla, soit placées dans l'épaisseur du thalle sous la cuticule, comme dans le Pellia épiphılla; on bien elles sont groupées el portées sur un pédoncule, comme dans les Marchantia, ou sessiles, comme dans le Targionia hypophilla.

Tous les eryptogamistes paraissent d'accord stir la nature des organes que nous venons de décrire, el cependant, pour constater d'une manière réelle le phénomène de la fécondation, peu d'expériences paraissent avoir été instituées d'une manière scienlifique.

La structure de l'anthéridie et les anthérozoüdes qu'elle produit ne peuvent laisser douter qu'il ne faille y voir un organe male qui suppose par suite l'organe femelle. Or des deux organes qui peurent fournir des corps susceptibles de reproduire la plante, comme le prowrent les germinations, un seul paraît réellement représenter ce dernier, c'est celui qu'on appelle sporange; sa structure, ses rapports mème de développement, de forme et de position avec les anthéridies sont suffisants pour justifier ee rapprochement, et d'ailleurs M. Hofmeister a observé des anthérozoüdes sur les fleurs à arehégones des Jungermannes. Quant aux col- 
beilles, on ne saurait y roir autre chose que des appareils de végétation bourgeonnants.

Mais comment s'effectue la fécondation, surtout Iorsqu'on songe aux difficultés que présente la position réciproque des organes dans des végétaux tels que le Marchantia, où les organes se développent sur des individus différents, oì les organes femelles ayant l'orifice placé inférieurement, sont ell outre élevés sur un long pédicule? Comment lesanthérozoïdes pourront-ils se mettre en rapport avec les spores primitives? Ce que nous allons voir dans le groupe suirant nous donnera la solution probable de ces difficultés. On peut préjuger que l'action de l'eau doit joner un grand rôle dans ces phénomènes, les anthérozoïdes paraissant ne pouroir se mouroir que dans un liquide; des faits que nous aurons l'occasion de citer dans d'autres familles le prouvent suffisamment. Le développement de la plante est d'ailleurs assez connu pour qu'on puisse ètre certain, surtout depuis les travaux de M. Groenland (1854) sur la ggermination des IIépatiques, qu’il ne se produit à aucune époque un proembryon sexuć semblable à cenx que nous aurons plus tard à décrire. 


\section{CHAPITRE V.}

MOUSSES.

Les Mousses méritent d'autant plus d'intérèt, aut point de vue de la reproduction, que c'est d'après la considération des organes de ces régétaux que, pour la première fois, Itedwig a cherché ì établir que la fécondation existait chez les Cryptogames comme chez les Phanérogames, et qu'on trouvait chez les uns comme chez les antres des organes mâles et femelles jusqu'à un certain point comparables. Les travaux à la fois anatomiques et descriptifs de Bruch et Schimper, ceux de M. Unger, de. M. Thuret, sont venus donner à cette idée une nouvelle sanction.

Les Mousses rappellent beaucoup par leur port les plantes plus parfaites phanćrogames; on peut facilement leur distinguer une tige, une partie radiculaire et des feuilles qui présentent souvent des rudiments de nervure médianc. Ces caractères se poursuivent dans les enveloppes accessoires des organes de la reproduction sexuelle; on y trouve en elfet des parties enveloppantes qui peurent être rapprochées des enveloppes llorales, et s'écartent notablement des appareils protecteurs que nous 
avons vus dans les groupes précédents, saufles Hépatiques. Ce sont les feuilles qui les constituent; ordinairement on en trouve d'extérieures, rémnies en rerticille el qui diffèrent pen des feuilles caulinaires; elles constituent ce qu'on appelle le périclieze; plus intérieurement s'en trouvent trois out six petites, modifiées, moins colorées et qui constituent le périgone; celui-ci est dit gemmiforme ou discoïde, suivant que les parties qui le composent ont une tendance à s'imbriquer comme les feuilles d'un bourgeon, on s'étalent. Dans certains cas il peut manquer, et les organes de la reproduction sont dits nus.

Dans ces enveloppes se trouvent les organes màles désignés sous le nom d'anthéridies, el les organes femelles appelés archégones; les fleurs peuvent ètre hermaphrodites ou unisexućes, ce qui a lieu le plus ordinairement, et daus ce cas il peut y avoir monæcic ou diøcie : ce dernier cas étant le plus favorable à l'étude des organes reproducteurs, c'est celui que nous examincrons en prenant pour type le Polytrichum commune.

Dans cette plante, les organes màles sont placés au sommet de la tige dans une cupule formée par le périgone; on doit remarquer que ce bourgeon floral ne termine pas la croissance du végétal, car, après la destruction des orģanes fécondateurs, du fond de la coupe part un nouveau bourgeon qui porte à son sommet une nouvelle inllorescence mâle, de telle sorte que. sur une plante un peu 
âgée, on peut distinguer plusieur's collerettes étagées les unes au-dessus des autres, et qui ne sout autre chose que les périgones des fleurs snecessives.

Dans cette cupule se trourent les anthéridies dont la forme est celle de boyaux allongés sontenus sur un pédicule rétréci, et présentant de fines ponctuations en longues séries longitudinales tant que la déhiscence ne s'est pas accomplie. Entre ces corps se trouvent des filaments cloisomnés formés de cellules placées bout à bout sur um seul rang, sauf à l'extrémité. qui est renflée el composée d'un certain nombre de cellules placées les unes à còté des autres; ces filaments, appelés paraphyses, sont comprarables à ceux que nous avons décrits sous le mème nom dans les végélaux précédents. On n’est pas d'accord sur leur origine, les uns voulant y roir des fenilles modifiées par métamorphose ascendante, d'antres des anthéridies arrètées dans leur déreloppement, et par suite en métamorphose descendante; enfin on a roulu les comparer anx nectaires, mais on sait l'abus du'on a fait de ce mot ¿̀ une certaine époque. La fonction de ees organes dans les fleur's màles est sans doute celle qu'on admet dans les organes femelles pour les corps analogues. Les anthéridies sont composées de denx tuniques que $\mathbf{1 1}$. Ungyer, dès 1837, a signalées. L'externe, revêtue par une cuticule, est composée de cellules allongées quadrilatères formant un réseau fort ćlegant: cette disposition est surtout bien visible 
après la déhiscence; l'interne est homogène, hyaline. Le contenu, composé dans l'origine de cellules transparentes résultant de la multiplication des éléments primitifs du tissu par les procédés habituels de génération cellulaire, forme une masse muqueuse où la transparence des cellules empèche souvent de les bien distinguer. Plus tard, le contenu de chacunc d'elles s'organise, et lor'squ'elles sont projetées hor's de l'anthéridie, on voit qu'elles contiennent un corpusenle enroulé sur lui-mème qui ne tarde pas à léchirer sa cellule mère, et se meut librement à l'extérieur comme les corpuscules analogues du Marchantia, auxquels il est complétement analoguc. Ciest en effet un corps allongé contourné en tire-bouchon et pourvu de deux longs cils vibratiles. N. Unger a étudié arec grand soin leurs monvements et l'action de différents réactifs, tels que l'alcool, les acides, qui les tuent rapidement, tandis que l'opium, la stychnine, semblent seulement ralentir leurs monvements. Ce mème auteur a observé que ces corpuscules conservaient toutes leurs propriétés sur des mousses conservées pendant plusieurs semaines dans une humidité convenable. Enfin, un fait à noter, c'est que l'anthéridic expulse son contenu par saccades et ì des iutervalles rapprochés.

Les organes femelles, à leur début, sont placés dans des périgones fort analogues à ceux des flemrs mâles. Au centre se trouvent des corps en forme de bouteille à col très-allongé, de couleur verte, et 
que leur aspect, dès l'abord, a fait comparer all pistil des plantes phanérogames; on les appelle archégones. Ils sont entremêlés, comme les anthéridies, de filaments paraphysaires. Suivant les remarques de M. Schimper, l'usage de ces derniers pour la fécondation serait facilement explicable, ils auraient pour but de lubréfier et d'entretenir dans un degré d'humidité convenable les organes femelles. En effet, on les tronve ordinairement, et très-developpés, sur les plantes des endroits secs, tandis que les mousses qu'on rencontre sur les terrains humides ell sont fréquemment privées.

Les archégones placés dans le périgone commencent par ètre trìs-simples dans leur structure; c'est IIn amas de cellules offrant une cavité où se tronve la spore primordiale; cette cavité communique librement arec l'extéricur par un canal qui parcomt tonte la partie rétrécic. Un scul de ces organes, celui sans doute qui a pu être fécondé le premier, se développe; les antres restent dans un état rudimentaire el disparaissent. Les changements que subit alors l'archégone sont très-remarquables et depuis longtemps avaient attiré l'attention des botanistes; sans entrer dans tons les détails de cette question, nous devons l’indiquer brièvement.

La partic interne de l'archégone, ce que l'on pent regarder comme la spore primordiale fécondée, prend un grand accroissement, tandis que la partie externe dont l'ouverture s'est fermée ne représente plus fu'ume simple enveloppe. Par suite du déve- 
loppement de la partic interne, cette enveloppe se rompt circulairement, de facon à former une sorte de cornet qui reste ì la partie supéricure et qui prend le nom de coiffe on calyptre, tandis que la partic inférieure, sous le nom de rayinule, subsiste comme une collerette à la base, et porte souvent à sa surface des appendices qui ne sont autre chose que les débris des archégones non développés. La calyptre n’a pas perdu pour cela sa vitalité, clle continne à s'accroitre et peut se couvrir d'appendices variés. Les changements que subit la partic intéricure sont plus considćrables : le plus frappant consiste dans l'élongation de la partie basiliaire, qui s'allonge en un pédicule auquel on'donne le nom de soie; la portion supérienre, qui grossit beaucoup, est appelée urne, en raison de la forme fu'elle prend habituellement; elle se partage ellemème en deux: une partic supérieure. appelée opercule; l'autre, à laquelle on applique plus particulièrement le nom d'urue. Celle-ci présente bientôt une différence de tissu très-frappante, et sur une coupe transversale on voit en son centre une premiere portion qui, se continuant dans toute la longueur, forme une colonne centrale appelée collumelle; ì l'extérieur se trouve la paroi de l'urne, qui, dans la suite du développement, se compose ellemème de plusicurs conches; enlin la partic intermédiaire est formée d'un tissu cellulaire dans lequel se passent des phénomènes très-importants. Les cellules, disposées généralement sur quatre 
rangs, se fractionnent chacune en deux, puis en quatre, el dans chaque division se forme un corpuscule ì double enveloppe qui u'est antre chose que la spore de ces végétaux. Un peu plus tard, les parois de l'urne deviennent en un point le siége d'un travail organique fort curieux, mais sur lequel nous ne pouvous insister; l'opereule se soulève, et la dissémination des corps reproducteurs peut s'accomplir. Remarquous qu'autour de l'ouverture de l'urne, ouverture commue sous le nom de péristome, se trouvent une ou plusieurs comromnes de dents qui ont une certaine importance dans ce phénomène. En effet, en vertu de leurs propriétés hygroscopiques, ils se rapprochent el ferment l'ouverture pendant les temps humides, et s'écartent s'ils se dessèchent, de façon à ne permettre l'issue des spores que dans ce dernier cas, qui, sans doute, est le plus farorable ì leur transport.

Les spores germent en produisant me sorte de procmbryon qu'il vandrait mieux appeler protnnema, d'où naît par bourgeonnement simple un végétal semblable à la plante mère.

La lamille des mousses présentant une trèsgrande homogénéité dans la disposition des parties fondamentales de ses organes de la reproduction, ce que nous arons dit du Polytrichum commune peut s’appliquer, ì de légères modifications près, à loutes les plantes de ce groupe.

Les Nousses peuveni aussi se propager par des 
bourgeons mobiles placés sur les feuilles, la tige, les racines, et conuus sous le nom de sporules, d'imnorations, de tubercules.

La fécondation chez ces végétaux ne peut être douteuse; outre la concordance qu'on remarque dans l'époque d'apparition des anthéridies et des archégones, outre la nature des produits de ces deux ordres d'organes, ce qui constitue déjà de grandes présomptions, des preuves physiologiques non contestables viennent s'y joindre. Tous les botanistes convicnuent en effet aujourd'hui, depuis les recherches d'Hedwig et les faits apportés à l'appui par M. Schimper, que les espèces diö́ques ne fructilient que quand des individus màles croissent dans te voisinage des pieds portant les archégones.

l'époque à laquelle se fait cette fécondation peut se déduire de l'histoire du développement des organes femelles; c'est évidemment dans les premiers temps de leur formation. Le mode suivant lequel l'anthérozoüde se met en contact arec la spore primordiale est moins facile ì comprendre; cependant le fait n'est plus niable depuis les recherches d'un observateur dont le témoighnage ne peut ètre contesté, M. Hofmeister (1851), (jui a "trouvé daus un archégone de Funaria hygrometrica des anthérozoïdes vivants qui avaient déjà parcouru le tiers de la longueur du col. "Il ne semblerait pas nécessaire d'ailleurs de croire que le corpuscule mâle descend, en quelque sorte volontairement, de la 
tige qui le supporte pour s'élever ensuite le long de la tige sur laquelle se trouve l'archégone, comme semble youloir l'admettre M. Thuret; la projection brusque du contenu de l'anthéridie paraît pouroir domner assez de chances pour qu'un de ces corpuscules soit transporté sur l'organe à féconder. Remarquons d'ailleurs que ces deux faits se passent dans des circonstances favorables pour l'un et pour l'autre élément reproducteur. La déhiscence des anthéridies a lieu par l'humidité; on l'observe particulièrement bicn sous l'eau : or, si l'on réfléchit que, dans ces circonstances, amenées par la rosée d'une façon presque régulière, l'organe femelle doit lui-même être rempli de liquide, il suffit que l'anthérozoïde tombe sur un point quelconque du périgone pour pouvoir gagner la spore primordiale, comme nous avons vu le fait avoir lieu pour les Algues. D'ailleurs une seule fleur fécondée en ce moment assure la perpétuité de l'espèce, les spores des Mousses, produits de bourgeonnement et analoğes jusqu'à un certain point des zoospores de certaines spores proprement dites, multipliant à l'infini le végétal après une seule fécondation. 


\section{CIIAPITRE VI.}

CHARACÉES.

Les plantes qne nous avous à examiner maintenant sont plus simples que les précédentes; on les rencontre habituellement dans nos eaux douces, et elles paraissent, suivant M. Alexandre Braun, ne devoir former qu'un seul genre, les Chara. Depuis longtemps leurs organes de reproduction sout connus, et nous y trouverons encore des anthéridies, des sporanges et un mode de reproduction asexuée par bulbilles.

Les anthéridies, d'une structure assez bizarre et élégante, ont été étudiées par MM. Bischoff, Meyer, Agardh, etc. Mais ce sont surtout les travaux de M. Thuret qui les ont fait comaître, et la disposition des cellules mères des anthérozoïdes permettant peut-ĉtre mieux que sur toute autre plante voisine d'examiner le développement de ces corpuscules, ce sujet présente un grand intérèt. Ces organes, dans le Chara fragilis, sont placés sur les parties latérales de la tige, au-dessous de ceux que nous décrirons plus bas sous le nom de sporanges; ils se distinguent au premier coup d'œil des autres partics du végéal par leur 
teinte rougeàtre dépendant de la couleur de certaines parties de leur enveloppe. Examinés à 1 m faible grossissement, ces corps, dont la grosseur est à peine d'un demi-millimètre, apparaissent comme de petits polyèdres sphéroüdes à huit faces. Celles-ci sont formées chacune d'une lame en triangle isocèle à sommet tronqué, élégamment festomnée sur les bords, ornée de ponctuations et de lignes blanches partant des angles rentrants des festons marginaux, mais s'arrètant avant d'atteindre le centre du triangle. Au milieu de la face tournée du còté intérieur s’insère une cellule allongée qui supporte la lame; les huit supports se rassemblent au centre de l'anthéridie sur une masse celluleuse, laquelle elle-mème est placée au bout d'une cellule quion doit regarder comme le pédoneule général de l'organe. Dans ces cellules, on peut observer des mouvements de circulation intra-utriculaire, sur lesquels N. Thuret a depuis longtemps attirć l'attention (1840).

Les lames triangulaires que nous avons décrites, encroùtées de carbonate de chaux, comme presque toutes les partics de la plante, sont couvertes, sur leur face interine de granules orangés qui, vus par transparence, donnent à l'organe sa couleur spéciale. De la masse celluleuse placíe au ecntre de l'anthéride part, cn outre des parties que nous avons mentionnées, une grande quantité de filaments transparents formés d'utricules quadrililères, aplaties, placées les unes ant-dessus des 
autres, leur's surfaces larges étant en contact: c'est dans l'intérieur de celles-ci que vont se développer les anthérozoïdes.

On peut facilement observer la manière dont ils se forment, gràce à la transparence du tube. Le contenu de chaque cellule consiste d'abor'd en un amas granuleux discoïde; plus tard, aux deux extrémités du plus grand diamètre, apparaissent deux points plus réfringents, transparents, cerclés de noir; ces points se multiplient de plus en phus sur la circonférence, et finissent, en se réunissant, par former le corps de l'anthérozoïde roulé sur lui-mème dans l'intérieur de l'utricule; l'amas gramuleux qui lui a donné naissance s'est résorbépendantce temps, ouplutôt a été absorbé par le corpuscule en voie de développement. C'est ver's cetteépoque que se fait la déhiscence; les lamelles triangulaires se reconrbanten dehor's sur leurs bords cessent d'ètre en contact; enfin elles se dissocient, el entrainent, chacune à l'extrémité de leur pédicule, une portion de matière celluleuse centrale, et avec celle-ci des lubes à anthérozoïles. Ces derniers s'agitent alor's énergiquement et finissent par se faire jour à travers les parois latérales des cellules qui les renferment; une fois dégagés, ils se présentent comme ceux des Hépatiques el des Mousses sous forme de filament spiral ayaut nne extrémité effilée pourvue de deux cils, et se déplarant suivant un monvement hélicoüde. M. Thuret a répété sur eux l'action de quelques-uns des réactifs employés par Unger 
sur les organes analogues des Algues, et a confirmé la plupart des faits avancés par ce savant. La teinture d'iode parait ètre de toutes les substances celle qui, en les tuant, les altère le moins, et doit par conséquent être préférée pour étudier leur structure.

Le développement des organes femelles paraît avoir été l'objet de moins de travaux. Nous avous déjà indiqué leur position par rapport aux organes màles au-dessus desquels ils sont situés. Quelques feuilles aciculaires se trouvent également auprès et au-dessous d'eux. Ils ont la forme d'une petite bouteille, d'abord ovoïde, allongée et à col court, ornée de cinq côtes saillantes qui, au sonmet, font saillie en formant unc couronne à cinq dents obtuses. Ces côtes sont constituées par des tubes creux dont le còté extérieur se détruit souvent, de telle sorte qu’ì la maturité de la spore il reste autant de gouttières séparées par des angyles solides aigus. L'extrémité supéricure du sporange paraît d'abord ouverte, juis elle se ferme, sans doute après la fécondation, comme nous l'avons vu dans les Algues; sa forme devient alor's beaucoup plus ventrue; clle finit par se détacher de la plante mère, et tomber au fond du liquide. Ces graines sont fortement encroùtées de sels calcaires, ce qui explique leur conservation dans les périodes géologiques. Les spores se développent directement.

Un autre mode de génération des Chara mode que M. Nontagne a déerit complétement (1852), se fait 
par des bulbilles qui, se développant tout autour de la tige, finissent par se souder en un corps discoïde qu'on peut comparer à un petit melon. Quand la tige se détruit, ces corps, mis en contact avec le sol, sont susceptibles de germer et de reproduire la plante mère.

Dans les différentes espèces, la structure des organes ne paraît pas s'écarter du type que nous avons décrit, la position des organes màle et femelle scule offre quelques variétés; souvent, comme dans le Chara fragilis, les arthéridies sont placées andessous du sporange et sur le côté de la tigge; dans les Nitella translucens et mucronata, c'est l'inver'se; dans le Nitella flexilis, les deux organes sont placés l'un à côté de l'autre et terminaux; enfin, dans le Chara aspera, le Nitella syncarpa, ils sont situés sur des pieds différents.

Les Characées étant des plantes aquatiques, lc mode suivant lequel peut s'opérer le contact de l'anthérozoïde et de la spore primordiale n’offre aucunc difficulté à comprendre, et ce que nous avons vu chez les Algues en donne une explication facile. Toutefois le phénomène n'a pas encore été constaté de visu; cependant le fait peut ètre considéré comme démontré par les analogies et les probabilités. Nous n'avons pas besoin d'insister sur la similitude relative des organes mâles et femelles, sur la nature des produits qu'ils renferment; mais un fait plus important est celui de la déhiscence des anthéridies comparée au développement du spo- 
range. En effet, c'est lorsque celui-ci est encore allongé et de petite taille que les anthérozoïdes sont mis en libertć; lorsque l'ovaire se gonfle et arrive à sa maturité, les organes mâles ont complétement disparu. Il est fàcheux, et cela n'a pas encore été fait à notre comnaissance, qu'on n'ait pas tenté d'expériences positives sur les espèces monoïques. 


\title{
CHAPITRE VII.
}

\author{
FOLGERES.
}

Dans les Fougères, les phénomènes de la reproduction sexuelle se compliquent encore davantage, et nous allons trouver une série de faits qui, an reste, auront leurs analogues dans les classes suivantes.

Les anciens botanistes ne soupconnaient en ancume facon le mode de reproduction sexuelle de ces plantes, et l'on peut mème dire qu'on devait être peu tenté d'aller chercher les organes réels de ce phénomène là où ils se trouvent, le développement de la plante paraissant simple et facile à saisir par un examen superficiel.

Depuis longtemps on a remarqué à la face inférieure des feuilles de ces végétaux, désignées sous le nom de frondes, des amas de corpuscules dont le ròle dans la reproduction de la plante n'a jamais paru douteux, et qu'on appela par cette raison spores. Le développement de ces organes est fort simple et a été très-exactement décrit. On voit daus les lieux où ils doivent se produire les cellules ordinaires de la feuille prendre m développement anormal; ces cellules hypertrophiées se segmentent. 
et l'amạs ovoïde qu'elles forment alors se sépare en deux portions. Les cellules extérieures s'organisent en membrane, et d'ordinaire quelques-unes d'entre elles devenant plus considérables en même temps que leur paroi externe s'épaissit davantage forment une sorte de saillie, de bourrelet semi-circulaire, auquel on a donné le nom d'anneau; le petit sac constituć par ces parties, a reçu le nom de sporange. Pendant ee temps, les cellules internes ont subi de tout autres modifications; leur contenu s'est subdivisé en deux, puis en quatre parties, et chacune de celles-ci s'entourant de deux membranes a formé la spore. Plus tard, par suite des progrè̀s de développement, et la dessiceation mettant en jeu ses propriétés élastiques, l'anneau tend it se redresser; lesantres cellules de l'enveloppe, ne pouvant se prêter à ce mouvement, se rompent, et la cavité du sporange largement ouverte laisse íchapper son contenu. Ce mode de développement est un des plus fréquents, et c'est en particulier celui du Polypodium que nous avons eu en vue, cette espèce étant l'une des plus connues. Les sporanges sont réunis ordinairement en amas appelés spores et souvent recouverts d'un appendice protecteur diversement configuré et quion appelle indusie. Ces différentes parties, très-variées dans leur forme et fort importantes au point de vue de la botanique descriptive, ne doivent pas nons arrêter ici.

On savait depuis longtemps que ees spores, dans 
des conditions favorables, élaient susceptibles de germer et de reproduire le végétal originaire; le cycle du développement de la plante paraissait done connu, et les partisans de de la génération sexuće des Eryptogames, voyant dans les sporanges des organes femelles, avaient cherché dans les parties voisines et homologues les organes màles, et avaient décrit comme tels des poils, des glandules, etc.

En 1844, M. Nogeli, étudiant la germination des Fougères, observa certains faits que nous allons décrire plus bas, lesquels le portèrent à penser que le phénomène n'était pas aussi simple qu'on l'avait pensé, et il montra sur les premiers rudiments développés de la plante des organes que l'analogic le porta ì rapprocher des anthéridies des mousses. En 1848, M. Thuret confirma es découvertes. Mais on continuait de regarder les sporanges de la fronde comme les organes femelles, lorsque à la mème époque, en Allemagne, M. Leszezye-Suminski annonça que ce mème rudiment de plante portait les organes femelles: cette découverte souleva de vires contradictions, dout M. Wigand (1849) fut un des principaux interprètes. Le fait fut donc regardé comme très-incertain, et c'était encore l'opinion de N1. Thuret en 1851 ; mais les observations rapportées depuis par M. Hofmeister (1854) ne peuvent plus laisser le moindre doute, sinon sur tous les faits avancés par M. Suminski, an moins sur le point capial de sa déconverte. 
Si l'on fait germer une spore dans des conditions favorables, on voit un phénomène se passer, qui, par ses analogies arec le phénomène analogue qu'on observe dans les grains polliniques des phanérogames, a depuis longtemps frappé les observateurs. La membrane externe résistante se fend souvent suivant des lignes quon peut aperecvoir sur le grain intact, et par l'ouverture qui en résulte la membrane interne fait hernie sous la forme d'une espèce de boyau. Bientôt la matière verte s'acenmule ì l'extrémité de celui-ci; il s'y forme des cellules qui, par scission, suivant M. Wigand, se multiplient, et finissent, en s'ćtalant sur un ou plusiems rangs, suivant les espèces peut-ètre, par former une sorte de petite feuille qu'on a comparée avee quelque raison au thalle verdàtre des Hépatiques, el à laquelle on a domé le nom de pro-embryon ( $\mathrm{No}$ gyeli; pseudo-colylédon, Thuret; protophylle, Wigand). Ce pro-embryou est cordiforme, échaucré profondément, au moins dans le P'leris serratula, que M. Suminsli a suivi dans tont son développement, et que nous citous de préférence anx exemples de M. Wigand, dont les dénominations ne sont pas aussi certaines; ses dimensions sont environ de 3 millimètres de large sur 2 millimètres de long. Sa forme est à peu près la même dans le Scolopendrium officinale; il serail en raquette dans le Pteris aquilina, espèces tontes deux éludiées par M. Thuret. A sa partic postérieure el inférieure apparaisseut de bonne heure des radicelles. C'est sur ce pro-em- 
bryon que vont se développer les orgganes sexuels.

Les anthéridies, par leur nombre, leur développement plus prompt, la singularité des corpuscules qu'elles contiennent, étaient si propres à éveiller l'attention qu'on ne doit pas s'étonner qu'elles aient été étudiées en premier lieu. A la partie inférienre du pro-embryon et du còté postérieur surtont (nous regardons comme coté postérieur celui qui se trouve dirigé vers la spore d'où le végétal est sorti), on roit les cellules se modifier sur certains points. Suiyant M. Wigand, ces cellules s'accroissent et se divisent en deux parties, une extérieure qui tend à faire saillie à la face inférieure du proembryon, l'autre basilaire; l'ensemble de ces deux cellules constituerait l'organe mâle. Suivant M. Thuret, le nombre de ces cellules serait de trois, l'une basilaire, une autre servant d'opereule; enfin - Ia troisième, en forme d'annean, disposition assez difficile à comprendre, serait placéce entre les denx autres, et c'est dans l'intérieur de l'espace qu'elle circonscril que se développeraient les corpuscules fécondants. M. Suminski a aussi décrit la formation de cet organe d'une manière un peu différente, mais l'opinion de M. Wigand paraît la plus simple et la plus vraisemblable. Le nombre des cellules du proembryon qui se métamorphosent en anthéridies peut ètre assez considérable, puisqu'on a pu en compter jusqu'à 60 et 70 sur un seul individu. Pendant que la cellule primitive se subdivisait, son contenu s'est modifié, el la chlorophylle a disparu 
dans la cellule externe, qui prend un développement plus considérable que la cellule basilaire; mais ce n'est que le début des phénomènes importants qui vont s'y succéder. Sa substance décoloréc se partage à la fois dans toute sa masse, suivant M. Wigand, en un certain nombre de cellules, environ une vingtaine, dont les contours vagues à l'origine s'accentuent ensuite de plus en plus. D'abord sphéricues, ces cellules ne tardent pas à prendre une lorme polyédrique par pression réciproque; c'est là que vont se développer les anthérozoïdes. On les roit bientòt s'agiter dans les cellules, les rompre et se disséminer dans le liquide ambiant; généralement le corpuseule ne sort de la cellule mère qu'après que celle-ci a été projetée hors de l'anthéridic. La déhisenese sait par déchirure du sommet de la cellule anthéridienne externe; l'organe, suivant M. Thuret, subirait alor's quelques modifications consistant dans le développement de la cellule ammulaire moyenne, et dans quelques cas en un dépòt de matière colorée brune sur les parois de la cavité vide. L'an thérozoüde libre est aplati, tordu en spirale, el présente à l'une de ses extrémites, dite rostre, une couronne de poils rayomnants; il se meut avec une grande agilité. M. Wigand pense que son aplatissement résulte de son mode de développement; il le regarde comme formé par un dépòt placé à la face interne de la cellule mère, lequel se découperait en lanière, à ce qu'on peut supposer.

l.es organes femelles sont moins nombreux que 
les précédents; un pro-embryon n'en porte pas plus de quatre à vingt: ils sont situés également à la face inférieure, mais en avant, du còté de l'échancrure; leurs dimensions varient de $0^{\mathrm{mm}}, 072 \dot{a}$ $0^{\mathrm{mm}}, 108$. M. Suminski leur a domné d'abord le nom d'ovule, surtout à cause des idées théoriques qu'il avait admises; le nom d'archégone a généralement prévalu depuis. Cet organe, qui dérive des cellules du pro-embryon par des multiplications scissipares analogues à celles qui amènent la formation des anthéridies, mais plus multipliées, se présente à son état complet de développement conme une cavité arrondie plongée dans l’intérieur du parenchyme, limitée par des cellules dépourvues d'endochrome, et communiquant avec l'extérieur par une sorte de cheminée que forment seize cellules transparentes disposées crucialement quatre par quatre, les unes an-dessus des autres, d'une façon régulière. Les archégones d'un pro-embryon ne sont pas généralement tous aussi développés les uns que les autres, et on remarque qu'ils sont d'autant plus jeunes qu'ils sont plus près de l'échancrure. M. Suminski regardait la cavité comme étant vide: on admet anjourd'hui qu'elle renferme elle-mème une masse qui serait assimilable à ce que nous árons appelé spore primordiale.

La comparaison des anthéridies et des archégones ne permet pas d'y voir, comme on a pu le croire, des états différents d'une seule et même partie, et aujourd'hui leur véritable nature n'est dou- 
leuse pour persomme. Ces organes peuvent aussi daus certains cas ne pas exister ì la fois sur le mème pro-embryon; il y a donc monøecie ou diœcie. Quant an fait de la fécondation, il ne peut plus ètre légitimement contesté depuis les dernières recherches de M. Hofmeister; ce savant a mène donné des détails qui permettent en quelque sorte de suiwe pas à pas l'anthérozoïde dans son trajet. Lorsqu'un semis de pro-embryons présente des individus diversement développés et munis, les ums d'arché. gones, les autres d'anthéridies, après l'avoir maintenu pendant quelques semaines dans un état d'humidité convenable pour achever la maturité des organes, on l'arrose abondamment; quelques heures après, on trouvera les pro-embryons couverts d'anthérozoïdes ì mourements très-vifs. En pratiquant alors des coupes convenables, on pourra voir des corpuscules mâles jusque daus la cavité embryofère et doués encole de mouvements : c'est un fait que M. Hofmeister a pu constater deux fois dans l'Aspridium filix-mas, et les anthérozoïdes continuèrent de s'agiter pendant sept minutes sous les yeux de l'observateur. Il n'est pas douteux non plus, d'après les figures données par M.Suminski, que ce savant n'ait vu aussi le corpuscule mâle dans la cavilé de l'archégone.

Les conclusions que ce dernier observateur avait tirées de ce fait remarquable pour la production de l'embryon proprement dit nont pas été sans inlluence sans doute sur l'opposition qu'il rencontra 
pour les faire admettre. Suivant lui, une des portions de l'anthérozoïde se plaçant au milien de la cavité s'entourait de matière verte, puis, se séparant de la partie restée dans le canal de l'ar'chégone, se développait alorsen rudiment de la jeune plante. Cette théorie, qu'on a voulu invoquer dans l'étude des phénomènes de la fécondation des Phanérogames, admet, comme on le voit, que le végétal est un simple développement du corpuscule fécondant màle. Ce que nous avons vu daus d'autres végétaux où l'observation plus facile donne moins de chances d'erreur ne parail pas favorable à cette théorie.

Suivant M. Hofmeister, le premier phénomène qui suit la fécondation est le développement de cellules qui ferment tonte communication avee l'extéricur ; c'est sans doute l'analogue de celte membrane rue nous avons vue chez les Algues se développer dans des circonstances analogues, au moins les faits paraissent-ils parfaitement comparables.

L'embryon une fois formé, ayant unc position horizontale, émee une ligelle sur laquelle s'élèverout les frondes sporangifères, et des radicules par sa face inférienre. On ne voit jamais sortir du pro-embryon qu'une seule plante : il semble donc qu’un seul archégone puisse ètre fécondé on tout an moins prendre $u$ développement si considérable que la croissance desautres en soit complé. tement empèchée. 


\section{CHAPITRE VIII.}

EQUISẺTA GÉES.

Les plantes de cette famille, dont le port offre au premier coup d'œil des caractères distinctifs si frappants, n'offrent dans leur mode de reproduction rien de bien différent de ce que nous avons vu dans d'autres Cryptogames des groupes précédents.

Le végétal parfait donne des spores qui fournissent un pro-embryon destiné à produire des organes sexucls : anthérozoïdes et spore primordiale.

La fiuctification de la plante adulte où se trouvent les premiers produits est depuis longtemps connne, et son élude au reste ne présentait aucune difficulté. Elle consiste en une sorte d'épi terminal, composé d'écailles portées sur un pédicule central; on ne peut mieux les comparer qu'à un clour. C'est à la face inférieure, c'est-à-dire celle qui regarde l'axe, que se trouvent les spores renfermées dans de petites capsules dites sporanges. Le développement de toutes ces partics est très-simple. Le long de l'axe, dans les points oǹ doivent se tronver les écailles, apparaissent de petites saillies d'abord arrondies, qui s'allongent et s'élargissent en disque 
à leur extrémité libre, en prenant dès lors l'aspect qu'elles doivent conserver; seulement, par la pression réciproque que les portions élargies exercent les unes sur les autres, leur forme arrondic se change en forme hexagonale. En mème temps, de petits mamelons celluleux se sont développés sur la partie marginale de la face inféricure du disque, les cellules périphériques subissent peu de modifications et formeront la paroi du sporange; les cellules centrales au contraire, dans lesquelles vont se développer les spores, présentent une série de phénomènes très-curicux. Le contenu s'isole d'abord de la paroi sous forme d'une sphère solide; on voit alors entre ces deux parties se produire une membrane qui se découpe en lanières placées en spirale autour de la sphère, et qui, lorsqu'elles pourront s'étendre, apparaitront sous forme de quatre prolongements étroits présentant une extrémité libre élargic en forme de pelle, adhérents par l'autre en un mème point de la spore et disposés crucialement; on les appelle élatères. On a aussi cru que ces organes singuliers provenaient simplement de la menbrane primitive d'enveloppe de la spore : cette opinion serait celle de M. Hugo Mohl, qui a porté particulièrement son attention sur ce point d'histologic. M. Sanio a étudić également le développement des élatères; il croit qu'ils se développent chacun en deux parties séparées à l'équateur de la spore, lesquelles se réuniraient plus tard: un fait très-important qu'il aurait constaté 
serait quaprès leur formation ces appendices contimuent de croilte, ce que prouvent leurs changements d'aspect et de dimensions. L'usage de ces parties est des plus simples et fort bien commu. Les propriétés hygroscopiques des filaments sont trèsfaciles à constater. Si on considère les spores en masse, on voit facilement à l'oxil nu que sous l'influence de l'halcine chargée de vapeur d'eau il s'y produit un fourmillement des plus remarquables. L'examen au microscope rend facilement compte de ce phénomène: on s'aperceit alors que si on fail varicr l'ćtat d'humidité de l'atmosphère, les filaments s'écartent ou se rapprochent de la spore avec une grande agilité; celle-ci peut mème ètre projetéc à une certaine distance toutes les fois que, par suite de sa position, les extrémilés libres des fils rencontrent dans la lame porte-objet un point d'appui résistant sur lequel ils aggissent à la manière d'un ressort. Il est donc évident qu’ils servent à la dissémination. Nous n'avous pas à mentionner l'opinion qui portait à les considérer comme des étamines, idée baséc sur leur forme el Icur position par rapport à la spore, mais qui ne reposait que sur une observation superficielle et ne saurait plus ètre admise.

Au moment de la maturité, les sporanges s'entronvrent par une f'ente tournée ver's le centre des écailles, et les spores sont projetées an loin. Peut-ètre lestilaments joucnt-ils alor's, par rapport à la spore, le ròle d'organe d'arrèt lorsqu'elle arrive sur im 
terrain humide, puisque dans ce cas, ils s'étendent et empêchent par conséquent le vent de les emporter aussi facilement que lorsqu'ìl'état de sécheresse ces parties sont roulées autour de la spore. Il se passerait quelque chose d'analogue an singulier phénomène qu'on a depuis longrtemps signualé pour la Rose de Jéricho (Anastica hierochuntica).

Quoi qu'il en soit, dans des conditions d'humidité fa vorables, ces spores germent avec une assez grande facilité; aussi, depuis longtemps, les observateurs s'étaient-ils attachés à suivre le développement de ces plantes; Agardt en 1822, Vaucher en 1823, ont publić de nombreuses observations à ce sujet. Mais c'est seulement à une époque beaucoup plus récente qu'on a reconnu l'importance de ces premiers déreloppements de la spore sous le rapport de la génération sexuelle. M. Thuret dans ses savantes recherches sur les anthéridies des Cryptogames, décrivit ces organes dans l'Equisetum limosum, ainsi que les anthérozoïdes qu'ils présentent. M. Hofmeister (1854), M. Milde (1852), firent comnaître l'organe femelle ou archégone; il convient également de citer M. Bischoff, qui en 18.53 publia d'intéressantes recherches sur l'organogénie de ces régétanx; enfin en 18.59 M. Duval-Jouve a fait paraître dans les bulletins de la Société botanique de France un très-intéressant mémoire sur la génération sexuelle de ces plantes, travail auquel nous cmpruntons les détails qui vont suivre.

Mise dans des conditions convenables, quion peut 
reproduire expérimentalement avec facilité, comme l'a exposé l'auteur que nous venons de citer, la spore des Prêles se divise d'abord en deux cellules, l'une qui parait dans la suite de son développement devoir domner naissance aux radicelles de la jeune plantule, l'autre qui se remplit de substance verte, el, par la subdivision cellulaire, forme cette jeune plantule même à laquelle on a donné le nom de pro-cmbryon ou prochallium (Sporophyme, DuvalJowe). Celui-ci se présente d'abord sous la forme d'une lamelle verte, irrégulièrement lobée sur les bords et homogène sur toute son étendue; plus tard tonte la partie médiane prend une strueture un peu différente, les cellules y sont plus petites, le tissu plus serré, el cela simule en quelque sorte tune espèce de nervure. C'est sur celle-ei que se développeront les organes femelles, tandis que les organes mâles seront situés à la périphérie, sur les parties lobées et à l'extrémité de celles-ci. Géméralenent, le développenent de ees parties est inverse, de telle sorte que là où les anthéridies se développeut, les organes femelles sont rudimentaires et stériles, el réciproquement; c'est au moins ce qui a lieu pour l'Equisetum arrense étudié par M. DuralJouve; cependant, l'Equisetum syluaticum, d'après M. Bischoff, serait monö̈que, el les orģanes mâle et femelle pourraicnt se trouver réunis sur un mème lobe du pro-embryon.

Le développenent des anthéridies n’est pas trèsexactement comm; arrivées à l'état parfait, elles se 
présentent sous forme de cavités ayant une paroi conposée de cellules régulières, surtout pour celles de la partic extérieure qui sont disposées en rayonnant à partir d'un centre. Le contenu en est finement granuleux et notablement plus opaque que le reste du pro-cmbryon. Au moment de la déhiscence, les cellules extérieures s'écartent de manière à former une couronne dentée fort régulière et d'une trèsgrande élégance; la cavité est alors largement ouverte, et les anthérozoïdes, souvent encore contenus dans la petite cellule où ils se développent, sont projetés ì l'extéricur. Les corpuscules mìles ont une forme singulière que M. Thuret a figurée arec beancoup de soin, et qu'on peut comparer grossièrement à une faucille dont le manche serait le rostre de l'anthérozoïle; an reste, cette apparence est sujette à de grandes variations que le dessin seul peut faire saisir; ces corpuscules sont pourvus à leur partie antérieure de cils vibratiles.

Les organes femelles ou archégones se développent comme dans les familles voisines. Au reste leur aspect à l'état adulte n'en est pas différent. Ils consistent en une cavité entourée de cellules qui se distinguent de celles du reste du parenchyme par l'absence d'endochrome, et qui du còté interne de l'or'gane forment un dessin assez régulier. Cetle cavité, de forme sphérique, est surmontée de huit cellules superposées sur deux rangs el se correspondant exactement cu hauteur et deux à deux; 
rues d'en haut, les quatre cellules supérieures forment une rosette régulière. Dans certains cas, chaque colonne de deux cellules est surmontée d'une sorte de lame foliacée; mais l'existence de celle-ci n'a pas paru constante à M. Duval-Jouve. Au milieu des huit cellules se forme un canal qui conduit directement dans la cavité de l'archégone au fond de laquelle est une saillie qui se développera après la fécondation pour reproduire la plante mère, et qui n'est autre chose, par conséquent, qu'une spore primordiale. Souvent, sur l'Equisetum arvense, l'intérieur du lube, de la cavité, et mème la face externe des quatre cellules supéricures sont teints en roux; ce phénomène, qui paraît dù à une simple coloration superficielle des cellules, ne se produirait que daus les organes non fécondés, et par suite, impropres à la reproduction.

Bien qu'on n'ait pu jusqu'ici constater d'une manière certaine la pénétration de l'anthérozoïde dans l'archégone, cependant la nécessité de la fécondation n'est pas douteuse, comme l'ont prouvé les observations de M. Duval-Jouve. Dans l'appareil employé par ec naturaliste pour obtenir la germination des Equisétacées, une disposition spécialc empèchail l'eau de tomber directement sur les plantes, et dans ees conditions, il remarqua qu'aucun des ârehégones ne lui présentait de phénomènes de développement. Frappé de ce fait, et guidé d'ailleurs par certaines observations sur lépoque de la journée à lacquelle s'opérait le plus 
habituellement la déhiscence des anthéridies, il crut devoir attribuer à cette circonstance la nonréussite de ses semis. Ayant alors arrosé directement les proembryons, il ne tarda pas à trouver une grande quantité d'archégones développés en rudiments de plantes mères. Il put surtout observer les anthérozoïdes dans le voisinage des organes femelles, et nième engagés dans le tube de l'archégone. Ces faits ne peuvent laisser aucun doute sur l'action réciproque de ces différents éléments; il est clair que lors de la déhiscence des anthéridies les corpuscules mâles projetés sur le pro-embryon femelle ne peuvent gagner l'archégone si la surface sur laquelle ils se trouvent étant privée d'eau ne leur permet pas de se servir de leurs cils natatoires.

Tous les archégones sont sans doute susceptibles d'ètre fécondés, an moins ne paraissent-ils jantais présenter entre cux de différences anatomiques sensibles. Cependant d'ordinaire, sur un pro-embryon femelle, on n'en voit qu'un qui se développe en plante mère, les autres restant rudimentaires et se détruisant avec le reste de la plantule primitive sortie de la spore; c'est an moins ce qu'on a remarqué dans l'Equisetum arrense; ce fait au reste nous a présenté des analog̣ues dans les plantes que nous avous étudiées précédemment. 


\section{CIHAPITRE IX.}

L Y COPO DIA CE ES.

la génération sexmelle des plantes de cette famille est fort bien comme pour quelques-umes d'entre elles, surtout depuis les recherehes des sarants modernes sur ce sujet; mais, pour quelques autres, le peu qu'on sait parait présenter de si grandes différences qu'elles motiveront peut-ètre un jour la séparation de ce groupe en plusieurs ypes distincts.

Jusqu'aux recherches de M. Hofmeister, les travaux faits sur les lycopodiacées ont été purement descriptifs, l'élégance de ces plantes qui rappellent par leur port les Mousses et les Irépatiques les ayant fait remarquer depuis longtemps. Le travail de l'observateur que nous venons de citer, publié en 1851, fit connaitre très-complétement le dévelopłecment des organes de la reproduction dans les Selaginella, et depuis cette époque les travaux de N. Thurel, de M. de Bary ont peu ajouté à ces notions.

Dans le selaginella denticulata qui a été particulièrement étudié, les organes mâles et femelles anthéridies (Coniothèques, Hofmeister) et sporanges (sphérothèques, Hofmeister) se trouvent placés ì 
l'extrémité des rameaux sur de petiles lenilles qui forment une sorte d'épi. Un seul organe femelle se développe sur l'une des feuilles de la base, les antres donnent des anthéridies, mais l'origine première de ces organes n'étant pas différente, nous pouvons d'abord les étudier simultanément.

On voit sur le côté des rameanx se former de petits mamelons celluleux dépendant de l'axe, car ce u'est que par suite du développement que les organes finiront par se trourer sur la fenille. Bientiot les cellules se différencient, l'une d'entre elles centrale se développe davantage, tandis que les antres se modifient de faron ì former autour d'elle trois rangées distinctes formant trois cuveloppes; lorsque le déreloppement est complet, la plus interne est formée de cellules allongées rayonnant autour de la cellule centrale, et pourvues d'un noyau; de plus à l'extéricur sont des cellules tabulaires contenant de l'amidon, enfin le tout est enveloppé d'une couche de cellules polyédriques transpareutes revètues d'une cuticule. A cet état de développement, le mamelon a grossi considérablement et est porté sur un pédicule rétréci. Pendant ce temps la cellule centrale a subi d'importantes modifications; dans son intérieur des cellules se sont produites par division régulière de son contenu; chacunc d'elles est pourrue d'un noyau et d'un nucléole. Arrivés à cette phase, les mamelons qui devrout donner les anthéridies ou les sporanges ne peurent encore se distinguer les uns des autres. 
Lor'squ'il devra se produire un organe mâle, on voit les cellules contenues se diviser chacune en deux, puis en quatre cellules précédées de l'apparition de noyaux nucléolés, ce sont les microspores de M. Hofmeister ; leur forme n'est pas sphérique, ce sout de petites pyramides tétraédriques à base courbe. Lors de la déhiscence, ees microspores tombées sur le sol humide grossissent notablement, et vers le cinquième mois de germination, leur contenu s'organise en cellules ou se forment des anthérozoüdes qui mis en liberté s'aģitent lentement. Ce développement n’a été observé jusqu'ici que sur le Selaiginella helvetica.

Si le mamelon doit donner naissance à un sporange, on voit une des cellules du contenu prendre un accroissement très-considérable, pendant que les autres s'atrophient. Arrivéc à un certain point de développement, elle se partage en quatre cellules, claprès un mode comparable à celui que nous avons signalé dans les céllules donnant naissance aux microspores, seulement ici ces cellules secondaires, auxquelles M. Hofmeister a domné le nom de macrospores, ne conservent pas la forme tétraédrique, mais se développent en sphères qui, dans l’intípieur du sporange sont disposées comme quatre boulets empilés. Pendant mìme que la macrospore est encore sur la plante mère, sur un point de sa enconférence il se forme un disque celluleux dislinel du reste du contemu par la forme des éléments composants, et qui n'est autre chose que le pudi- 
ment d'ur pro-embryon. Quand la macrospore s'est détachée, le développement de ce disque se continue, et les cellules où derront se former les archégones, c'est-à-dire les véritables organes femelles, se distinguent par leur contenu granuleux. Chacune de ces cellules se divise en deux parties par une cloison horizontale. La cellule inférieure se développera en corps reproducteur femelle. La cellule supérieure se partage d'abord eu quatre, par deux cloisons verticales disposées crucialement, puis une cloison horizontale prorte le nombre total des cellules à huit, lesquelles forment un canal comparable à celui que nous avous décrit dans les archégones des Fougères, des Equisétacées, etc. Le développement de ces parties demande environ six mois.

Le temps nécessaire pour la formation des anthérozoïles, d'une part, de la spore primitive. d'autre part, paraît done un peu différent, ee qui peut porter à penser que ces ćléments reproductemrs doivent ètre fournis par des plantes ou au moins des rameanx différents, pour arriver en mème temps à maturité. Quoi qu’il en soit, bien que la fécondation u’ait pu jusqu’ici ètre constatée d'une manière certaine, la simple considération des organes ne peut cependant laisser aucun doute à cet égard, quand on se reporte aux faits que nous avons cités dans les groupes précédents. Aussitòt après la fécondation, M. IIofmeister a coustaté que la cellule inférieure preml un développenent con- 
sidérable, si bien qu'elle sort du pro-embryon pour descendre dans les cellules propres de la macrospore, où son accroissement continue. l'embryon ainsi formé reproduit la plante mère.

Chez les Isoëtes et les Lycopodes, la reproduction sexuelle a été moins étudiée; chez ces derniers, les microspores étant seules connues, on s'est demandé si, au licu de produire simplenent les anthérozoïdes, ces corpuscules, conme Ies spores de la fronde des Fougères, ne donnaient pas naissance i un pro-embryon portant les organes des deux sexes. Les recherches de M. de Bary sur la germination des Lycopodes ne permettent pas encore de se prononcer à ce sujet, bien qu'elles tendent à justifier cette assimilation. 


\section{CHAPITRE $X$.}

RHIZOCARPÉES.

Les phénomènes de la reproduction sexuelle chez les Rhizocarpées se rapprochent assez de ceux que nous avons décrits chez les Lycopodiacées, au moins en ce qui concerne le développement, pour que nous ne croyions pas devoir nous y arrèter longuement.

Dans les Pilularia, qui ont été le plus étudiés, et sur la propagation desquels M. Naegeli, en 1847, a publić un article assez étendu, les organes màles et femelles se déreloppent dans une mème capsule, et depuis longtemps B. de Jussieu (1739) arait indiqué ces partics qu’il regardait comme des anthères et des pistils. Dans les plus petits de ces organes, microspores, se forment des anthérozoïdes résultant de cellules mères produites elles-mêmes par la division quaternée de cellules préexistantes. Dans les organes femelles, où le développement est identiquement le mème, une seule de ces dernières cellules se développe et donne par division quatre corps, macrospores; chacun d'cux, comme l'a montré M. Hofmeister, est susecptible par la germination de donner des arehégones que les anthérozoüdes 
viennent féconder. La déhiscence de la microspore qui représente l'anthéridie paraîtrait s'opérer par la production d'une espèce de boyau formé par la membrane interne, ce qui rappelle la déhiscence des grains de pollen des Phanérogames. Cependant jamais ce boyau ne paraît, d'après M. Nacgeli, pénétrer directement dans l'archégone où l'anthérozoüde se pend an moyen de cils vibratiles.

Les corps reproducteur's des Azolla ont aussi été observés par M. Mettenius (1847), mais ces études demanderaient à ètre reprises; la description des différentes parties de ce que l'anteur appelle ovule indiquerait une complication beaucoup plus grande que celle qu'on observe dans les genres voisins. 


\section{CONCLUSIONS.}

Si on jette un coup d'œil sur les différents faits que nous venons de passer en revue, en cherchant à comparer les modes de génération sexuelle observés chez les Cryptogames, on peut, il nous semble, y reconnaître chez tous le phénomène désigné sous le nom de génération alternante. Nous ne parlons pas, bien cntendu, ni des Champignons ni des Lichens, chez lesquels le mode de reproduction dont nous nous occupons n'est pas encore suffisamnient colnmu.

Eu observant le cycle complet de charque espèce et laissant de còté les modes de reproduction par zoospores, bulbilles, innovations, tubercules, qui sont en quelque sorte irréguliers, ou pour mieux dire parallèles à la génération sériale par laquelle l'espèce se perpétue normalement, on trouve en général, à côté de la reproduction par fécondation, c'est-à-dire résultant dı concours des sexes, uı mode de reproduction asexuelle et la suecession régulière de ces phénomènes constitue une véritable alternance. Mais en partant d'un point fixe de la 
série, soit, par exemple, du développenent de la spore proprement dite (nous désignons sous ce mot le corps reproducteur provenant par fécondation de la spore primordiale, développée dans le sporange des Algues ou l'archégone des autres plantes), on voit que la reproduction asexuclle se place par rapport à ce qu'on appelle généralement le végétal parfait et que nous appellerous plante mère, de deux facons différentes, ou elle la précède, ou elle la suit. Le plus grand nombre des plantes dont le développement est bien connu peuvent rentrer dans l'un ou l'antre cas.

Dans les Algues, par exemple, dans le sphteroplea anuulina (voy. pl. I et explication des planches), la spore proprement dite donne par segmentation, c'est-à-dire génération asexuclle, des zoospores (bourgegens mobiles), lesquels se développent en plante mère sur laquelle les anthéridies et les arrchégones (nous employons ee dernier mot pour exprimer l'organe qui renferme la spore primordiale) produiront les anthérozoïdes et les spores primordiales, ce qui lerme la série.

Dans les Fougères qui nous serviront d'exemple pour le second cas (voy. pl. In et explication des planches), la spore proprement dite donne la plante mère, laquelle produit des corps que nous appellerons, faute de mot meilleur, spores des anteurs; c'est la génération asexuelle. Les spores des anteurs, en se développant en pro-embryons, donneront les authéridies et les archégones, et par 
suite les anthérozoides ct les spores primordiales.

Au premier type se rapportent les Algues, les Hépatiques, les Mousses; au second, les Fougères et les Equisétacées d'une part, les Characées, les Lycopodiacées, les Rhizocarpées d'autre part.

Nous divisons ces derniers en deux groupes, parce que, comme l'a fait remarquer M. Grisebach, chez eux, les phénomènes, bien qu'au fond les meemes, offrent une différence assez frappante. La plante mère, au lieu de fournir par la génération asexuelle une seule sorte de corps, en donne deux : les microspores, qui fourniront les anthérozoïdes et sont, si l'on veut, les anthéridies; les macrospores où se développeront les archégones. Il semble done que la génération sexuelle ait en quelque sorte remonté d'un rang. Cette différence a une autre importance en ce qu'elle nous conduit à ce qui a licu normalement dans les régétaux phanérogames, te pollen pourant ètre comparé aux microsporcs, l'ovule aux macrospores, cette dernière assimilation étant donnée sous toute réserve. Cette division dans les végétaux à développement sur le lype des Fougères a été faite déjả par M. Grisebach qui désigne les uns sous le nom de l'térides (Fougères, Equisétacées, les autres sous le nom d'IIyitroptérides Characées, Lycopodiacées, Rhizocarpées,

Le tableau suivant fera mienx saisir ces idées en les résumant : 


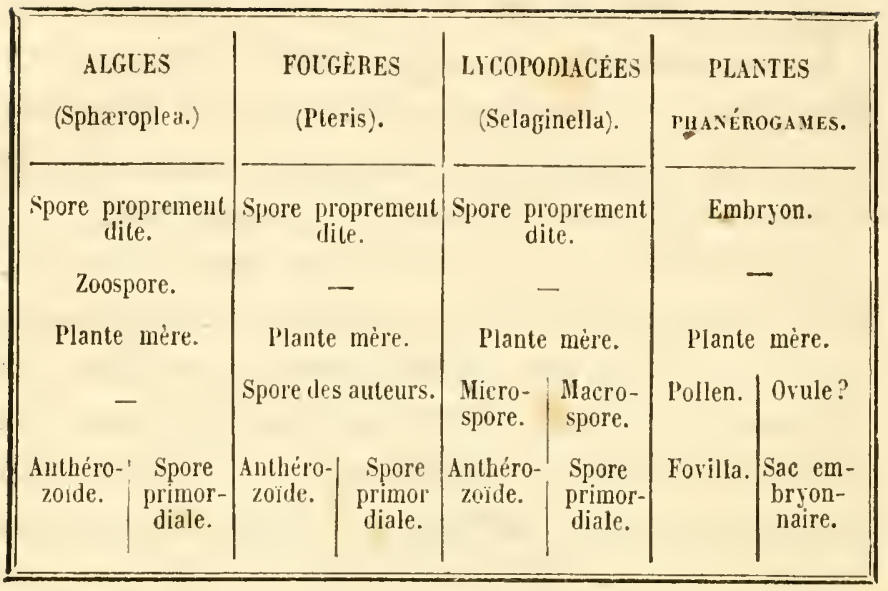

Il faut ajouter que ces faits ne sont pas absolus. Ainsi chez bon nombre d'Algues que nous avons citées, la spore proprement dite donne naissance directement à la plante mère; dans certaines espèces (Saprolegnia monö̈ca), l'un et l'autre cas se présentent peut-être à la fois. Dans les Lycopodiacées, les véritables Lycopodes produisent, ou pent le croire, un pro-embryon comme les Fougères et non des macrospores et des microspores comme les Selaginella. Les Characées paraissent produire directement sur la plante mère les anthéridies et les archégones. Enfin, comme remarpue générale, observons qu'un trop petil nombre de plantes ont été étudiées jusłu’ici pour qu'on ne doire pas regarder comme prémalurée me généralisation trop absoluc.

Ces considérations nous amènent encore à con- 
clure que la prétendue limite entre les végétaus phanérogames et cryptogames est récllement si peu considérable, qu'on peut presque la regarder dès à présent comme nulle, et une fois de plus est pronvée la justesse de la pensée de Limné que la marche de la nature est régulière.

Au point de rue de la botanique et de la physiologgie générales, l'étude de la fécondation chez les Cryptogames nous paraît aider à la solution de quelques questions importantes.

Les observations de M. Leszczyc-Suminski sur la fécondation des Fougères ont paru d'abord donner des prewes à l'appui de la théorie de Schleiden sur le développement de l'ovule, mais saus parler des décourertes récentes de M. Hofmeister. sur les mèmes régétaux, qui sont vemues montrer les faits sous un tout autre jour, on peut dire que Ies derniers travaux sur la fécondation des Algues ne peuvent plus laisser aucun doute sur la faron dont les ćléments sexuels se comportent l'un par rapport à l'autre. Il est démontré par des faits en quelque sorte tangibles chez les végétaux dits cryptogames:

"Que les denx éléments pris isolément sont in"féconds;

"Pue le contact de l'élément mále ne suffit pas "pour féconder l'élément femelle;

"Que l'élément mâle ne se dévelopne pas sim"plement dans l'élément femelle, mais que tous deux. "se confondent pour se vivifier." 
En royant chez les autres êtres régétaux et animaux les éléments sexucls si semblables dans leur essence et dans leurs rapports, pour ne pas dire identiques avec ce que nous avons observé dans les plantes que nous venons de passer en revue, il est difficile de ne pas regarder les lois qui les réģissent comme générales dans tout le monde organique.

PIX. 


\section{BIBLIOGRAPHIE}

\section{ALGUES.}

AGARDH (J.-G.). Observations sur la propagation des Algues. (Ann. sc. nat., $2^{\mathrm{e}}$ série, t836, Bot., t. V1, p. 193.)

BARY (A. DE). Sur la génération sexuelle des Algutes. (Ann. sc. nat., $4^{\mathrm{e}}$ série, 1856, Bot., t. V, p. 262.)

_- Sur la copulation des Desmidiacées, des Zygnémacées et des Champignons (Syzygites), sur la germination des produits de cette copulation, et sur les opinions relatives à l'importance de la copulation. (Comptes rendus des trasáux de la section botanique du $33^{\mathrm{e}}$ congrès des naturalistes et médecins allemands, par H. R. Caspary, in Bolan. Zcil., t857, $11^{05}$ 41, 45.)

BONNEMAISON (Th.).Essai sur les Hydrophy tes loculées (ou articulées) de la famille des Ẻpidermées et des Céramiées. (Him. Mns. hist.nat., 1828 , t. XYI, p. 49.)

BORNET (Ev.). Description d'un nouveau genre de Floridées des còtes de France. (Ans. sc. nal., $4^{\mathrm{e}}$ série, 1859, Bot., t. XI, p. 88.)

CARTER (J.-H.). On specific character...... (suru les caractères spécifiques, la féeondation et le déreloppement anormal des OEdogonium). (Ann. and Magaz. of nat. hist., $3^{\mathrm{e}}$ série, $n^{0} 1$, janץ. 1858.) 


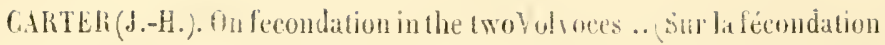
dans les deux Volvox, et sur leurs différences spécifiques; sur les Eludorina, Spongilla, Aslasia, Euglcna el Cryplosłcna. (Ann, and Magaz. of nal. hist., $3^{\mathrm{e}}$ série, janv. 1859.)

CASPARY (Ков.). Sur les zoospores des Chroolepus, Ag. et lemr légngument. (Ann. se. nal., 4 $^{\mathrm{e}}$ série, 1858, Bot., 1. IX. p. 307.)

CuHN (F.). Hémoire sur le développement et le mode de reprodiuction du Sphæroplea annulina. (Anu. sc. nat., ${ }^{\mathrm{C}}$ série, 1856, Bot., t. V, P. 187.)

_- Observations sur les Tolrocinées, et spéeialement sur l'orgirnisation et la propagation du Volvox globator. (Ann. sr. Hat., 4 série, 1856, Bot., 1. V, p. 323.)

Sur le déreloppement d'une Tolrocinée. (Comptes rendus des travaux de la section de botanique du $33^{\circ}$ congrès des naturalistes et médecins allemands, par H. R. Caspary, in "io-

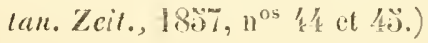

CRUUAN (frères). Obserrations sur les tétraspores des Algues. (fun. sc. nal., 3e serie. 1814, Bot., t. II, p. 36e\%.)

Rudes microscopiques sur quelques A'gues nourelles ou peu eommes constituant un genre noureau. (Ann. sc. hal., $3{ }^{\mathrm{e}}$ séric, $18 \mathrm{8}$ 1, Bot., 6. 17, p. 389.

Note sur quelques Aigues marines nourelles de la rade di Brest. (Ann. sc. nat., te séric, $1898 \%$, Bot.. 1. IX, p. (69.)

DECAISNE (J.). Plantes de l'Arabie heurense, reencillies par M. P.-F. Botta, et dierites par Decaisuc. (Arch. Mhus. hist, nat., 181, 1. II, p. 8\%.)

Mémoire sur les Corallines on polypiers caleifères. (Ann. sc. nat., $2^{\mathrm{e}}$ séric. 1812, Bot., 1. XYIII, p. 96.)

Essais sur une chassification des Algues el des polypiers 
Palcifères de Lamouroux. (Ann. sc. nal., 2e sépie, 1819, Bol., t. XVII, p. 297.)

DECAISNE (J.) et THURET ( $\boldsymbol{G}_{\text {. }}$ ). Recherches sur les anthéridies et les zoospores de quelques Fucus. (Ann. sc. nal., $3^{\mathbf{e}}$ série, I8łö, Bot., I. III, p. ஜ̈.)

InRBiS. Decription d'une nouvelle espère de Floridée, dexant former un nomrean genre, ct observations sur quelques Algurs. (f fun.

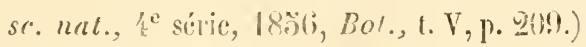

Sur la fructification de l'Haliscris polypodioides. (Bull. Soc. bot., 1839, p. 83.)

IERBES et SOLER. Sm les organes reproducteurs des Agnes. (Ann. sc. nat., 3e série, 18000 , Bct., 1. XIV, 1. 361.)

DESHAZIRRES (J.-B.). Recherches micruscopiques et physiologiques sur le genté Mjooderna (Ann. sc. nat., f'r série, 1827, t. X, p. 12.)

- Observations sur le Sporendonema casei, nourean genre de Incédinées. (Ann. sc. nat., f'e série, 1827, t. X, p. 246.

_-__Lettre sur l'animalité de quelques hydiophytes, et des mycodermes en particulier. (Ann. sc. nat., fre série, 1s28, 1. XIV, p. 2045.)

Mémoire sur l'Lilsa goranulala, Lin. (Ann. sc. nat., $1^{\text {re }}$ série, 1831 , t. XXI1, p. 193.)

DUBY L.-E.). Second mémoire sur lez Céramiées. (Anu. se. nat., $2^{e}$ séric, 1831, Bol., t. I, p. 191.)

Troisieme mémoire sur le groupe des Céramićes et sui le mode de lem propagation. (Ann. sn. nal., 22" série, Isis, Bot., t. IX, p. 18:.)

Forkk. Sur la copnlation des Builluries et Desmidiarées. (Comptes rendus des travaux de la section de botanique du $33^{\mathrm{e}}$ congrès 
des naturalistes et médecins allemands, par M. R. Caspary, in Bol. Zeil., 180\%, $\mathrm{n}^{\text {os }}$ 41, 40.)

GAILLON (B.). Obserrations microscopiques sur le Conferwa comoides, Dillw. (Ann. sc. uat., $1^{\text {re }}$ série, 1824, 1. 1, p. 309.)

HARWEY (W.-H.). Nereis Boreali-Americana; or contributions to the history of the marine alga of north America. (Sinithsonian contributions 10 linowledge, t. X, Washington, 18008 , pars III, clilorospermæ.)

ITZIGSOHN (H.). De l'existence des spermatozoides dans certaines Algues d'eau douce. (Ann. se. nat., $3^{\mathrm{e}}$ série, 180̈2, Bol., 1. XVII, p. 1\%0.)

_- Observations sur diverses Algues microsmopiques. 'Bolan. Zeit. du 18 janries $18 \%$ \%6.

De fabrica spora Mongeolice genuflexa, broch. in-X. Neudamm., $18 \% 6$.

LEGLERG (Léon). Sur la fruetifieation du genre Prolifere de ir. Taucher (Mèn. Hus., hist. nat., 1817, t. III, p. 162.)

MuXTAFre (C..). Des Coniongstes ou Sporanges découverts sur le Bryoprsis balbisiana, de la famille des Algues. (Anu. se. net., ge súrie, 1839, Bot.: 1. XI, 1. 370.)

-..- Du genre Kiphophora, etc.; à son occasion, recherches sur celle question: Trouve-t-on dans les Fucacées les deux modes de propagation qu'on observe chez les Floridées? (Anu. sr. nat., 2e série, 18\$2, Bot., 1. XVIII, p. 200.)

... Quelques observations tonehant la strneture et la fructification des genres Clenodus, Delisea et Lenormandia, de la famille des Floridées. (Ann. sc. nat, ge série, 181', Bot., 1. I, p. İi.)

..- Description d'une unurelle forme de fruit du genre Poss. 
sonnelia DCne; suivie de quelques considérations sur les Némathécies. (Ann. sc. nal., ¿3e série, 18ł̄, Bol., t. VII, p. 179.)

MORREN (Gh.). Mémoire sur les Clostéries. (Ann. sc, nal., 2 e série, 1836, Bol., t. V, p. $25 \%$ el 321.)

ORBIGiY (C. D'). Essai sur les plantes marines des côtes du golfe de Gaseogne, et particulièrement sur celles du département de la Charente-Infér. (Mém. Mus, hist. nat., 1820) 1. YI, p. 163.)

PETROWSKY (André). Eududes algologiques (Ann.sc.nat., q série, 1862, Bot., 1. XV], p. 368.$)$

PRINGSHEL (N.). Sur la fécondation et la germination dro Algues. (Ann. sc. nat., 4 qérie, 183ั, 1. III, p. 363.)

__ Observations sur la fécondation et la génération alternante

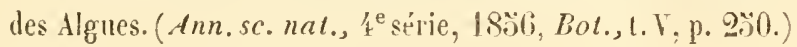

Sur les fruits des Floridées. (Comptes rendus des traraux de la section botanique du $33^{\mathrm{e}}$ congrès des naturalistes et médecins allemands, par M. R. Caspary, in Bot. Zeit., $1803 \%$,

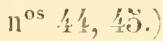

Natérianx pour servir à la norphologie et à l'étude sy̧sté-

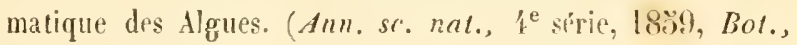
i. XI, p. 273.)

Celer die... (Sul les zoospores permanentes de l'Hydrodyction el sur quelques organismes analogues. (Comples rendus de l'ścad. des se. de Berlin, dér. 1860).

-_- Sur les chronispores ou ehronizoospores de l'Hydrodiction, et sur quelques corps reproducteurs analogues. (Ann.

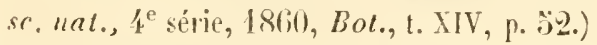

SANIO (i.). Beitrag zur...... (Notice sur le développement des spores de l'Equisetum palustre. Botan, Zeit. dı l's mar's lnisi.) 
SOLIER (A.-J.-J.). Mémoire sur deux AIgues zoosporées devant former un genre distinel, le genre Derbesia. (Ann. se. kat., $3^{\mathrm{e}}$ série, 1817, Bot., 1. VII, p. 18\%.)

THURET $\left(\mathrm{C}_{\mathrm{x}}\right.$ ). Recherches sur les organes locomoteurs des spores des Algues. (Ann. sc. nat., $2^{\mathrm{e}}$ série, 1813, Bot., 1. XIX, p. 2666.)

- Nute str le mode de reproduction du Tosioc verrucosum. (Ann.sc. nat., 3" série, 1811, Bot., t. II, p. 319.)

-..- Note sur les spores de quelques Algues. (Ann. sc. nul.),

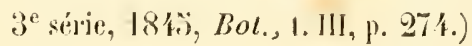

Recherches sml les zoospores des Algues at les authéridies des Cryptogames. (Ann. sc. nat., Qe série, 18\%̆), Bot.,

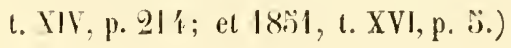

-... Recherches sur la fécondation des Fucacées, suivies d'observations sur les anthéridies des Algues. (Ann. sc. nat., $4^{\mathrm{e}}$ série, 18:i', Boi., t. II, p. 197.)

a._._. Deuxième note sur la fécondation des Fucacíes. (Ann. sc.

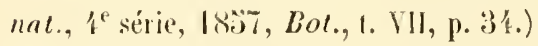

- - Sur la reproduction de quelques Yostochinées. (Mém. de la

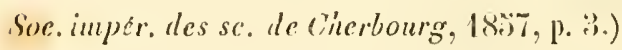

- Extrait d'une leture an rédacteur des Aunales. (Ann. sc. nat., te série, (8.9), 1. XII, p. 372.)

THWAITES (G.-H.-K.). Sur la coujugaison des Diatomíes. (Ann. si. nal., $3^{\text {e }}$ série, 1817. Bol., t. VII, p. 37'

-_- Deuxième note sur la conjugaison des Diatomées. (Ann. sc. nat., 3ie série, 1818, 1. IX, p. 60.)

TLRPIN (P.-J.-F.). Aperçu organographique sur le nombre deux, etc..., suivi de la description de plusieurs genres et espèces uomrelles très-remarquables, dérouverts parmi les productions 
végétales et microscopiques. (Hém. Mus. hist. nal., 1828 , t. XVI, p. 29\%.)

_- Obserrations sur le nouveau genre Surirella. (Mém. Mus. hist. nal., 1828, 1. XVI, p. 361.)

UNGER. Sur les métamorphoses et le mourement des corps reproducteurs de diverses Conferres, cl particulièrement de l'Ectosperma clavata de Vancher. (Ann. sc. mat., I se série, I828, t. XIII, p. 348.)

VAUPELL (Cu.). Sur la reproduction et la fécondation d'une espèce du genre OElogronium. (Ann. se. nal., te série, 18599, Bol., t. XI, p. 199.)

WORONINE (Miches). Recherches sur les Algues marines Acelabularia, Lamk el Espera DCne. (Ann. sc. Mal., tesérie, IsG2, Bol., t. XVI, p. 200).

\section{LICHENS.}

NYLANDER (W.). Synopsis methodica lichenum omnim hacusque cognitorum premissa introductione lingua gallica tractata. 18008.

- Qnelques observations sur le genre Cocnogonium. (Ann. sc. nat., 隹 série, 1862, But., t. XVI, p. 83.)

THURET (G.). Recherches sur les zoospores des Algues et les anthéridies des Cryptogames; $2^{e}$ partie. (Ann. sr. nat., $3^{\mathrm{e}}$ série, I80̈।, Bot., t. XVI, p. ّ̋.)

TULASNE (L.-R.). Note sur l'appareil reproducteur dans les Licheus et les Champignons. (Ann. sc. nat., 'je série, 18301 , Bot., t. XV, p. 370.)

_- Mémoire pour servir à l'histoire organographique el physio- 
logique des Lichens. (Ann. sc, nat., $3^{\mathrm{e}}$ série, 18\%2, Bol.. 1. XVII, p. ï et Iös.)

\section{GHAMPIGNONS.}

RARY (A. wE). Sur la formation de zoospores dans quelques champiguons. (Ann. se.nat., fe série, is60, Bot., t. XIII, p. 236.)

BURY (A. LE) et HOFFHANT (A.). Des Myxomycètes. (Ann, sc, nat.,

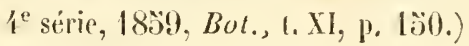

BERKELEY (J.). Sur la fructification des genres Lycoperdon, Platlus et de quelques autres gemres voisius. (Amm. sc. nat., ge série, 1839), Bol., 1. XII, p. I60); et 1840, 1. XIV, p. 12T.)

BRONGNIART (AD.). Observations sur le déreloppement du charbon dans les rraminées et sur les modifications qu’il détermine dans les parties de ces plantes qu'il attaque. (Ann. sc. nal., $1^{\text {re }}$ série. 1830, t. XX, p. 171.)

_- Rupport sur un mémoire de MH. L.-R. et Ch. Tulasne, intiInlé: Histoire des Champignons hypogés, suivi de leur monographie. (Ann. sc. nat., 3ै série, $\mid 8 \%$ I, Bot., t. XV, p. 267.)

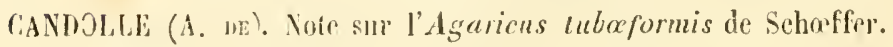
(Auit. se. nat., 1'e série, 1821, 1. I, p. 317.)

CASSIXI (ne) et MIRBEL. Rapport sur un mémoire de M. Turpin ayant pour object'organisution el lit reproduction de la truffe eomestible. (Ann. sc. nat, fre série, 1827, t. XII, p. 209.)

DEBat (L.). Notice sur le développement dn Psilonia buxi el du Chetostroma buxi. (Ann. sc. nat., $1^{\mathrm{e}}$ série, 18:38, Bot., t. IX, p. 81.)

JESMAZIERES (J.-B.-H.-J.). Note sur la Sclerotium stercorarium. (Ann. sr. nnt., $1^{\text {re }}$ sírie, 1827, L. X, p. 1 色.) 
DESWAZIËRES. (J.-B.-H.-J.) Sur le Lucoperdon radiatum de Sowerby, et l'Agaricus radicins, espèee nourelle. (Ann, sc.nat., $1^{\text {re }}$ série, 1828,t. XIIl, p. 2006.'

-_._ Obserrationsmicroscopiques sur le b'anc du rosier, Oidium leuconium Desmaz. (Ann. sr. nal., 1 1'e série, 1829, t. XVII, p. 98.)

- - Obserrations sur le Kiloma mullicalee, D.C. (Ann. sc. nal., $3^{\mathrm{e}}$ série, 1818, Bol., t. IX, p. 330.)

DURIEU DE MASONTELVE. Totice sur le Pilobolus Crystallinus. (.tnu. sr. nat., Ire série, 1820, t. 1., p. 221.)

DUThOCHET (H.). Observations sur les Chnmpignons. (Dans ses mémoires, 1. Il, p. 173; et dans Your. Ann. du Mus. hist. nal., 183ห, t. III, p. วั9.)

-_- Observations sur lorigine des moisissures. (Dans ses mémoires, t. II, p. 190.)

FRIES (Elids). Calendrier des Champignons sous la latitude moyenne de la suède. Ann. sc. nıt., 'térie, 18.99, Bot., t. XII, p. 298.)

HOFFIANX (H.) Die pollinarien...... (Les pollinies et les spermaties (les Aggarics). (Bot. Zcilung des 2 ! fér. et i mars 18:̈6.)

_- Leber Pilzkeimungen (sur des germinations de Champignons). (Bot. Zeitung, 18\%9, $\mathrm{n}^{\mathrm{os}}$ 24 et 93.).

LESPIAULT M.). Note surle Tuber allum de Bulliard. (Ann sc.naı,, $3^{e}$ série, 181', Bol., t. 11, p. 316.)

- Note sur la fructification dez genres Clathrus et Phallus.

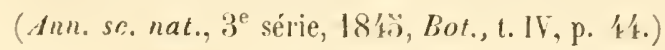

LEVEILLE J.-H.) Recherehes sur l'hymenium des Champignons. (Ann.sc.nal., ge série, 1837, Bol., t. VIII. p. 301.) 
LEVEILLE (J.-11.). Recherches sur le déreirpement des Crédinées. (Anu. sc. nat., ge série, 1839, But., 1. XI, p. ̈̈.)

_-_ Hémoire sur le genre Sclerolium. (Ann. sc.nal., ge série, 1818$, Bol., t. XX, p. 218.$)$

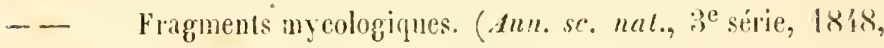
Bol., t. IX, p. 119.)

Organisation ef disposition méthodique des especes qui

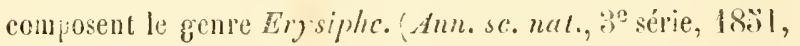
Bot., 1. XV, p. 10\%)

MAEGELl (Ch.). Sur les Champignons virant dansl'intérieur des cellules régétales. (Ann. sc.nat., 2" série, 1813, Bot., t. XIX, p. 860.)

SETNES (J.DE). Essai d'une flore ning cologique de la région de Montpellier el du Gard. - Observations sur les Agaricinés, suivies d'une énumération méthodique. Paris, 1863.

THURET (G.). Recherches sur les zoozpores des Algues ct les anthéridies des Cryptogames; $2^{\circ}$ partie. Ann. sc. nat., $3^{\mathrm{e}}$ série, I8̈̈l, Bol., 1. XY1, p. ̈̈.)

TLLASNE (L.-R.). Note sur l'appareil reproductenr dans les Lichens

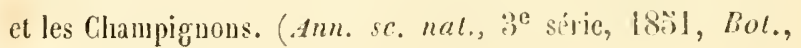
t. $X V$, p. 370.$)$

- Observations sur l'or'yanisation des Trémellinées. (Ann.sc. nat., 3ै série, 1833, Bot., t. XlX, p. 19\%.)

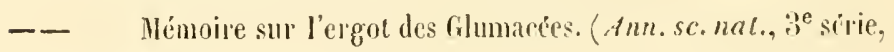

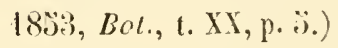

- Nouvelles recherche sur l'appareil reprodncteur des Champignons. (Ann. se. nal., $3^{\mathrm{e}}$ scrie, 1893 , Bot., t. XX, p. 129.)

__ Second Hémoire sur les Urédinées et les Ustilagimies. ( $1 \mathrm{nn}$. sc. nat., iécie, 18:4, Bot., 1. II, p. 77.) 


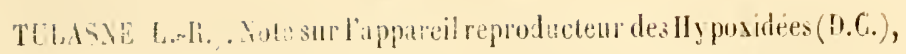
on Pyrénomycetes, Fr.). (Ann. se. nat., $4^{\mathrm{e}}$ série, Kröt, Bol., 1. $1,1,107$.

_- Nourclles observations sur les Erysiphe. (Ann. sc. nat., 1. série, 1830, Bot., 1. VI, p. 999.)

_- Note sur les Isaria et Sphoria entomogènes. (Aun. sc.nal., i'série, 183\%, Bol., 1. VIII, p. 33̈.)

TULASXE (L.-R. et G.). Obscrvations sur le genre Elaphomyces, et description de quelques espèces nouvelles. (Aın. sc. nat., 2e série, 1841, Bol., 1. XV1, p ̈̈.)

- De la fiuctification des Sclerolima comparée à celle des Lycoperdon el des Borista. (Ann. sc. nat., 2 séric, 1812, Bot., ı. A III, p. ̈̈.)

_- Sur les genres Polysaccum el Scaster. (Ann, sc. n.7t., ge sćrie, 1842, bol., t. XVHI, p. 129.)

Recherches sur l'organisation et le mode de fructification des Champignons de la tribu des Vidulariées, suivies d'un essai monographiqque. (Ann. sc. nat., żérie, 1841, Bot., 1. I, p. 1.)

_- Sur lorganisalion et le mode de fructification des Oay -

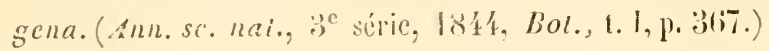

- De gen. Cliroiromycele el Picoa e Tuberacearum familia.

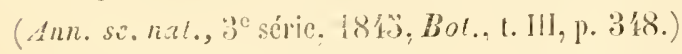

_- Mémoire sur les Ustilaginées comparées anx Urédinées.

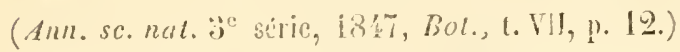

- Fungihippogei. (In-80. Paris, 18:il.)

De quelques sphories forgicoles à propos doun mémoire de II. Ant. de Bury sur les Myctalis, in Botan. Zeitung, 18:39.

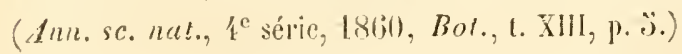




\section{IIEPATIQUES.}

BISCHOFF (T.-G.). De Hepaticis imprimis tribuum Marehantiearum et Riceieartum commentatio. IJeidelberg, $1838 \%$.

- Kemarques sur l'organogénie des Hépatiques. (Ann. sc. nat., $3^{\mathrm{e}}$ série, 18003 , Bot., 1. XX, p. 07 .)

BORY DE SAINT-VINCENT CI C. HONTAGNE. Sur Un noureau gem'e de la famille des Hépatiques (Durica). (Ann. sc. nat., פ série, 1844, Bot., 1. I, p. 223.)

GROENLAND (J.). Mémoire sur la germination de quelques Hépatiques. (Ann.sc. nat., $4^{\mathrm{e}}$ sirie, $18 \ddot{3} 4$, Eot., t. I, p. 5̈.)

HUBENER (J.-D.-P.). Hepaticologia germanica, oder.... (Description des Hépatiques d'Allemagne). In-8, Mauheim, 1834.

HUGO MOHL. Sur le déreloppement des spores de l'anthoceros loevis. (Ann. sc. nat., $2^{\mathrm{e}}$ série, 1840, Bot., t. Xill, p. 208.)

LINDENBERG (J.-B.-G.). (Species hepaticarum recensuil, partim descripsit iconibusque illustravit.) Bonne, in-1 1 .

MEIEN. Lette sur les animaux spermatiques des régétanx d'organisation inférieure. (Ann. sc. nal., $2^{\mathrm{c}}$ série, 1838, Bot., 1. X. 1).319.)

AIIRBEL (be). Recherches anatomiques et physioloziques sur le marchantia polgmorpha, pour servir à l'histoire du tissu cellılaire, de l'épiderme et des stomates. (Nouv. ann. N'us., 183\%, t. 1, p. 93.$)$

MONTAGNE (G.). Des organes mâles du genre Targionia décourerts sur une espèce nourelle du Clili. (Ann. sc. nal., $2^{\mathrm{c}}$ série, 1838, Bot. 1. 1X, p. 100.)

NEES v'ESENBECK (C.-G.). Materriaux pour servir à l'histoire natu- 
relle des Hépatiques d'Allemagne. (Flora, 1833, $11^{05} 200$ et 26.)

RADDI (Gıșerpe). (Jungermannicgrafia etrusca del signor). Bonna, 181.

THURET (G.). Recherches sur les zoosporcs des Algues et lcs Authéridies des Cryplogames; 2 e partie. (Ann. sr. nat., $3^{\mathrm{e}}$ série, 183̈!, Bot., t. XVI, p. ॐ̈.)

\section{MOUSSES.}

BRUCH (Fн.), SCHIMPER (W.-PH.) et GCYBEL (TH.). Bryologia enropœa, seu genera Muscorum europoarum monographice illustrata.

DOZY (F.) et HOLKENBOER (J.-H.). Husci frondosi ex archipelago indico et Japonica conjunctis studiis scripserunt. (Ann. sc. nat., $3^{\mathrm{e}}$ série, 1814, Bot., t. 1I, p. 297.)

IIOFMEISTER (Wiln.). Note sur la fécondation des Fougères. (Ann. sc. nal., 4 ${ }^{\mathrm{e}}$ série, 183 ', Bo!., 1. 1, p. 17/.)

MEYEN. Lettre sur les amimaux spermatiques des régétaux dorgani. sation inférieure. (Ann. sc.nat., 2érie, 1838, Bot., 1. X, p. 319.)

DEES D'ESENBECK (C.-G.). (Spiridens, noureau genre de Housses découvert par II. G.-C. Reinward, et décrit par M.). (Ann. sc. nat., $1^{\text {re }}$ série, 1824, t. 1, p. $330 \%$.)

SCHIIPER. Synopsis Nuscorum europœarum premissa introductione de elementis bryologicis tractante. Stuttgart, 1860 .

THURET (G.) Rechcrches sur les zcospores des Algues et les anthéridies des Cryptogames; $2^{\mathrm{e}}$ partic. (Ann. sc. nal., $3^{\mathrm{e}}$ série, 18วั1, เ. XVI, p. ̋̈.) 
LGER (F.) Rerherches sur l'anthire des Splagonum. (Inu. sc. mat., ๖e série, 183', Bot., t. II, p. 188.)

_- Nourelles observations sur les anthères des Housses et sur les animalcules spermatiques qu'elles contiennent. (Anı. sc. nat., $2^{\text {e }}$ série, 1839, Bot., I. XI, p. 23\%.)

_- Nouvelles observations sur les animaleules spermatiques des plantes. (Ann. sc. nal., $2^{\mathrm{e}}$ série, 1839, Bot., I. XI, p. 271.$)$

\section{CIIARACÉES.}

AGAR[H. Observations sur le genre Chara, extraites d'une lettre.... (Ann. sr. nat., $1^{\text {re }}$ série, 182\%), t. IV, p. 61.)

AnICI (J.-B.). Obserrations microscopiques sur diverses especes de plantes. (Ann. sc. nat., I'e série, ISEt, I. II, P. \&1.)

BRAUN (At.). Esquisse monographique du genre Chara. (Ann. sc. nat., 2ze séric, 1831, Bot., 1. I, p. 319.)

MONTAGNE (C.). Mémoire sur la multiplication des Charagnes par division. (Ann. sc. nat., $3^{\mathrm{e}}$ série, 18.92, Bot., 1. XVIII, p. 129.)

THURET (G.). Note sur l'anthère du Chara et les aminalcules qu'elle renferme. (Ann.sc, nat., ge série, 1810, but., I. XIV, 1. 63. .)

- Recherches sur les zoospores des Algues, el les authéridies

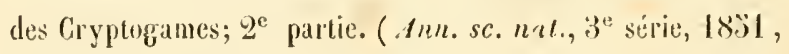
Bot., I. XVI, 1. ̈.).

\section{FOUGEARES.}

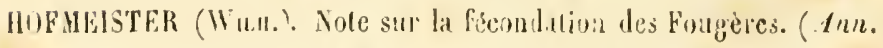
sc. nat., $1^{\mathrm{e}}$ série, 1831, Bot., 1. J, p. T71.) 
LESZCZYG-SUMINSKI. Sur le déreloppement des Fougères. (Ann. sc. nat., $3^{\mathrm{e}}$ série, $181 \%$, Bot., t. XI, p. 114.)

THURET (G.). Note sur les anthéridies des Fougères. (Ann. sc.nat., $3^{\text {e }}$ série, 1819, Bot., t. XI, p. 亏̈.)

_- Recherches snr les zoospores des Algues et les anthéridies des Cryptogames; $2^{\mathrm{e}}$ partie. (Ann. sc. nat., $3^{\mathrm{e}}$ série, $180 \% 1$, Bot., t. XVI, p. ̈̈.)

WISAND (ALr.). Sur le développement des Fougères. (Ann. sc, nnt. $3^{\mathrm{e}}$ série 1819 , Bot., t. XI, p. 126.)

\section{EQUISE'TACEES.}

AGAKDH. Observations sur la germination des Prêles. (Mém. Mus. hist. nat., 1822, เ. IX, p. 283.)

BISCHOFF (G.-W.). Remarques snr l'organogénie des Equisctum. (Ann. sc. nat., $3^{\mathrm{e}}$ série, 18ə̃3, Bot., t. XIX, p. 232.)

BRAUN (A.). Tableau des Equiselum d'Europe. (Flora, 1839.)

DUVAL-JOUVE (J.). Sur les organes de reproduction de l'Equisclum arvense (Bull. Sc. bot. Fr., 180̃9, p. 699.)

HAMPE et SCHLEGHTENDAL. Notice sur les Equisctum umbrosum et pratense. (Ann. sc. nat., $2^{\mathrm{e}}$ série, 1837, Bot., t. VII, p. 3i8.)

SANIO (G.). Beitrag zur...... (Notice sur le développement des spores de l'Equisetum palustre. (Botan. Zeitung, du 14 mars 18气ั6.)

THURET $(\mathbf{G}$.). Recherches sur les zoospores des Algues et les authéridies des Gryptogames; $2^{\mathrm{e}}$ partie. (Ann. sc. nat., $3^{\mathrm{e}}$ série, 18\%̈1. Bot., t. XVI, p. ̈.). 
VAUCHER. Mémoire sur la fructification des Prêles. (Mém. Mus. hist. nat., 1823, t. X, p. 129.)

\section{LYCOPOIIACEES.}

BARY (A. DE). Ueber die Keimurg der Lycopodien (sur la germination des Lycopodes). (Berichte d. naturl. Gesellsch. an Frriburg, Bd. I, nº 28 , mars 180̈8.)

BORY DE SAINT-VINCENT. Note sur l'Isoëtes du Midi de la Franee, et sur le Marsilea Fabri. (Ann. sc. nat., $2^{\mathrm{e}}$ série, 1838, Bot., t. X, p. 378.)

IIOFHEISTER (Wilh.). Histoire du développement des organes reproducteurs dans les Lycopodiacées. (Ann. sc, nat., $3^{\mathrm{e}}$ sérịe, 1852 , 1. XVIII, p. 172.)

SPRING (A.-Fr.). Matériaux pour servir à la eonnaissance des Lyeopodiacées. (Aun. sc. nal, $2^{\mathrm{e}}$ série, 1839, Bot., t. XI, p. 218.)

THURET (G.). Recherches sur les zoospores des Alggnes et les anthéridies des Cryptogames; $2^{\mathrm{e}}$ partie. (Ann. sc. nal., $3^{\mathrm{e}}$ série. 18s̈l, Bot., t. XVI, p. ̋̈.)

\section{IRIIZOCA PÉES.}

BORY DE SAINT-VINCENT. Note sur l'I soètes du Midi de la France et sur le Marsilea Fabri. (Ann. sc, nat., $2^{\mathrm{e}}$ série, 1838, Bot., I. X, p. 378.)

BRAUN (Al.). Observations sur les Marsilea. (Ann. sc. nat., $2^{\mathrm{e}}$ sé- $^{\mathrm{s}}$ rie, 1839 , Bot., t. XII, p. $293 \%$.)

FABRE (Esprit) et DUNAL. Observations d'Esprit Fabre sur la strueture, le développement et les organes reprodueteurs d'une es- 
pice de Marsilea trouvée daus les environs d'Agde. (Ann.se. nat., $2^{\mathrm{e}}$ série, 1837, Bot., t. VII, p. 221.)

Germination du Marsilea Fabri. (Ann. sc. nat., $Q^{\mathrm{e}}$ série, 1838, Bot., t. IX, p. $11 \%$.)

JUSSIEU (B. oE). Histoire d'une plante connue des botanistes sous le nom de Pilularia. (Hist. de l'Acad. ro). des sc., 1739, p. 240.

METTEXIUS (F.). Observations sur les Asolla. (Ann. sc. nal., $3^{\mathrm{e}}$ série, 1818, Bot., t. IX, p. 111.)

NAEGELI (Ch.). Sur la propagation des Rhizocarpées. (Ann. sc. nat., $3^{\text {e }}$ série, 1848, Bot., t. IX, p. 99.)

THURET (G.). Recherches sur les zoospores des Algues et les anthéridies des Cryptogames; $2^{\mathrm{e}}$ partie. (Amn. sc. nat., $3^{\mathrm{e}}$ série, 1851, Bot., t. XVI, p. š.)

\section{GÉNÉRALITÉS.}

ENDLICIER (Ér.). Grundzuge einer....... (Éléments d'nne théorie noirvelle sur la génération des plantes). Vienne, 1838, in-8º.

GdILLON (B.). Aperçus d'histoire naturelle, on observatious sur' les limites qui séparent le règue végétal du règne animal. In-8\%. Buulogne-sur-Her, 1833.

HEDWIG. Theoria generationis el fructificationis plantarum Crypto-

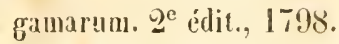

HoFFMAN (H.). Etudes mycologiques sur la fermentation. (Ann. sc. nat. 隹 série, 1860, Bot., t. XIII, p. 19.

HUGO DE HOHL. De l'utricule primordiale. Ann. sc, nal, , te serir, 18:T, Bot., (. VII, p. 233.) 
KAhsten. De la vie sexuelle des plantes el de la parthénogénèse. (Ann. sc. nat, te série, 1860, Bot., 1. XIII, p. 28̈2.)

KUETZING (Fr-Tr.) Recherches sur la formation el la métamorphose des organismes végétaux iuférieurs. (Ann. sc. nut., $2^{\mathrm{e}}$ série, 1834, Bot., t. II, p. 129.)

OGILVIE $(G$.$) . On the genetic...... (Des phases de la reproduction$ ehez les êtres organisés?. In-8, Londres, $183 \% 7$.

PAYER (J.). Botanique eryptogamique ou histoire des familles naturelles des plantes inférieures. Paris, 18000.

BADLKOFER (L.). Ueber das Verhaeltniss..... (Sur les rapports de la parthénogénèse aree les autres sortes de reproduction. Broch. in- $8^{\circ}$, Leipzig, 180ั8.)

SIEBOLD. Observations sur les plantes unicellulaires. (Ann. se. nal.,

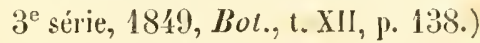

TURPIN (P.-J.-F.). Organographie végétale. Observations sur l'origine commune et la formation de tous les corps propagateur végétaus, et particulièremeut sur un nonveau mode de ces corps propagateurs. (Mem. Mus. lisi.nal., 1828, 1. XVI, p. 15\%.) 


\section{EXPLICATION DES PLANCHES.}

\section{PLANGHE 1.}

Iéveloprement des organes sexuels et germinalion dans le Sphéropica annulina, Algoues (d'après les travaux de H. Colın; voy. Anu. sc. nal., -4 série, l.V).

Fig. 1. - Cellules qui se développent en sporanges el renfermeront les spores. - A, la natière verte, s'est rassemblée arec les grains de Chlorophylle en anas silués suivant l'axe du végélal. B, la substance, s'est partagée en masses inégales, ovoïdes; la paroi présente dis perforations.

Fıg. 2. - Les spores.jprimordiales se sont constituées; les anthérozoñdes pénètrent dans la cellule par les perforations pariétales, el ront féeonder les sprores.

Fig. 3. - Cellules qui se développent en anthéridies et renfermeront les anlliérozołdes. - A, les corpuscules fécondants non 'ncore dévelopjés. - B, les anthérozoïdes parvenus à l'étal parfitit sortent de l'anthéridie par leş̨perforalions pariélales.

Fig. 4. - Spore primordiale sur la portion transparente de laquelle uir anthérozoinde s'est fixe par le rostre, puis s'es! appliqué rar te colé, comme le montre la figure.

Fig. 5. - Spore fécondée; une membrane s'est formée autour d'elle; l'anthérozoìde s'est fondu dans sa masse, à l'exeeption du rorjuscule ronge qu'il contenait, lequel est encore visible à la parlie supérienre.

Fic. 6. - Spore entourée de la seconde el de la lrisième memlorane, la première s'élant détruite par suite des progrès du léveloppement. La seconde membrane, ornée de saillies, n’a pas été réprésentée dans les trois figures suivantes pour plus de simplieité.

Fig. 7, 8 el 9. Fractionnement du contenu de la spore cn 2, 4, ete. parties qui don reront chacune naissance à une zoespore.

Fig. 10. - Zoospore complétement développée.

fic. 11. - Prenier rudiment de la plante mère résultant de la germination de la zoospore. 


\section{PLANCHE $I 1$.}

Reproduction chez les Fougères, d'après les travanx de MM. Suminski, Wigand, Thuret. (Voy. Ann. sc. nat., 3e série, I. XI.)

Fı́. 1. - Fougère, plante mère. 0n voit en $a$ la face inférieure d'une des frondes sur laquelle se trouvent les amas (sores) formés par la rénnion des corpuscules de la reproduction asexuelle (spreso des autems).

Fic. 2. - Pro-embryon sortanl d'un des corpuscules des frondes (spore des auteurs. $a$, corps reproducteur; $b$, thalle ou pro-cmbryon.

Fig. 3. - Portion du pro-embryon portant les organes de la reproduction sexuelle, vute par la face inférieure. $-a$, radicelles du pro-embryon; $-b$, organes mâles, anthéridies; les mis contiennent encore les corps fécondants, les autres sont déjà vidés et ouverts; - $c$, organes femelles, archigones, correspondant: ux sporanges des Algues.

Fra. 4. - Antluéridie; on voit qu'elle se compose de deux cellules: l'une basilaire, peu développée; l'autre contenant les cellules nères des anchérozoüdes. L'organe est représenté au moment de la déliscence.

Fí. 5. - Anthérozoïdes; l'un d'eux, $a$, encore contenu dans sa cellule mère; - d'autres, $b, b, b$, tels qu'ou les voil s'agitant daus le liquide; $-c$, l'!n d'enx, mort.

Fig. 6. - Archégone (correspondant au sporange des Algues); dans sal cavité se voit la sprote proprement dite; le canal, formé de seize cellules, fui conduit celte cavité, est fermé, comme cela a lieu peu de temp's après l'entrée de l'anthérozoïde. 
$\operatorname{lig}$
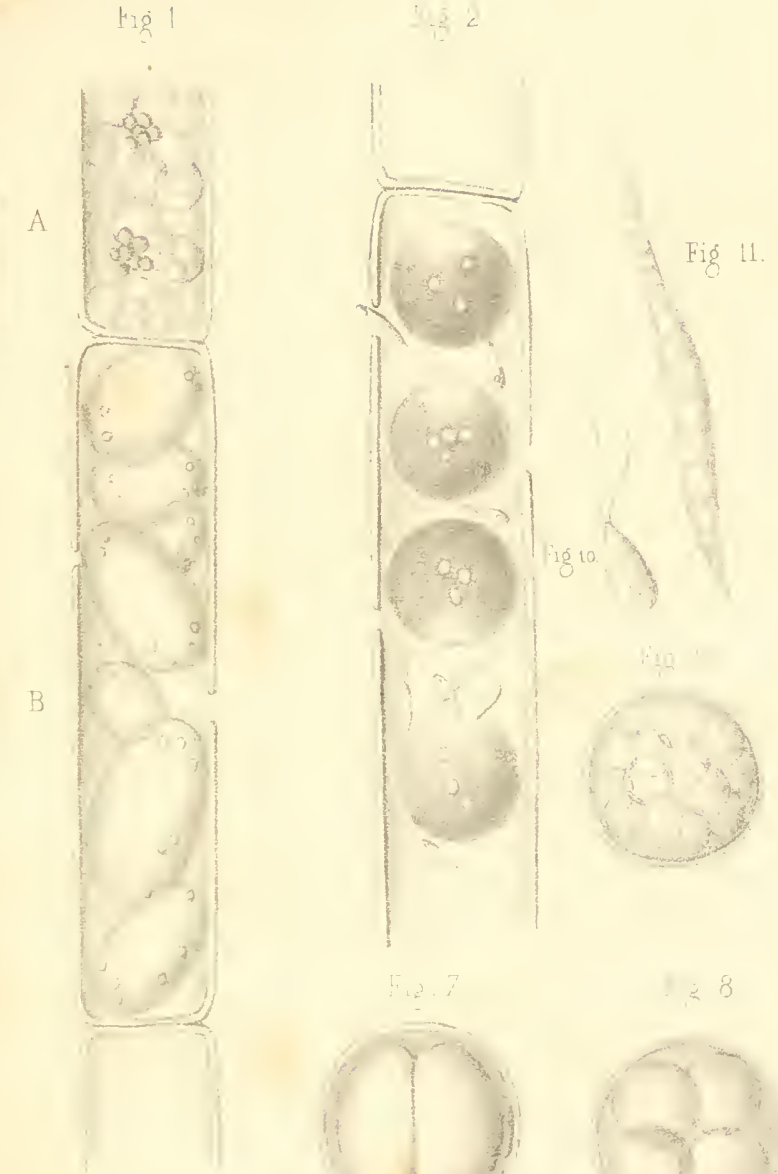

1.3 .3

(4).

$(2 \cdot-24)$

knt

हin.

$(-2,0)$

and $A$

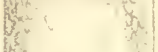

Ei $\quad 1=2$

ris.

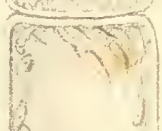

i?
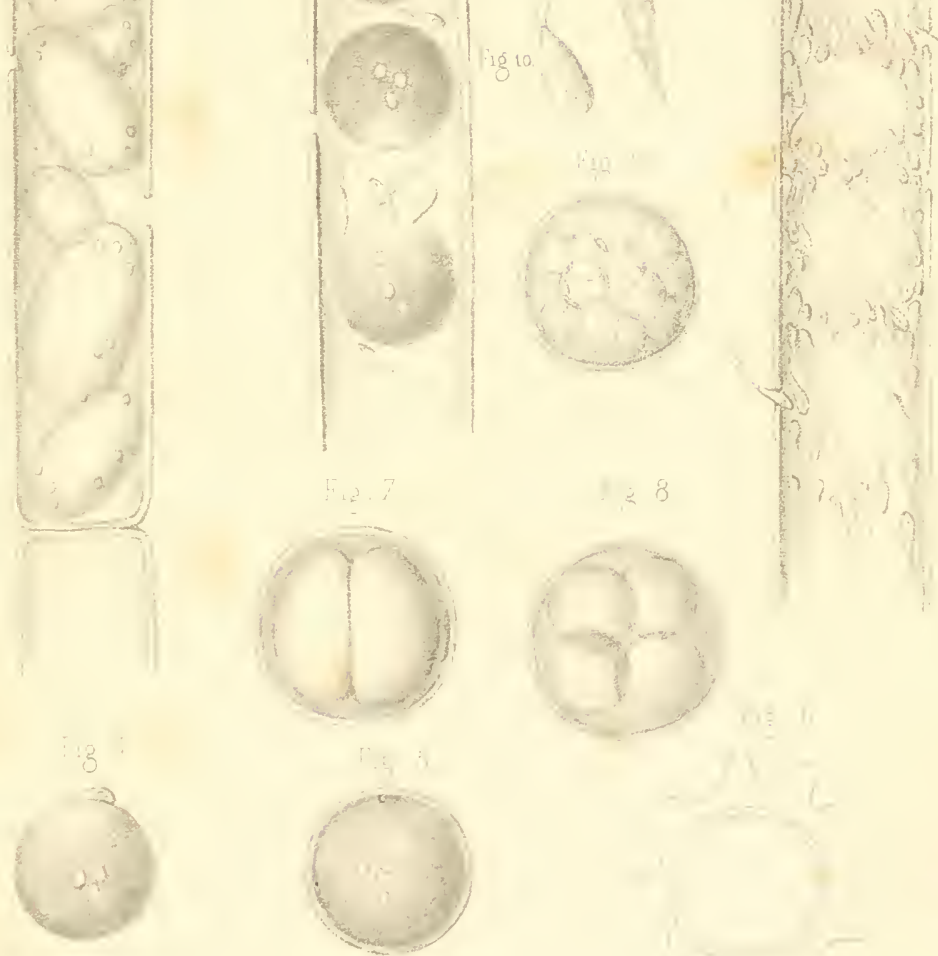

I. $\int 2 x .2 \geq n$ 




\section{TABLE DES MATIERES}

Introduction.................... i

Chap. I. Algues..................... 5

Cinap. II. Lichens...................... $5 \mathbf{5}$

Ghap. III. Champignons.................. 58

Gusp. IV. Hépaticées $\ldots \ldots \ldots \ldots \ldots \ldots \ldots \ldots \ldots \ldots 6$

Chap. V. Mousses.................... 70

Chap. VI. Characées.................. 79

Снар. VII. Fougères ................ 85

Chap. VIII. Equisétacées ................. 94

Chap. IX. Lycopodiacées................. 10 2

Снар. X. Rhizocarpées.................... 107

Conclusions......................... 109

Bibliographie....................... 115

Explication des planches................ 133

FIN DE LA TABLE. 




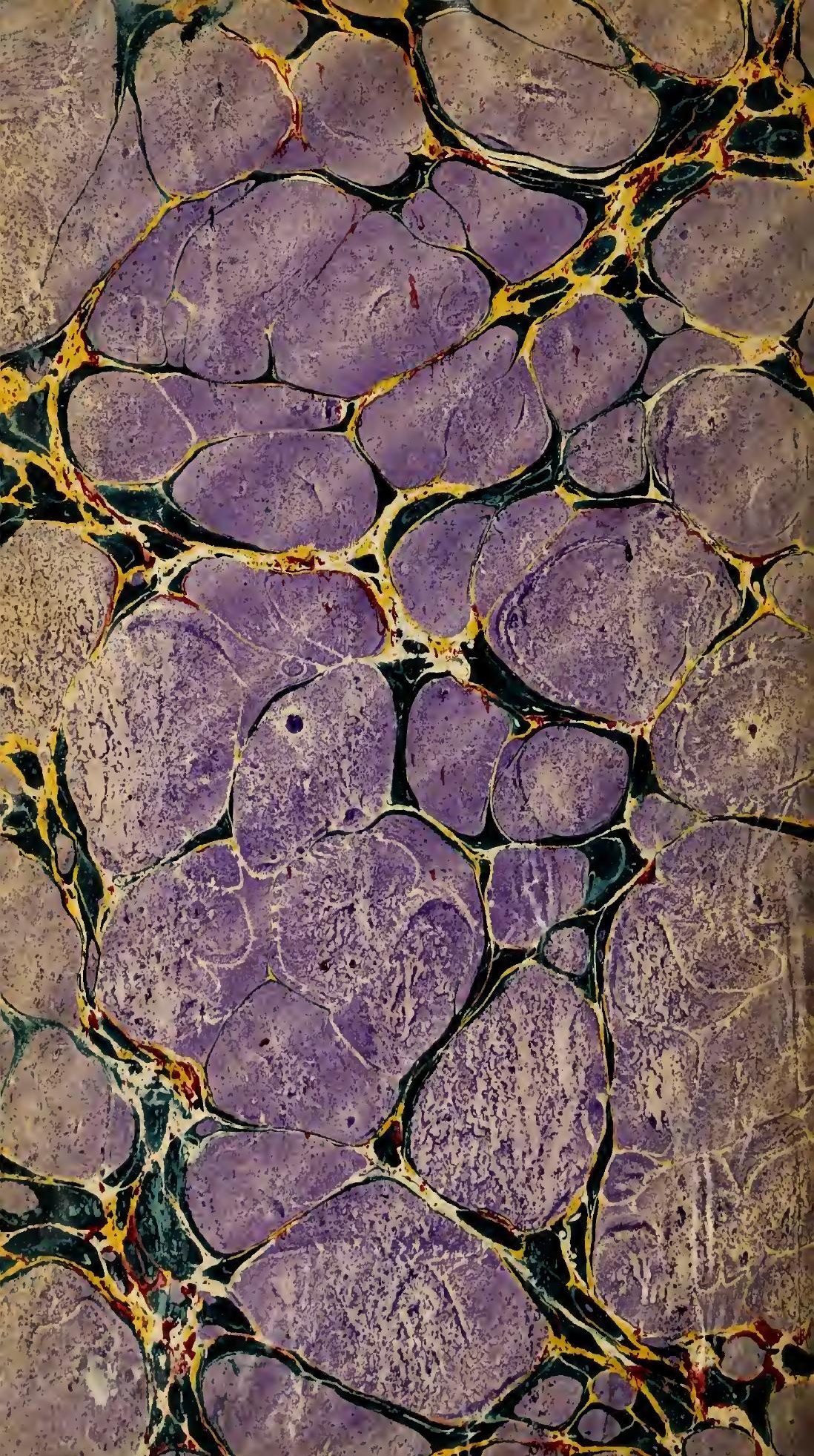




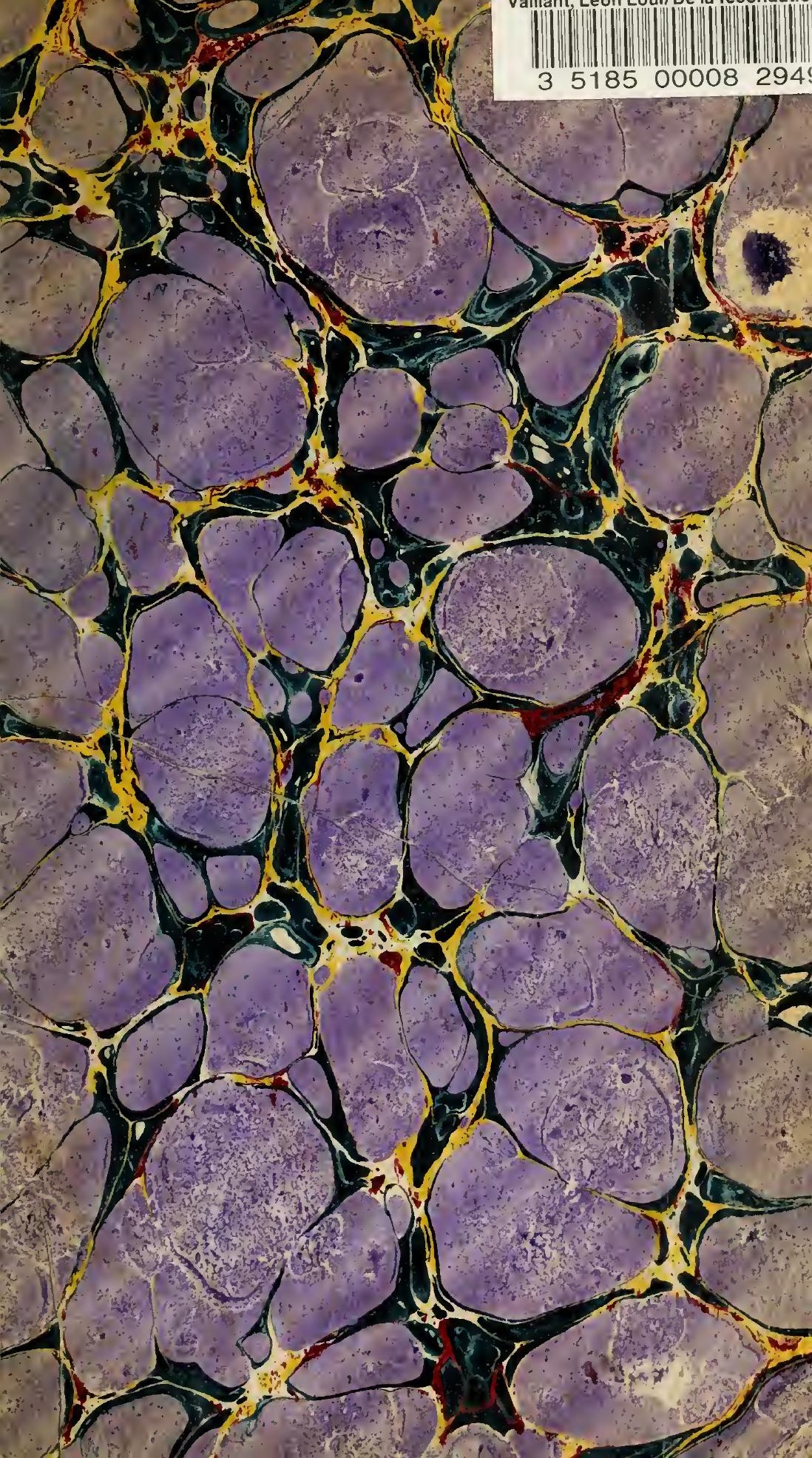


